\title{
Osteoporosis around the menopause : occurrence, determinants and preventive drug treatment
}

Citation for published version (APA):

Leusink, G. L. (2001). Osteoporosis around the menopause : occurrence, determinants and preventive drug treatment. [Doctoral Thesis, Maastricht University]. Datawyse / Universitaire Pers Maastricht. https://doi.org/10.26481/dis.20010518gl

Document status and date:

Published: 01/01/2001

DOI:

10.26481/dis.20010518gl

Document Version:

Publisher's PDF, also known as Version of record

\section{Please check the document version of this publication:}

- A submitted manuscript is the version of the article upon submission and before peer-review. There can be important differences between the submitted version and the official published version of record.

People interested in the research are advised to contact the author for the final version of the publication, or visit the DOI to the publisher's website.

- The final author version and the galley proof are versions of the publication after peer review.

- The final published version features the final layout of the paper including the volume, issue and page numbers.

Link to publication

\footnotetext{
General rights rights.

- You may freely distribute the URL identifying the publication in the public portal. please follow below link for the End User Agreement:

www.umlib.nl/taverne-license

Take down policy

If you believe that this document breaches copyright please contact us at:

repository@maastrichtuniversity.nl

providing details and we will investigate your claim.
}

Copyright and moral rights for the publications made accessible in the public portal are retained by the authors and/or other copyright owners and it is a condition of accessing publications that users recognise and abide by the legal requirements associated with these

- Users may download and print one copy of any publication from the public portal for the purpose of private study or research.

- You may not further distribute the material or use it for any profit-making activity or commercial gain

If the publication is distributed under the terms of Article $25 \mathrm{fa}$ of the Dutch Copyright Act, indicated by the "Taverne" license above, 
Osteoporosis around the menopause 
O.L. Leusink, Eindhoven 2001

ISBN 9052733047

Vormgeving en druk

Datawyse / Universitaire Pers Mastricht

Het schilderij algebeeld op de voorkant van dit proefschrift, heeft als titel "Sigaretje roken" en is geschilderd in 1917 door Joseph Seckel. Dit prachtige kunstwerk is in 1919 tentoongesteld op de Tentoonstelling van Nederlandse Beeldende Kunst in Zwitserland. Joseph Abraham Seckel is geboren in Rotterdam 23 december 1881, woonde en werkte in Rotterdam, Amsterdam en Parijs, overleed 3 maart 1945 in Den Haag. Hij signeerde meestal met Jos. Seckel. Hij schilderde, tekende, aquarelleerde, etste en lithografeerde stillevens, figuren, portretten en landschappen. [Dit kunswerk is particulier eigendom] 


\section{Osteoporosis around the menopause}

occurrence, determinants

and preventive drug treatment

\section{PROEFSCHRIFT}

ter verkrijging van de graad van doctor aan de Universiteit Maastricht, op gezag van de Rector Magnificus, Prof. Dr. A.C. Nieuwenhuijzen Kruseman, volgens het besluit van het College van Decanen, in het openbaar te verdedigen op vrijdag 18 mei 2001 om 16.00 uur door

Gerrina Lenette Leusink

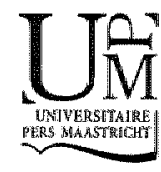




\section{Promotores}

Prof.dr. J.A. Knotrnerus

Profdr. V.J.M. Pop (Katholieke Universiteit Brabant)

\section{Beoordelingscommissie}

Prof.dr. S. van der Linden (voorzitter)

Prof.dr. G.l. Dinant

Prof.dr. J.M.W.M. Merkus (Katholieke Universiteit Nijmegen)

Dr. R. de Vet (Vrije Universiteit Amsterdam)

Dr. B. Wolffenbuttel

The sucly presented in this thesis was performed at the Diagnostic Center Eindhoven (DCE) in co-operation with in the Netherlands School of Primary Care Research iCaRel, acknowledged in 1995 by the Royal Dutch Academy of Science (KNAW).

The situdy was made possible by a grant from the Praeventiefonds thuidige Zorg Onderzoek Nederland, ZON), Grant No.28-2401

The printing of this thesis was supported by an educational grant from Solvay Pharmaceuticals. The opinions expressed herein are those of the author and do not necessarily reflect the views of the sponsor. 
Als ik oud word neem ik blonde krullen ith neem geen spataders, geen onderkin, en als ik rimpels krijg ondat ik vijfig ben dan neem ik vrolijke, niet van die lange om mijn mond alleen wat kraajepootjes om mijn ogen.

JUDITH HERZBERG

Wit het gedicht Een kinderspiegel' 



\section{Contents}

Chapter 1 General introduction

Chapter 2 Osteoporosis: Epidemiological and clinical aspects 13

2.1 Definition of osteoporosis $\quad 14$

2.2 Pathophysiology of osteoporotic fractures 15

2.3 Risk factors 17

2.4 Measurement of bone density $\quad 20$

2.5 Identification of patients at risk 23

2.6 Prevention of osteoporosis 25

2.7 Treatment of asteoporosis $\quad 28$

2.8 Compliance $\quad 36$

Chapter 3 General design of the Eindhoven

Perimenopausal Osteoporosis Study (EPOS) 47

3.1 Introduction 48

$\begin{array}{ll}3.2 \text { Background } & 48\end{array}$

$\begin{array}{ll}3.3 \text { Design of the Study } & 49\end{array}$

Chapter 4 The prevalence of low bone mineral density in Dutch perimenopausal women: The Eindhoven Perimenopausal Osteoporosis Study

Chapter 5 Is depressed mood a risk factor for low bone mineral density in perimenopausal women?

Chapter 6 Prevention of early postmenopausal bone loss: A randomised trial of calcium, HRT and pamidronate in women with low bone mass selected from a population-based cohort and one-year follow-up 77

Chapter 7 Compliance to an oral bisphosphonate therapy in women with early postmenopausal bone loss

Chapter 8 General discussion 
Chapter 10 Samenvating

Publications

127

Appendix

129

Dankwoord

149

Curriculum vitae 
CHAPTER 1

General introduction 
Over the past wenty years, osteoporosis has been the subject of intensive research, and the results have been encouraging. Therefore, it is generally accepted that, today, osteoporosis can be diagnosed, and to a large extemt prevented and treated. Already in 1941. Albright et al. 'defined osteoporosis pathologically and reviewed the clinical history of 42 patients. In their study, they described several etiological factors, including postmenopausal status. Subsequently, in 1947, they reported that osteoporosis was atuributed to the decrease in oestrogen production following the menopause. ${ }^{2}$

In many countries, osteoporosis is the most common metabolic bone disease. In view of increasing life expectancy and changes in lifestyle, osteoporosis is now recognised as being one of the most common and serious problems faced by postmenopausal women and aging persons of both sexes, and is seen as an important health problem in the Westen world and Asia. In the USA, approximately 1.5 million fractures a year are attributable to osteoporosis: these include 700,000 vertebral fractures, 250,000 distal forearm (Colles') fractures, 250,000 hip fractures, and 300,000 fractures at other limb sites. The lifetime risk of fractures of the spine (symptomatic), hip, and distal radus is $40 \%$ for white women and $13 \%$ for white men aged 50 years or older. Following a hip fracture, there is $10-20 \%$ mortality over the subsequent six months, $50 \%$ of patients will be unable to walk without assistance, and $25 \%$ will require longwterm home care. ${ }^{3}$ The annual cost of osteoporosis to the US health system is at least US\$ 5-10 billion. ${ }^{3}$ In 1999 in the Netherlands, there were 18.475 registered hospital admissions for hip fractures in a population of 15 million, a quarter of which occurred in men. The one-year incidence of hip fractures (per 100,000 persons) increased from around 40 at the age of $55-59$ years to about 3150 over the age of 95 years in men, and from around 40 to about 4450 in women of the same ages. 4 The annual costs of treating patients with hip and spinal fractures amount to NLG 330 million and NLG 35 million, respectively, and accoumt for around $0.6 \%$ of the national health care budget. 5 These already high costs will increase further with the continued aging of the population, and will lead to at least a doubling of the number of patients with fractures over the coming 40 to 50 years. Seventy-five percent of all hip fractures accur in women. Women have a lower peak bone mass than men at many skeletal sites. In addition to this lower peak bone mass, women have a greater age-related loss, which is accelerated by the menopa use. The average rate of bone loss in both men and women is approximately $1 \%$ per year starting from middle age, whereas, in women, higher rates of bone loss $2-4 \%$ per year) occur in the first five to ten year following the menopause, due to oestrogen deficiency to Women also have a longer life expectancy than men and so they are exposed to lower bone mass and a higher cumulative risk for falls for a longer period during their lives. Although differences in bone mass are important, there are other factors that account for the differences between the sexes. For example, elderly women fall more often than men, and the differences in bone mass may not entirely explain the different patterns of risk that are found between cultures and races. 
Assuming that the literature on risk factors for developing osteoporosis and fractures related to osteoporosis is correct, the incidence, age of the elderly, and care and costs of osteoporotic fractures, will increase world-wide as the ageing population expands. Although we are still uncertain as to the best time for, and best methods of, intervention to prevent this increase ${ }^{7-9}$ we do have effective methods for the diag. nosis, prevention, and treatment of this disorder.

\section{Background and overview of the thesis}

In 1991, the Health Council of the Netherlands (Gezondheidsraad) advised the Secretary of State for Welfare, Public Health and Culture (WVCy on the prevention of osteoporosis: osteoporosis is an important cause of disease, especially in elderly women, and preventive measures of a general nature are strongly recommended. The plea for prevention was that bone mineral density measurements should be carried out in women of menopausal age, in order to gain insight into their bone mineral density and risk of developing osteoporosis and vertebral and hip fractures. In order to evaluate the possibility of prevention of osteoporosis using the measurement of bone mineral density, the Committee recommended that an exploratory study should be carried out in women around the menopause.

Based on the above recommendations, the Prevention Fund approved a research proposal, which resulted in this thesis. The aims of this thesis are:

- to determine the efficacy of two treatment regimens compared to calcium in preventing postmenopausal bone loss in women around the menopause, who are at risk for developing osteoporosis;

- to evaluate compliance to the respective treatment regimens, and to assess the rate of change in bone mineral density after treatment is withdrawn.

\section{Contents of the thesis}

Chapter 1 is the general introduction of this thesis.

Chapter 2 provides a general overview of the epidemiology, prevention, and treatment of osteoporosis. Moreover, it considers the effect of medications used in the prevention and treatment of osteoporosis, as well as the different measuring instruments used in this thesis, such as dual X-ray absorptiometry (DXA) and electronic lids for measuring compliance.

Chapter 3 describes the general design of the study, which is divided into a population-based cohort study and a randomised clinical trial, the intervention study.

Chapter 4 presents the baseline characteristics of all women of menopausal age living in the city of Eindhoven: the Eindhoven Perimenopausal Osteoporosis Study 
(EPOS), as well as the relationship of these characteristics to osteopenia and osteoporosis.

Chapter 5 describes the relationship between depressive mood and low bone mineral density in this population-based cohort. A validated questionnaire, the Edinburgh Depression Scale (EDS), to assess the suggested association of depressed nrood and low bone mineral density (BMD) was used.

Chapter 6 reports the outcome of the wo-year intervention study and the follow-up of 392 perimenopausal women who were all treated with $400 \mathrm{mg}$ calcium. The first group (129 women) received calcium only, while in addition the second group (133 womeni) received homone replacement therapy (HRT) and the third group (130 womenl pamidronate treatment. This chapter also describes the changes in bone loss during the year following cessation of treatment.

Chapter 7 describes the compliance of patients receiving pamidronate during the two years of treatment, measured by electronic microcircuitry, which monitored the opening and closing of the medication package.

Finally, Chapter 8 , the general discussion, reflects on how this study was designed and carried out. It evaluates the relevance of population-based screening for BMD with DXA in women around the menopause. Further, it discussed the recommendations of the second Health Council Committee (Gezondheidsraad) on the prevention and treatment of osteoporosis from 1998. This advice is compared with the first Dutch Association of General Practitioners (Nederlands. Huisartsen Genootschap, NHG) standard on osteoporosis, published in 1999. Recommendations for practice are made, and suggestions for further research are given, with regard to the prevention and treatment of low BMD in women.

\section{Literature}

1. Abright F, Smith PH, Richatdson AM. Postmenopausalosteoporosis, ils clinical features. JAMA 1941:116:2465-2474,

2. Abright F. Osteoporosis. Ann Int Med $\$ 947 ; 27: 861-882$

3. Riggs BL, Melton L.) III, The Wortwide problem of osteoporosis: insights afforded by epidemiology. Bone 1995:17:5055-5115.

4. Prismant, Malieban $50,35085 C$ Unecht.

5. Crzondheidstad: Commissie osteoporose. Preventie van aan osteoporose gerelateerde Practuren. Dent Hag: Gezond heidsad 1998; publicatienummer 1998/05.

6. Davis IW, Ross PD, Wasnich RD et a! The long tem precision of bone loss rate among measurements among postmenopausal women. Calcif Tissue lnt 1991;48:311-318.

7. Kanis JA. Theatment of osteoporosis in ellderly women. Am J Med. 1995;980A):605-635.

8. Black DM Why elderly women should be screened and treated to prevent osteoporosis. Am J Med. 1995-98(2A):765-75s.

9. Wood A]1. Treatment ofPostmenopausal Osteoporosis. N Engl Med.1998;11:736-744. 
CHAPTER 2

Osteoporosis: Epidemiological

and clinical aspects 


\subsection{Definition of osteoporosis}

Osteoporosis is defined as a condition of skeleal fragility, characterised by reduced bone mass and microarchitectural deterioration of bone tissue. Consequently, there is an increase in bone fragility and susceptibility to fracture. Put more simply, osteoporosis is a reduction of both the quantity and quality of bone.

Implicit in the defintion of osteoporosis by bone mass alone is the insight into the relationship between low bone mass and risk of fracture. Low bone mass is comparable to high blood pressure or an elevated concentration of serum cholesterol. The risk of hacture rises when bone mass declines, just as the risk of stroke rises together with blood pressure, and as hypercholesterolemia leads to an increased risk of myocardial infarction. Clinically, osteoporosis is recognised by the occurrence of fractures, such as those of the hip and wrist, or by spinal impressions.

According to the World Health Organiatsion (WHO) criteria, the term osteoporosis is defined as a bone mass value of over 2.5 standard deviations (SD) below the mean value in young adults (T-Score $)^{2}$ Low bone mass of osteopenia is defined by a bone density level of between -1 and -2.5 SD below the young normal mean. Established osteoporosis: a bone mineral density (BMD) value of more than -2.5 SD below the young adult mean value ( $\mathrm{T} \leq 2.5$ ) and the presence of one or more fragility fractures.

$B M D$ can also be compared with the mean value in normal subjects of the same age and sex (Z-score). A Z-score of less than - 1 at either the lumbar spine or the proximal fermur would indicate a value in the lowest $25 \%$ of the reference range. At this value, the risk of fracture is approximately doubled. A Z-scone of less than -2 would indicate a value in the lowest $2.5 \%$ of the reference range, a level associated with a considerably increased risk of fracture.

There are two categories of osteoporosis: primary and secondary. Primary osteopom rosis is related to postmenopausal conditions, the loss of ovarian function with, thereby, the loss of oestrogen leading to exponential bone loss ${ }^{3}$ and also to agerelated osteoporosis. ${ }^{4}$

In addition to these primary aetiologies, there are many secondary causes, including a large number of illnesses, medications, habits, and lifestyle factors. These secondary causes contribute significantly to bone loss and to the risk of fracture (Table 1). These factors may be solely or partially (together with a primary aetiology) responsible for the individual risk of osteoporosis and fracures. About $20 \%$ of women with postmenopausal osteoporosis also have a secondary cause contributing to bone loss. The reported presence of secondary aetiologies for osteoporos is in women with postmenopausal osteoporosis is as high as $64 \% .^{5}$ 


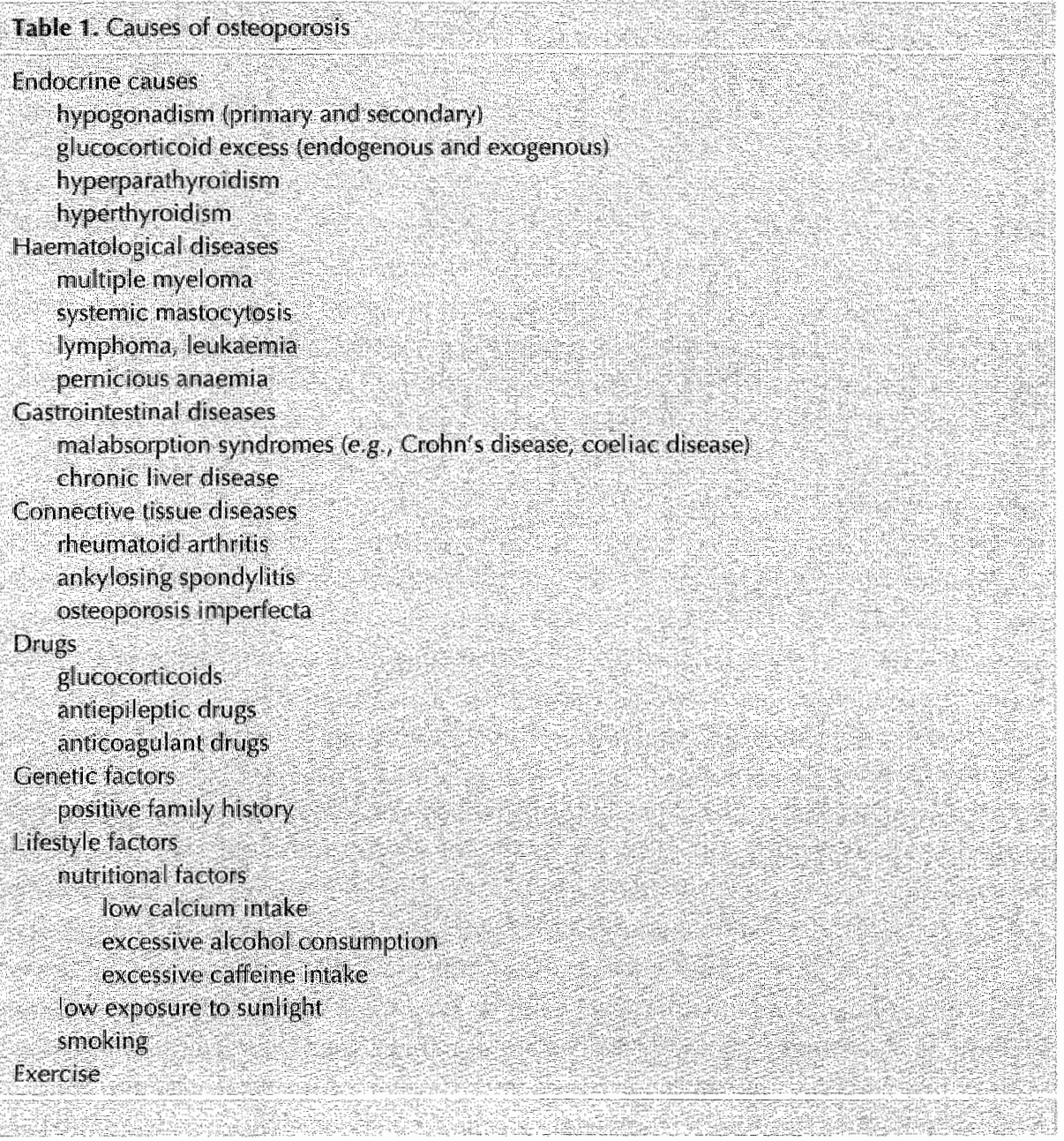

\subsection{Pathophysiology of osteoporotic fractures}

As the population ages, the number of people at risk for developing fractures increases. The risk of fracture is correlated with bone mass and to age and menopausal state 6,7 The pathophysiology of osteoporosis involves more than just bone mass. Other skeletal components, such as fragility and extraskeletal factors, can lead to fracture. In later life, BMD depends upon the peak bone mass achieved in adolescence $\%$ After about $20-25$ years of age, no further increase in bone mass is observed, however, peak bone mass is one of the major determinants of $B M D^{10}$ The bone mass at skeletal maturity differs between the sexes, and is about $30 \%$ higher in men than in women 8.11 The interplay between the factors associated with low bone 


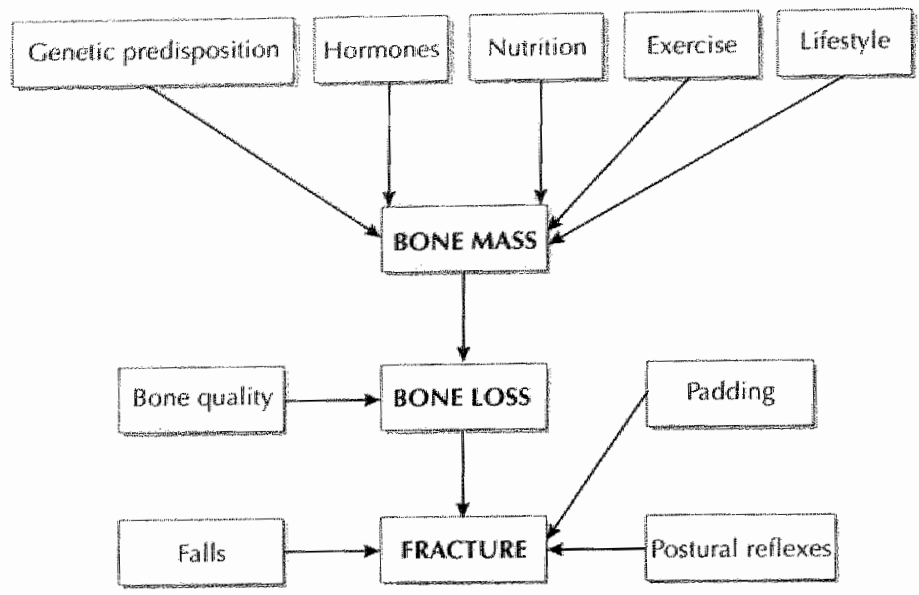

Figure 1. Factors associated with the development of bone mass, leading to osteoporotic fractures.

mass, leading to osteoporotic fractures, is illustrated in Figure 1. These factors will be discussed later in this chapter.

Bone mass can be used as a predictor of the risk of fracture. Cummings et al. 31 studied hip fractures in 8134 subjects aged 65 years or older, who were enrolled in the study of osteoporotic fractures. Each 1 SD decline in BMD was associated with a 2.4-3.0-fold increase in the age-adjusted risk of hip fracture, depending on the exact site measured. Although bone mass is frequently considered to be the most important determinant of fragility, this is not correct. Ross et a/. ${ }^{13}$ found that a pre-existent rracture is a stronger predictor of future fractures than low bone mass. Each pre-existing fracture increases the risk of additional fractures two-or three-fold.

A number of other studies 19,20 have demonstrated that a past history of fracture is an important independent risk factor for further fractures. Thus, the presence of wo of more vertebral fractures was associaled with a twelve-fold increase in fracture risk for any given BMD, 19 and women with a past history of non-vertebral fractures were found to have a three-fold increased risk of subsequent spine fractures. ${ }^{20}$

According to Hui er al ${ }^{14}$ and De Laet et a/. ${ }^{15}$, age is also an important factor regarding the risk of fracture. They have described the relationship between age and bone mass as being a predictor of the risk of fracture. Particularly in elderly persons, the age effect is greater than the bone mass effect, because age is correlated with a multitude of factors, such as medication, dizziness, loss of vision, and alcohol abuse. 16.17 Ageing also includes: the tendency to fall more often; slow postural reflexes, causing a person to fall to the side; loss of soft tissue; and a decrease in the quality of the bone. Kanis ${ }^{18}$ describes the quality of bone as: architectural abnormal- 
ities of bone, fatigue damage due to self-repair from repeated stress and the number of microfractures.

Most osteoporotic fractures result from injury. Such injuries usually occur during a fall. The three fracture sites most closely associated with osteoporosis are the hip. spine, and forearm. The likelihood of falling increases with age, and is greater in elderly women than in elderly men. Among postmenopausal women in the USA, the likelihood of experiencing at least one fall annually increases from about one in five women aged 60-64 years to one in three women aged between 80 and 84 years. ${ }^{12}$ Both the frequency and the mechanics of falling change with age. These changes can be the result of altered tread and postural stability, decreased muscle strength, malnutrition, comorbidity, and medication. Medication associated with hypotension, as well as psychotropic drugs have been implicated. ${ }^{16,17}$ Even more important than falling is the way in which the elderly fall. They more often fall to the side, directly onto the hip ${ }^{21}$ and, because of less sott tissue padding, there is no protection. Lauritzen ${ }^{22}$ studied the positive effects of external hip protectors on hip fractures. This randomised study was undertaken in a nursing home where half the patients were allocated to wearing a padded polypropyllene external hip protector. The other halves were untreated, and hip fractures were significantly more frequently observed in this group. Of all osteoporotic fractures, those of the hip have the highest impact on morbidity and mortality. The mortality rate in the first year is as high as 25\%, and the morbidity $40 \%,{ }^{23}$ In the USA, women who are currently 50 years old have a $15 \%$ risk of a Colles fracture, a $16 \%$ risk of hip fracture, and a $32 \%$ risk of a vertebral fracture occurring in the future. ${ }^{24}$ The lifetime risk of sustaining a hip, wrist, or clinically diagnosed spinal fracture is at least $40 \%$ for Caucasian women and $13 \%$ for men. 25,26

\subsection{Risk factors}

Risk factors are present before fractures occur and often provide insight into the aetiology of bone fragility and fracture. For osteoporotic fractures, there are at least two etiological factors

1. Low bone density.

2. Falls (This has been discussed in section 2.2).

In many cases, it is difficult to determine whether a risk factor is related to peak bone mass or bone loss. The regulation of peak bone mass is not fully understood, but a number of factors have been identified. Of these, the most important are genetic influences; other determinants which are potentially modifiable, include physical activity, nutritional factors, and hormonal status. Risk factors can be used to identify those persons who are at greater risk and who would benefit from preventive intervention before fractures occur. This section discusses the risk factors for low BMD. 


\section{Genetic factors}

Genetic factors have important effects on peak bone mass. In dizygotic twins, much greater differences in bone mass are observed than in monozygotic twins, 27, 28 which shows that between 60 and $80 \%$ of peak bone mass is genetically determined. There is also evidence that some aspects of bone architecture and geometry relevant to bone strength are inherited. The physiological mechanism by which genetic factors influence bone mass has not been clarified; effects on body size are likely to be important in this respect, and there may al so be genetic effects on bone modelling and remodelling.

tt has been observed that daughters of women with osteoporosis have reduced bone mass in the lumbar spine and femoral neck. Compared to daughters of non. osteoporotic women, the bone mineral content was about $5-7 \%$ lower. ${ }^{29}$ in addition, a prospective trial in 1857 premenopausal women showed that daughters of women with osteoporosis had a risk rario (RR) of $3.7(1.6-8.9)$ for fractures. 30

\section{Weight}

Tallness and low weight are risk factors for hip fractures. The high incidence of hip fractures in Norway and Sweden and the low incidence in Japan are related to greater or lesser stature. ${ }^{154}$ Large epidemiological trials have shown that height is a risk factor in hip fractures, with an RR of 1.3 per $6 . \mathrm{cm}$ height. ${ }^{31}$ Moreover, in the Longitudinal Ageing Study, an increased risk of fracture with a RR of 1.6 per $10 \mathrm{~cm}$ height was reported. 32 A low body mass index is an important risk tactor for osteoporosis. Many studies have shown a relationship between body weight and bone mass in osteoporosis and the risk of hip fractures. $2,32,33$ Those persons with a greater body weight or higher body mass index have a lower risk of fracture, although this relationship is not linear and the increase of risk is most pronounced in thin women. Thinness may affect rates of bone loss because plasma oestrone and oestradiol are proportional to body weight in postmenopausal women, possibly related to the efficacy of conversion of androstenedione to oestrone by the adipose tissue. However, individuals who weigh more have higher repetitive skeletal loads, and the rate of bone loss could be lower for this reason. In addition, extra weight in the form of more soft tissue padding helps to protect the hip in a fall to the side.

\section{Hormonal factors}

Although the most common cause of osteoporosis is related to oestrogen deficiency from ovarian failure associated with the menopause, many other causes of hypogonadism contribute to bone loss and fractures. Bone loss may also occur in relation to diseases and conditions associated with primary or secondary amenorr- 
hea. ${ }^{34-36}$ Even women without amenorhea, but with subclinicall oestrogen levels, have lower femoral bone densities compared to age-matched controls. 37

In men, hypogonadism is also an important cause of osteoporosis and gives rise to fractures, for example, in Klinefelter's syndrome and hypopituitarism.

\section{Nutrition}

Adequate intake of calcium, 800-1000 mg/day, and vitamin D, 400 IU/day, is necessary for achieving optimal peak bone mass. Maintaining a sufficient inlake of calcium and vitamin D also helps in reducing the rate of bone loss and in preventing fractures in later life. ${ }^{12,38-40}$ In the elderly, poor nutrition and low exposure to sunlight may contribute to calcium and vitamin D deficiency. ${ }^{4}$

\section{Lifestyle}

In most studies, smoking appears to be associated with increased bone loss and the risk of fractures. Accelerated bone loss may be related to the direct effects of smoking or, indirectly, to a sedentary lifestyle or other factors. $38,41,42$ The consumption of caffeine may contribute to a decline in BMD, and has been associated with an increased risk of hip fracture due to increasing calcium in the urine. ${ }^{12.43}$ Alcohol abuse is associated with low bone mass and the increased risk of fractures in both men and women. Possible mechanisms are impaired calcium metabolism secondary to liver disease, and an increase in falls related to poor balance and other physical regression. $42,44,45$

\section{Exercise}

Physical activity helps to maintain BMD and to reduce the risk of fractures at overloaded skelletall sites. $12,38,46-48$ Some studies have demonstrated increases in bone density as a result of increased exercise. Increasing the strength of loading seems to provide more benefit to BMD than the frequency or duration of exercise. 49 Although both children and adults obtain skeletal benefit from exercise, the potential for increasing bone mass is probably greater in children. Immobilisation and bed rest often results in rapid bone loss, which increases the risk of fractures, 18

Chronic health problems can increase the risk of fracture due lo loss of physical function, leading to an increased risk of falling, and to impaired bone strength. Some diseases, such as hypogonadism, contribute to low bone mass. Other diseases, such as osteomalacia and Paget's disease, can cause defects in the structure and quality of the bone. Other factors that can contribute to fractures, e.g., pre-existing fractures and age, are described in section 2.2. Table 2 provides an overview of the risk factors for fractures, bone loss, and falls. 
Table 2 (common risk factors for fractures, bone loss, and falls

\begin{tabular}{|c|c|c|c|}
\hline $\begin{array}{l}\text { Frow } \\
\text { Prot? }\end{array}$ & $\begin{array}{l}\text { Risk factor } \\
\text { for fractures }\end{array}$ & $\begin{array}{l}\text { Risk fatctor } \\
\text { Tor bone loss }\end{array}$ & $\begin{array}{l}\text { Rishle factor } \\
\text { hor lalls }\end{array}$ \\
\hline Low bone denity & 44 & NA & 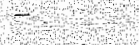 \\
\hline History of frag Winy ratwires & $\Delta$ & & \\
\hline M listory of Trequent lalls & 4 & $=$ & \\
\hline I yrogbonardism unchuling nenopause) & 4 & 42 & \\
\hline remate gender & 4 & 4 & 4 \\
\hline Shilerveight & 4 & 4 & \\
\hline Otucasian race & 4 & ?a & 4 \\
\hline homobilitysnactivity & 4 & $\Delta$ & 4 \\
\hline Bong geometry longrer bip axis length) & 4 & & \\
\hline Alcoliot aburse & 4 & 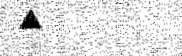 & $\Delta$ \\
\hline Chatrue snoling & 4 & 4 & $?$ \\
\hline Canferne excess & 4 & 4 & 4 \\
\hline Crlowm deftriency & 4 & 4 & \\
\hline Chronic heallt prollems & 4 & 4 & 4 \\
\hline Genetics (famuly bistory) & 4 & 4 & 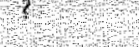 \\
\hline Drugs: & & & \\
\hline Ceoticoidisteroud use & $\mathbf{4}$ & 4 & ? \\
\hline Anticonvulsants & 4 & 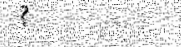 & 3 \\
\hline Long acing benzodiazepines & 4 & a & 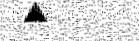 \\
\hline Homone Replacenent Therapy (IITI) & 7 & 7\% & 1 \\
\hline Thazide use & $?$ & 7 & 7 \\
\hline Noter Modifred lrom Ross, ret: 50 & $3 \%$ & & \\
\hline 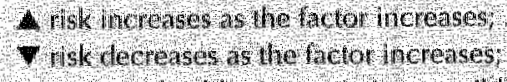 & $\begin{array}{l}\text { Mrocieases } \\
\text { decrease }\end{array}$ & Wast & increases, \\
\hline
\end{tabular}

\subsection{Measurement of bone density}

With regard to the interest in asteoporosis over the last decades, the technique for measuring BMD has been the subject of intensive reseanch for the last 30 years. A large variety of non-invasive techniques are awailable for the assessment of bone mass. These techniques vary widely in precision and complexity. In Table 3, several aspects of the various non-invasive bone mass measurement methods are presented. 
Table 3 . Features of the various non invasive methods of measuring bone nass

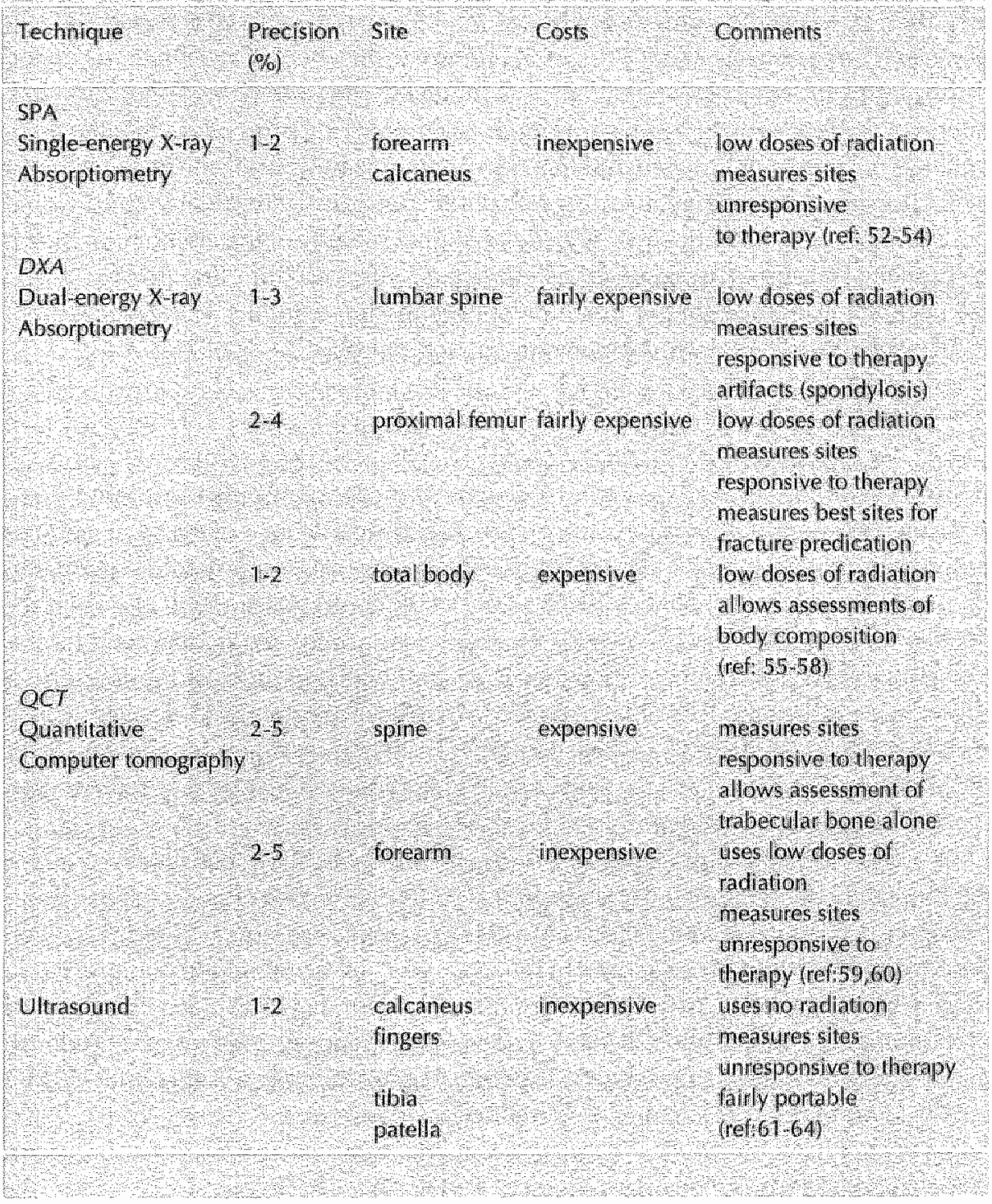

For the study described in this thesis, DXA (dual X-ray absorptiometry) was used to measure BMD in women, because it is a nom-invasive method, it is precise, uses low doses of radiation, and the measurement sites are responsive to therapy.

In this section, the important aspects of this technique are described. The principle behind DXA is the measurement of transmission through the body of X-rays, using two different photon techniques. The absorption of photons depends on three vari- 
ables the photon technique, the kind of absorption material, and the thickness of the absorber. With the measurement of bone mineral mass, the absorber consists of soft tissue and bone mineral in bone tissue. To eliminate the effect of the soft tissue on the results of bone mass measurement, wo different measurements lone with low energy, the other with high) are performed. The underlying principle is that the mass attenuafion coefficients of two different measurements (soft tissue and bonel differ as a function of photon energy. By using two photon energies, it is possible to calculate the attenuation in the bone (hydroxyapatite) independently of the attenuation by the soft tissue. The result is expressed as grams (g) hydroxyapatite (ha) per $\mathrm{cm}$, BMD means bone as the weight per unit area of bone scanned $\mathrm{g} / \mathrm{cm}^{2}$. Multiplying mean BMD by projected area yields bone mineral content (BMC).

$$
B M C=B M D \times \text { area }
$$

DXA scans of the lumbar spine and hip are the most commonly performed bone densitometry studies. This is because of the clinical significance of the spine and the hip as sites of osteoporotic fractures. Although osteoporosis is a systemic disease, the correlation coefficients between BMD values at different sites are typically approximately $0.7,51$ and therefore, a BMD measurement at one site is far from being a predictor of the BMD at any other site. The significance of a hip scan alongside a spinal scan is essential in elderly patients in whom spinal BMD is likely to be elewated due to degenerative disease (osteoarthritis), fracture, or arteriosclerosis of the abdominal aorta. In such patients, a scan of the spine should be disregarded, and skeletal status should be determined from the hip.

BMD measurements of the spine are of interest because the rapid turnover of the metabolically active trabecular bone in the vertebrae makes changes in the spine particularly responsive to the effects of ageing or other diseases.

Several measurement sites are used in the evaluation of the femur: the femorall neck, Ward's triangle, and the trochanteric region. The femoral neck represents an area of predominantly cortical bone, while Ward's triangle represents an area of predominantly cancellous (trabecular) bone. Total hip BMD is the area weighed mean BMD for the femoral neck, trochanter, and intertrochanteric sifes.

To be of any use clinically. BMD results for individual patients must be related to values obtained from a healthy reference population. The reference population is described in tems of the mean $B M D$ and the population SD correlated for age, sex,
and race.

The $T$-score result is a parameter widely used to assist in the interpretation of BMD results. It measures patients' BMD values from the mean BMD of a young adult population in units of the population SD. The young adult mean and SD are derived from a group of healthy subjects aged 20-35 years and correlated for sex and race. In this group, subjects are expected to attain the maximum BMD possible. The WHO working group has published an interpretation of BMD measurements, based on a 
classification of patients into nomal, osteopenia, osteoporosis, and established osteoporasis $(2.2)$.

Working definition for diagnosing osteoporosis by the World Health Organisation Normal BMD not more than I SD below the value of young adults

Osteopenia

$\mathrm{BMD}$ of $1 \mathrm{SD}$ lower than the average value of young adults, but not more than $-2.5 \mathrm{SD}$

Osteoporosis BMD more than 2.5 SD lower than the average value of young adults.

Established osteoporosis $\mathrm{BMD}$ more than $2.5 \mathrm{SD}$ lower than the average value (Severe osteoporosis) of young adults and the presence of one or more fragility fractures

However, caution should be exercised in interpreting the T-scores of elderly patients because of the normal age-related bone loss, and even the BMD values may be below $T$-scores of -2.5 . To identify the need for treatment in patients aged 65 years and over, who are most at risk for fragility fractures, the use of Z-scores rather than T-scores may be more appropriate.

The $Z$-score is similar to the T-score, except that the mean BMD and SD of a healthy age-matched population are used as reference group, instead of the mean BMD and SD of a young normal group.

Apart from the measurements of bone mineral mass in the various regions of the skeleton, it is also possible to measure total body bone mass and to detemine soft tissue composition. For the Eindhoven Perimenopausal Osteoporosis Study (EPOS), we used DXA measurements of the lumbar spine and thip regions. The response to rreatment in this study was shown as a proportional $(\%)$ increase of BMD, and the interval between measurements was one year.

\subsection{Identification of patients at risk (risk factors used in clinical practice)}

The bone mass of an individual is a function of peak bone mass and subsequent losses. Since osteoporosis may arise from abnormalities at all stages of skeletal life, it is difficult to provide an accurate classification of osteoporosis, or to provide a classification for patients who are at risk for osteoporosis. Rather, it may be more usefulto consider osteoporosis as being predominantly multifactorial, and to describe the factors and their relative importance. For example, as described in Table 2, factors such as age, sex, and disease, are important determinants of bone mass, fractures, and falls, as are lifestyle influences including diet, exercise, and smoking.

Although many risk factors have been identified for osteoporosis and fractures, we have not yet been able to determine why some persons show a marked reduction of 
bone mass and are prone to multiple fractures, while other persons with similar risk factors do not have these characteristics. In a longitudinal study, Cummings et al. 12 described 9516 women aged over 65 years, with different numbers of risk factors for hip fractures. These women were followed for a mean period of 4.1 years, and $15 \%$ had $B M D$ in the lowest tertile and five or more risk factors for a hip fracture. It was calculated that, under these conditions, the risk of a hip fracture in this population was $27 / 1000$ women per year. When there were only wo or less risk factors, the risk of a hip fracture was $1.6 / 1000$ women per year.

Different kinds of gynaecological parameters, such as premature menopause, age of menarche, hysterectomy, pregnancy rates, and breastleeding, are described as being risk factors for low bone mass. However, the literature cannot agree as to the extent to which these factors lead to the development of fractures. 12,65-67

When considering the European Community, it is interesting to see how doctors are dealing with osteoporosis in the different European countries. In the Netherlands 68 and the United Kingdom ${ }^{69}$ (UK), guidelines for identifying and treating patients with osteoporosis have been published. Although the Dutch guidelines are aimed at general practitioners and the UK clinical guidelines at all workers in the field of osteoporosis, it is remarkable that these guidelines for the prevention and treatment of osteoporosis are rather conflicting, as can be seen from Table 4. The definition of osteoporosis is different in both guidelines. The Dutch guidelines describe osteoporosis as a state, while the UK clinical guidelines describe it as a disease. The most remarkable difference between these guidelines is the rejection of case-finding in the Dutch ones. Case-finding is focused on those subjects at highest risk. The policy behind this rejection is the lack of evidence for risk factors which, in the long term, contribute to low bone mass, and the lack of evidence regarding the medical prevention and treatment for osteoporosis. The consequences of this rejection of case-finding will be considered in the general discussion together with the results of our study.

Osteoporosis should be considered in all patients presenting with the following clinical features: back pain, kyphosis, loss of height, and fractures 70 , and patients at risk. Explicit indications are: early menopause, oophorectomized women, use of corticosteroids, mulfiple traumatic fractures, osteoporosis in primary relatives and anorexia nevvosa. Serious indications are: history of late menarche, secondary amenorhed, history of prolonged bedrest 18 Possible indications are: heavy smokers and women concerned about osteoporosis. When a patient is recognised and is being considered for treatment, bone densitometry is justified in those individ. uals in whom the result obtained will be used in treatment decisions. In patients with crush fractures of the lumbar spine, there is already satisfactory evidence of osteoporosis, and DXA is not reliable in these cases. 


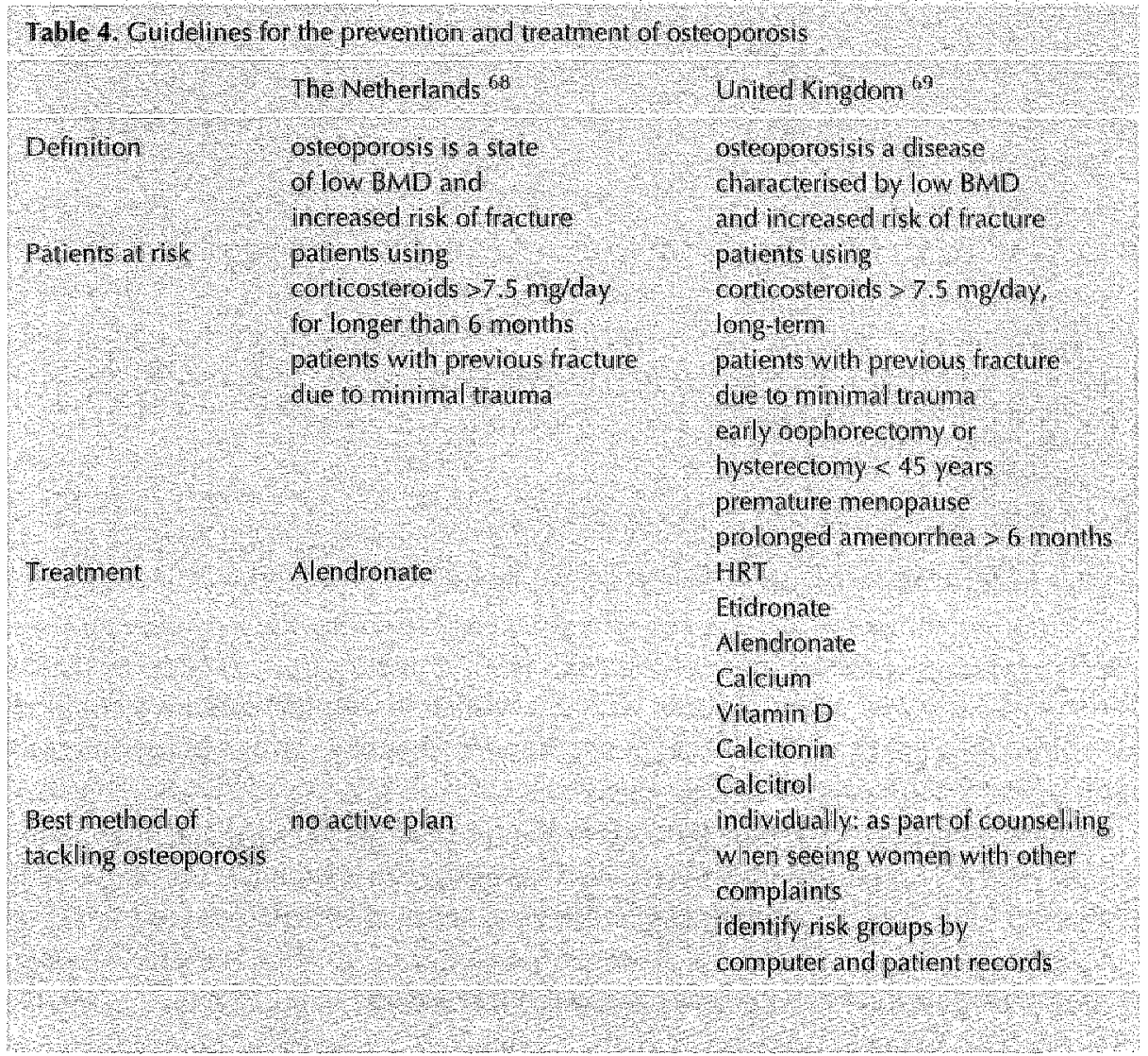

\subsection{Prevention of osteoporosis}

\section{Introduction}

The primary aim of any anti-osteoporotic intervention is the prevention of fractures in patients who have not yet experienced fractures, or the prevention of the disease in patients who have already sustained a fragillity fracture. 71

Prevention can be considered according to the stage in the natural history of the disease at which intervention is implemented:

Primary prevention is aimed at subjects without the disease, by reducing the risk factors for and/or causes of the disease.

Secondary prevention is aimed at those in whom the disease is potentially reversible and in whom intervention may reduce progression at an early, often asymptomatic stage. 


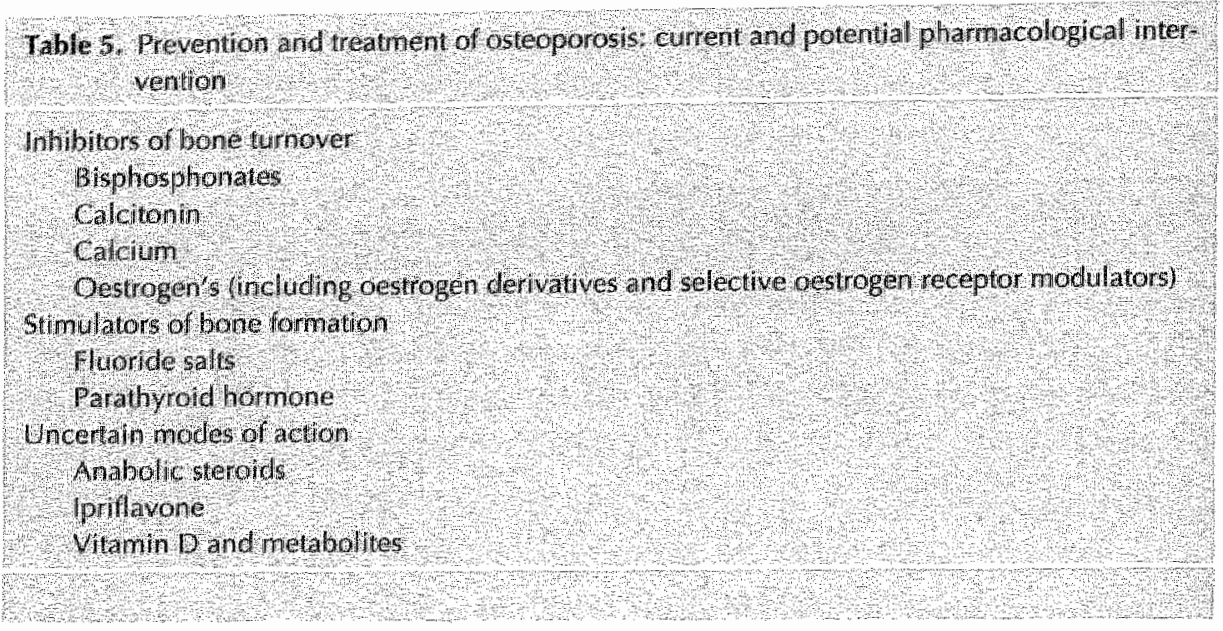

Tertiary prevention is aimed at those with established disease in whom intervention may limit associated disability or progression. In practice, tertiary prevention is synonymous with treatment of the disease.

The management of patients can include both non-pharmacological and pharmacological interventions. The ultimate goal of the different prevention and treatment strategies is to decrease the incidence of new osteoporosis-related fractures.

\section{Non-pharmacological and pharmacological interventions}

\section{Nom-pharmacological interwention}

Several non-phamacological interwentions may reduce the risk of fracture by increasing bone mass, reducing age-related bone loss, decreasing the risk of falling, improwing the protective neuromuscular responses associated with falling, or reducing the impact of falls with the use of for example, hip protectors (see 2.2). Nutritional factors as vitamin $D$ and calcium, as well as physical exercise, have multiple effects, influencing peak bone mass, age-related bone loss and muscle strength.

\section{Phamacological intervention}

Current phamacological interventions for the prevention and treatment of fractures in patients with osteoporosis are intended to reduce bone resorption and bone turnover or to stimulate bone formation. An overview of current pharmacological interventions is provided in Table 5, and the pharmacology is described in section 2.7 . 


\section{Primary prevention}

The goal of primary prevention is to obtain a maximum bone mass (peak bone mass) during the growing period. The general group for primary prevention are children and adolescents. The high-risk group includes children or adolescents in whom inferior bone development can be expected due to, for example, chronic illness or medication. Primary prevention consists of information regarding the importance of calcium, vitamin $\mathbb{D}$ intake, and of undertaking physical exercise and weight bearing exercise, for example, during childhood and adolescence.

\section{Secondary prevention}

The goal of secondary prevention is the early detection of those who are at risk for developing osteoporosis. The group for secondary prevention is all women around the menopause and women with an early menopause or a history of osteoporosis in relatives, patients with gastrointestinal infections (Crohn's colitis), hyperthyroidism, and other chronic illnesses (2.2).

In general, a healthy lifestyle is important. A good vitamin-D status texposure to sunlight) and good general health from taking part in sports, should be the rule. Calcium must be part of the diet; women around the menopause need $800-1000 \mathrm{mg}$ calcium daily. In case of a calcium-deficient diet, calcium should be taken as tablets. Some authors ${ }^{72,73}$ emphasise increased bone resorption rates during the night, and recommend the use of calcium supplements at bedtime, although DawsonHughes $^{74}$ prefers small doses of calcium to be taken with each meal (calcium carbonate) and at bedtime, or only at bedtime (calcium lactate-gluconate). The effects of exercise on postmenopausal bone loss are described in a meta-analysis by Bérrard et al ${ }^{75}$ A significant effect due to moderately intense physical activity was detected on lumbar spine BMD, but no consistent effect was seen on femoral neck or forearm bone mass. Exercise programmes in these studies consisted of running. walking, physical condition training, and aerobics.

Increases of between 2.5 and $5 \%$ in spinal BMD have been reported in postmenopausal women after seven to nine months on an exercise programme, 76,77 al though there was no additional benefit between 9 and 22 months and all gain was lost in those who left the programme. As in young adults, there is some evidence that callium and exercise thave additive effects on bone mass in postmenopausal women. ${ }^{78}$ Overall, the gains from vigonous exercise compared to everyday activities are probably small, and must be maintained to retain any effect.

Preventive intervention such as oestrogen's or alendronate should be prescribed on an individual basis, taking into account bone density, hormone status, and family factors (e.g, breast cancer, if hormonal substitution therapy is an issue). The success of treatment is largely due to compliance to therapy. 
An overview of double-blind, placebo-controlled randomised clinical trials asses. sing $B M D$ in peri- and early postmenopausal women shows the reatment with regard to secondary prevention.

\section{Terhiary prevention}

Tertiary prevention is aimed at patients with established disease. This group consists of those people with a low bone density compared to persons of the same age (Z-score) or to the peak bone mass (T-score), and patients who have already had a fracture. Intervention consists of information about calcium-rich nutrition or calcium supplements, and supplementation of vitamin $D$ also therapy such as ocstrogen's or alendronate should be prescribed on an individual basis.

In the elderly, and people in retirement and assisted homes, exercise programmes based on balance, strength training and low impact aerobics, may be beneficial. From randomised controlled studies, there is evidence that such regimens reduce the risk of falls. ${ }^{79}$ Walking and climbing stairs can be beneficial, and daily activities, social dancing, and group exercise should be encouraged, although motivation for long-term compliance is essential for the success of such programmes. The social aspects of exercising in groups can be an effective way to encourage elderly people to participate. A meta-analysis of trials in exercise prevention in community-based subjects suggested that it is possible to increase BMD, particularly if the exercise is of moderate intensity and enjoyable, and to reduce falls by $10 \% .80$

\subsection{Treatment of osteoporosis}

The treatment of osteoporosis still constitutes a problem. The ultimate goal of treatment is to obtain a reduction in (further) fractures. Nevertheless, it is important to remember that an increase of bone mass does not directly indicate a reduction of fractures. The skeleton in postmenopausal osteoporosis is reduced in mass cquartity), but the loss of tissue in cancellous bone also causes important architectural changes, with thinning and elimination of the trabecular structures. ${ }^{18}$ As stated above, mass and fragility of the bone are important determinants of fractures.

Bone is remodelled throughout life, and the rate of remodelling is increased in older adults. 87 The rate of resorption exceeds that of formation in older adults, resulting in osteoporosis. Bone remodelling occurs at all sites within the skeleton and proceeds in a well-ondered way, with bone resumption always being followed by bone formation. This process is similar in the contical and trabecular bone. 88

The process of resorption of bone, followed by synthesis of the bone matrix and mineralization, takes up to several months. ${ }^{18}$ If the processes of bone resorption and bone fomation are not well-matched, there is remodelling imbalance. In addition to the efrect on remodelling activation, it is assumed that there must also be a defect 
Table 6. Effect of preventive intenvention on bone nineral density of the lwabar spine in early menopausal women Double blind placebo contro led randomised inals

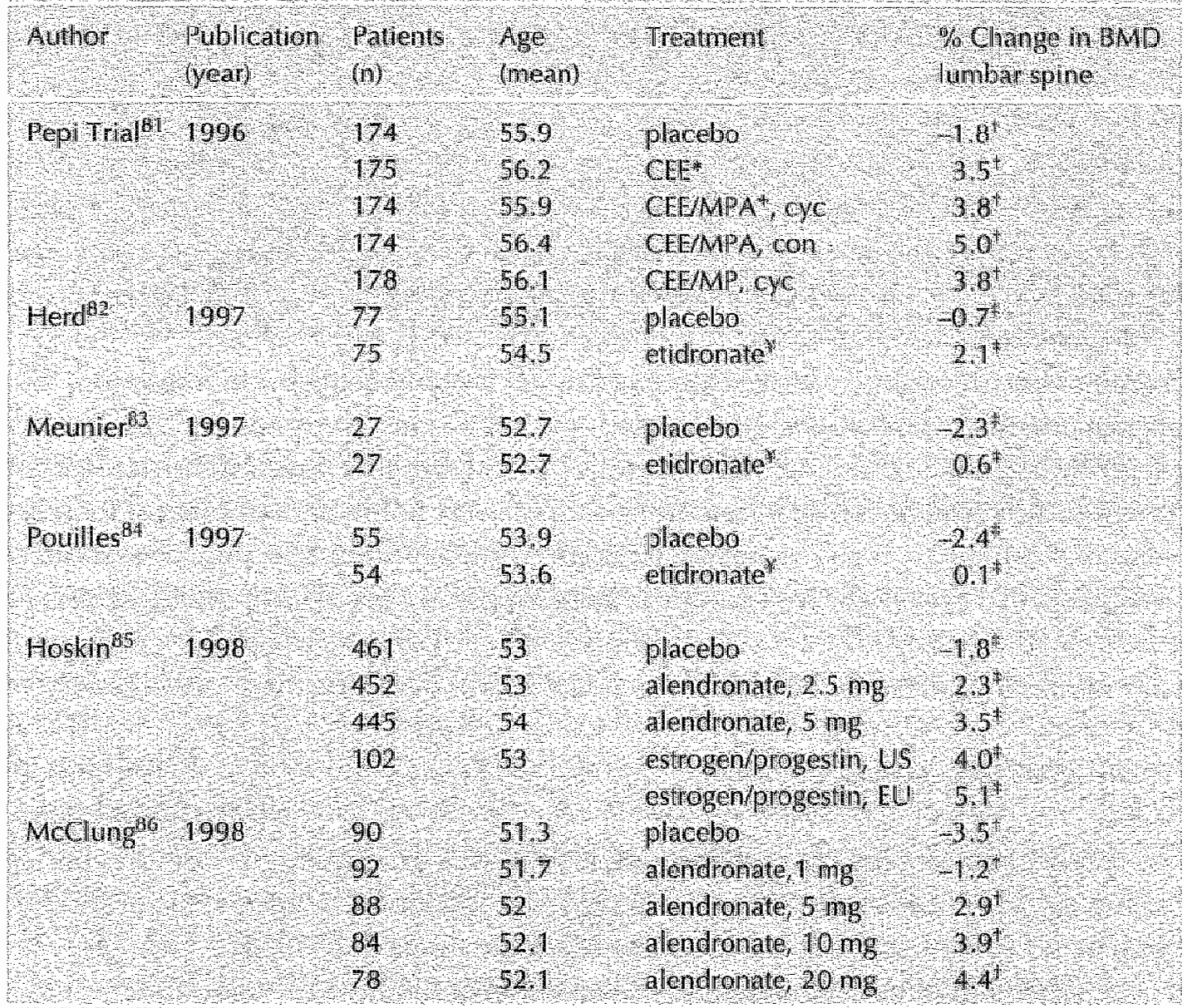

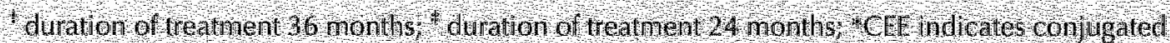
equine oestrogen, MPA nedroxyprogesteron acelate, MP micronzed progesteron cy, cyclic adninistration, con, continuous administration? Yndicates oral etidronate 400 myday 14 days, calcuim $500 \mathrm{mg} 76$ days, 90 day treatment cycle, US indicates conj, oestrogen $0.625 \mathrm{mg}$ daily, medroyprogesterone acetare $5 \mathrm{mg}$ dilly $1 \mathrm{U}, 2 \mathrm{mg}$ nikronized esinadial 22 day $1 \mathrm{mig}$ norethindrone acetate, day $13-2$ and 1 mg of estradiol day 2328 .

within each remodelling cycle, such that the amount of new bone synthesised is less than the amount removed by the osteoclasts. Whether this results from excessive action of the osteoclasts or from inefficient osteoblast activity, remains a matter of speculation, although the general opinion is that the osteoclasts are responsible. Medications used to treat osteoporosis can be grouped into those that decrease bone resorption and those that stimulate bone formation, as summarised in Table 5. Most of the drugs used act by decreasing bone resorption ${ }^{88}$, and are referred to as antiresorptive drugs. This group includes oestrogen, bisphosphonates, calcitonin, anabolic steroids, and the more recently developed SERM. Because the processes of 
bone resorption and bone formation are related, these drugs decrease the effect of both processes. When an antiresorptive drug is given, the rate of bone resorption decreases within weeks, and that of bone formation within months. This difference in timing is a result of the coupling mechanism.

Antiresorptive therapy decreases the rate of new remodelling siles, resulting in fewer remodelling spaces and a decrease in remodelling spaces. The filling in of the remodelling spaces accounts for the $5-10 \%$ increase in BMD occurring in postmenopausal women receiving antiresorptive therapy. This process usually takes two to three years. After this filling in of the remodelling spaces, the bone density changes very little.

Some of the drugs used to treat osteoporosis act by increasing bone formation. This group includes fluoride and parathyroid hormone. The newly formed bone either overflows resorption capacities or overfills the surfaces that have not been resorbed previously. ${ }^{18}$ Drugs that stimulate bone formation result in annual rates of increase of BMD similar to those resulting from antiresorptive therapy, but this increase continues for more than two years, although, in studies using fluoride, there was no effect on fractures. 89,99

A brief description of the results of the treatment of asteoporosis is given below.

\section{Oestrogen replacement therapy}

The mechanism by which oestrogen affects skeletal remodelling is not fully understood. Although oestrogen receptors have been identified in bone cells in culture, there is no evidence that these cells represent the target cells in wivo. ${ }^{91}$ In vivo, the effect of oestrogen's is thought to involve the inhibition of osteoclasts, ${ }^{92}$ thus slowing bone turnower and improving the balance between bone formation and bone resorption. Oestrogen also improves calcium retention through increased calcium and renal reabsomption. ${ }^{93}$ There is also evidence that oestrogen influences other factors related to the risk of fractures, e.g., extraskeletal effects, such as improved balance 94,95

Information on the effects of oestrogen replacement therapy on the rates of vertebral fractures is limited. In a onemear study of transdermal oestrogen therapy in 75 women with osteoporosis, the relative risk of vertebral fractures was $0.39(95 \% \mathrm{Cl}$ $0.16-0.95$ ) in the treatment group compared to the placebo group, 96 although these numbers were expressed by means of 100 persons/years at risk.

Additional evidence that oestrogen therapy prevents fractures has been derived from prospective cohort studies. ${ }^{97-100}$ A meta-analysis described 11 studies in which oestrogen therapy was used to prevent fractures; ten of these studies showed a relative risk of 0.75 . More than ten years use of oestrogen showed a relative risk of $0.50{ }^{101}$ Moreover, a case control study from the Swedish Hip Fracture Study group showed that, for hip fractures, current HRT users had an odds ratio of $0.35(95 \% \mathrm{Cl}$ 0.2440 .53 compared to non-users in the reference category; while former users had 
Table 7. The benefits and risk of festrogen therepy in pos tmenopaisal women

Benefits

Relief of climacteric symptons

Prevention of bone loss and fractures

Prevention of ischemic lieart disease
Risks:

Menstrualbleeding

Findonetral carcinotial

Breast carcinoma 107.100

Deep venous throribosis and

puthonary embolism 9 ö?

The risks and benefils of I IRT Use are included in the Cenelal Discussion

an odds ratio of $0.76(95 \% \mathrm{Cl} 0.57-1.01)$. The protective effect increases with duration of use and higher doses of oestrogen's, and the oestrogen sparing effect is higher when progestins are included in the regimen. 102

There are conflicting data regarding the time to start treatment. Significant protection from hip fractures among women who started HRT within five years after the menopause was noted in a study of asteoporotic fractures, but not among women who started HRT later. 100 However, in the Swedish Hip Fracture Study 102 and the study of Sneider ${ }^{103}$, similar bone conservation was seen after oestrogen therapy started either before or after the age of 60 years. The daily doses of oestrogen needed to obtain a reduction in hip fractures are $2 \mathrm{mg}$ estradiol and $0.625 \mathrm{mg}$ conjugated oestrogen's, or equivalent. 102,104 Treatment with skin patches produces similar results as oral regimens.

Bone mass declines after HRT is stopped, and therefore, for optimal protection, this should be continued for a long period, with five to ten years usually being recommended. ${ }^{102,105}$ Other beneficial effects and side-effects of oestrogen are listed in Table 7 .

\section{Bisphosphonates}

Bisphosphonates are synthetic, stable analogues of natural pyrophosphate. They are poorly absorbed from the intestine (absorption of less than $1-5 \%{ }^{110}$ of the adminis* tered dose, but absorption is nearly zero in the presence of calcium-containing foods). Bisphosphonates are potent inhibitors of bone resorption, acting via a mechanism not yet fully understood, but there are three possible mechanisms by which bisphosphonates may affect osteoclast bone resoiption. Firstly, they may interfere with the function of mature osteoclasts. Secondly, they may maintain a concentration gradient at the bone surface of sufficient magnitude directly to affect the cellular processes involved in the initiation of osteoclast activation. Thirdly, they may alter the properties of the bone matrix responsible for the final formation and activation of osteoclasts. "11 Their net effect on osteoclasts or their precursors is an increase in cell 
death, and therefore, a decrease in bone resorption. Bisphosphonates are deposited in the bone at sites of mineralization and in the resorption lacunae, and are eliminated by the kidneys.

Bishosphonate therapy results in increased BMD and a decrease in fracture rate. Several compounds from this family have been evaluated for the prevention of bone loss (alendronate, clodronate, pamidronate, tiludronate, risidronate, and ibandronate). Data on fractures are available for etidronate, alendronate and risidronate, and are discussed below.

Two studies (RCTs) of similar design examined the effect of cyclical etidronate on fracture frequency in postmenopausal women with prevalent fractures both found a decrease in vertebral fracture frequency with intermittent use. 112,113 in neither study were vertebral fractures a specified endpoint, both were difficult to interpret, and both used questionable criteria for vertebral fractures. The follow-ups of both studies have been extended. 114,115 Five years after starting his study, Storm 115 showed a significant increase $(5.5 \%)$ in spine BMD compared with a $2.7 \%$ decrease in the placebo group. There was also a significant reduction in the vertebral fracture rate in patients treated with etidronate.

Etidronate given continuously at high doses can result in impaired mineralization, which can be avoided by low doses of intermittent therapy. 16 Therefore, this drug is usually given at a dose of $400 \mathrm{mg}$ per day for two weeks, followed by $500 \mathrm{mg}$ per day of supplementary calcium for $11-13$ weeks. This regimen resulted in an increase of BMD, ${ }^{84}$ and also in a decrease of non-vertebral fractures. 117

Alendronate is given at a dose of $10 \mathrm{mg}$ for the treatment of osteoporosis in postmenopausal women. This results in an increase in BMD and a decrease in fractures. $85,86,117-120$ Karf et al. ${ }^{121}$ described the overall effectiveness of alendronate in the prevention of non-vertebral fractures in a meta-analysis of five RCTs. The efficacy of alendronate in decreasing fractures has also been demonstrated in the Fracture Intervention Trial. ${ }^{118}$ In 2027 women (mean age, 71 years) with at least one vertebral fracture and femoral neck BMD of less than 2 SD of peak bone mass were randomised to receive $5 \mathrm{mg}$ allendronate daily or placebo. After two years, the dose was increased to $10 \mathrm{mg}$ per day for the final nine months of the study, as in parallel trials, this dose has been shown to induce optimal effects on the bone mass. New vertebral fractures (including clinical ones) occurred in $15 \%$ of the placebo group and in $8 \%$ of the alendronate group. Active treatment also significantly reduced the risk of multiple vertebral and wrist fractures. Alendronate has been associated with esophagitis, including the erosive type. 163 To mimimize the risk of esophagitis and to increase drug absorption, the patient should take alendronate with a glass of water, not when lying down, at least 30 minutes before breakfast.

Pamidronate is also used in studies of the treatment of osteoporosis, both orally ${ }^{122-124}$ and intravenously. ${ }^{125}$ These studies showed a significant increase in spinal BMD. The most widely used regimen is pamidronate $150 \mathrm{mg}$ daily. 
Risidronate was recently evaluated in the treatment of women with established osteoporosis. 162 Compared to placebo, BMD increased significantly at the lumbar spine $15.4 \%$ versus $1.1 \%$ ), femoral neck $(1.6 \%$ versus $-1.2 \%)$, frochanter $(3.3 \%$ versus $-0.7 \%$, and midshaft of the radius $(0.2 \%$ versus $-1.4 \%)$

The optimal duration of bishosphonate therapy is still not known.

\section{Calcium and vitamin $\mathrm{D}$}

Ninety-mine percent of total body calcium is found in the bones. If the supply of calcium is inadequate, mineralization can become sub-optimal. Calcium deficiency can also affect the bone mass by causing secondary hyperparathyroidism, which leads to increased bone resorption. Some patients in whom clinical osteoporosis develops may have a low calcium intake, but may also be vitamin-D deficient, due to low exposure to sunlight or gastrointestinal disease, and may have some degree of secondary hyperparathyroidism resulting from these problems. Therefore, adjustment of calcium intake may improve a given physiological situation, but is unlikely to reverse other problems affecting the bone metabolism. Vitamin $D$ increases intestinal calcium absorption and the active metabolite of vitamin D, calcitrol and related alfacalcidol, increases calcium absorption, and may have a direct effect on the bone cells.

In a study of 3270 institutionalised women in France, who were treated with calcium $1200 \mathrm{mg}$ per day and vitamin D 800 IE per day for three years, the risk of hip fractures was $30 \%$ lower than in the placebo group. This therapy also resulted in a reversal of secondary hyperparathyroidism and in an increase of BMD in the femoral neck. 126 Care must be taken not 10 generalise the results of this study. In the Netherlands, in approximately 3000 women of similar age, studied by Lips et al. 127 who were treated with vitamin D (400 IE per day) or placebo for three and a half years, but not with supplemental calcium, the rate of hip fractures was similar between the groups. The probable explanation for the differences between these wo studies is the differ. ences between the women studied. The French women had lower dietary calcium intake, were frailer, and had lower serum 25-hydroxy vitamin D concentrations. Dawson-Hughes et al. ${ }^{28}$ reported on approximately 400 older men and women in the USA who were treated with $500 \mathrm{mg}$ calcium and $7001 \mathrm{U}$ vitamin D per day, or placebo. Over the three years of the study, the rate of nonvertebral fractures decreased. This was surprising because the increase in BMD was small (lumbar spine $0.9 \%$, femoral neck $1.2 \%$, total bodly $1.2 \%$. The major differences between this study and the Dutch one were the lower baseline dietary intake of calciun and the higher serum 25-hydroxy vitamin D concentrations in the US patients.

In general, a proportionate effect on BMD from calcium supplementation can be expected in cases in which the calcium intake is below $500 \mathrm{mg}$ a day. In the Netherlands, the mean calcium intake is relatively high, $800 \mathrm{mg}$ or more daily. 


\section{Calcitonin}

Calcitonin is a 32 -amino-acid peptide nomally produced by the thyroid C cells, and results in decreased bone resorption. Osteoclasts have calcitonin receptors, and calcitonin rapidly intibits the action of osteoclasts. Salmon or human calcitonin is given by subcutaneous or intramuscular injection at doses of up to $100 \| U$ daily. Calcitonin therapy results in an increase in BMD, although the numbers of convincing trials are relatively small. Calcitonim is expensive and can have side-effects, such as nausea, flushing, and diarhoea. The development of intranasal salmon calcitonin may make this therapy more acceptable, but at least 200 IU must be given to have an effect on BMD. The largest double blind, placebo-controlled trial, with a two-year follow-up, consisted of 208 postmenopausal women with low BMD. BMD increased as the doses increased. The total number of fractures in this study was too small for an effect to be proved. 129

Four placebo-controlled trials have been performed to determine the analgesic effect of calcitonin in patients with bone pain related to osteoporosis. In the largest trial, 130 60 women who had experienced a vertebral fracture due to low trauma were given subcuteanous injections of human calcitonin three times each week compared with placebo. There was a significant analgesic response in the treated group over a four-month period, but no change was observed in forearm BMD over the study period. These observations are supported by other short-term placebocontrolled studies. 131,132

\section{Fluoride}

Sodium fluoride stimulates bone by unknown mechanisms. In one study of 202 women with osteoporosis, who were treated with sodium fluoride, lumbar BMD increased by $8 \%$ per year in all four years of the trial. ${ }^{13} 3$ There was substantial bone loss in the forearm, indicating a redistribution of bone mineral from the cortical to cancellous bone. Biochemical markers of bone formation increase in fluoride-treated women, but markers of bone formation do not. The large increase in BMD should be associated with a decrease in fracture rate, alhough, in most studies, the effect was limited. 13:135 In one study, there was a significant reduction in the rate of vertebral fractures, the relative risk being 0.3 .136 In this case, the dose of fluoride was smaller than in earlier studies, and it was given intermittently as slow-release sodium fluoride. Fluoride can cause gastric irritation, but this can be reduced if the crug is taken together with a calcium supplement. It can also cause lower-extremity pain syndrome. 133 In the Dutch literature, fluoride is characterised as being controversial and experimental. 137,138 


\section{Raloxifene}

Raloxifene has mixed oestrogen-agonist and oestrogen-antagonist activily and is referred to as a selective oestrogen-receptor modulator. ${ }^{139}$ In a wo-year study, raloxifene therapy resulted in a decrease of bone resorption. ${ }^{140}$ Ettinger et al. 141 published data from a large trial of raloxifene to the effect that it prevents bone mass and reduces the rate of vertebral fractures in postmenopausal women. The acute effect is less marked than that of oestrogen's because a smaller increase in bone mass is seen. ${ }^{142}$ Raloxifene also appears to decrease the risk of breast cancer, 143 but long follow-up trials are necessary to prove this effect. It decreases serum low-density lipoprotein cholesterol concentrations, but not does stimulate endometrial growth. Raloxifene increases the risk of venous thromboembolic events, as do pestrogen's. ${ }^{144}$ Other selective oestrogen-receptor modulators are under development (droxifene, idroxifene, and Ivomeloxifene) and may provide an alternative to oestrogen therapy.

\section{Tibolone}

Tibolone is a synthetic steroid with an affinity for oestrogenic, progestogenic and androgenic receptors. The parent is structurally related to norethnodiel and appears preferentially to bind to oestrogenreceptors, whereas its metabolites have a greater affinity for progesterone and androgenreceptors. 145 Tibolone shows tissue-specific oestrogenic activity in controlling hot flushes and sweats. It does not stimulate endometrial proliferation (2.5 mg) and eliminates the need for progesteron administration. Androgenic effects have been observed with tibolone, and can improve mood and libido. ${ }^{146}$ Clinical studies have shown oestrogenic activity on the bone in preventing postmenopausal bone loss. 147,148 in elderly postmenopausal women with vertebral fractures, treatment with tibolone significantly increased bone mass. 49 Open, non-randomised studies suggest effects at all skeletal sites. "50 The long term-effects of tibolone on cardiovascular morbidity have not yet been evaluated, but it decreases both fipoprotein-(a) and low-density lipoprotein (LDL). Tibolone should only be used in women who are at least one year postmenopausal.

\section{Parathyroid hormone}

Daily injections of parathyroid hormone stimulate bone formation. It may be given as intact homone or as a symhetic fragment. Treatment for up to two years results in an increase in bone density of the spine but in no change of that of the femoral neck, and an increase in the biochemical markers of bone formation and bone resorption. ${ }^{151}$ The effect of parathyroid hormone on fractures is not yet known. 


\section{Nandrolone}

Nandrolone is an anabolic steroid and is given as an intramuscular injection. It appears to increase BMD, but only a few studies are available and these are all of short duration. 152,153 The effect of nandrolone on fractures is not yet known.

\section{Other therapies}

A number of cytokines and growth factors have potent effects on bone cells. These factors also affect other organs. For example, cytokines modulate the immune system. The challenge will be to target such factors to the bone alone. Other therapies that have been developed for the treatment of osteoporosis include vitamin $D$ analogues, strontium salts, and ipriflavone.

Women most at risk for fractures ane the ones who should be treated, among whom those who have already sustained a fracture with minimal or no trauma, and those who have low BMD or other risk factors for fracture (section 2.4). It is important to select the appropriate treaiment. Oestrogen or bisphosphonates are the treatments of first choice, depending on the age and risk profile of the patient. HRT should be given for at least five years, or preferably longer, because the benefits may not persist after treatment. Detailed discussions with the patient to consider the risks and benefits of oestrogen therapy can enhance compliance (Table 6). Bisphosfonates are particularly useful in women who are concerned about the side-effects of oestrogen therapy, or who are at risk of developing breast carcinoma. Elderly women with osteoponosis are also candidates for treatment with bisphosfonates.

\subsection{Compliance}

\section{Measuring compliance}

Patienl compliance can be defined as "the extent to which the actual dosing history conforms to the prescribed dosing history" 155 in many areas of medicine, but most notably in non "Symptomatic diseases such as hypertension, patient compliance to a drug regimen has been shown to be less than optimal. ${ }^{56.157}$ Unlike patients with symptomatic diseases, those with non-symptomatic diseases such as hypertension or osteoporosis should have a strong motivation to conform to drug prescription orders tor up to ten or even wenty years. Compliance measurements can vary enormously. Patients can administer more or less than, or exactly the amount of the medicine prescribed. Patients may take their medicine erratically isometimes taking more and sometimes less than prescribed). Finally, patients may neglect the recom- 
mended method or time to administer the medicine. Therefore, compliance is both a term for a behaviour and a measure of it.

in general, clinical trials rely on returned tablet counts as a measure of compliance. Each participant is given a package with a known number of doses, enough for the interval between scheduled visits, plus a few extras. At the following visit, a new package is dispensed, and the number of doses remaining in the old package counted. Of course, patients may discard untaken doses and return an empty or almost empty package, with the suggestion of good compliance. A series of trials in which oral dosage forms contained small quantities of a slow tumover chemical marker, subsequently assayed in plasma as a direct measure of compliance, showed that returned tablet counts overestimate compliance, 157 Another trial found that most patients returned an empty or near-empty container, imespective of the number of tablets dispensed, although more tablets were given than necessary. ${ }^{157}$

Patient compliance to a drug regimen can be accurately measured by the use of electronic monitoring. A time-keeping microcircuit integrated into the drug package records the time and date of opering of the medication package. Although this is only an indirect measurement (no prof of ingestion of the drug is acquired), the method has sufficient advantages over other compliance measurement instruments to make it the current gold standard. ${ }^{158}$ Moreover, many studies using electronic monitoring have also included returned tablet counts, and have also found that many poorly compliant patients returned few or no tablets. 159

\section{Drug holidays}

The majority of patients take their medication almost as prescribed. When they do not, electronic monitoring has shown that the most common error is a lapse in dosing, creating longer intervals between doses than prescribed, often of hours, sometimes of days, occasionally of weeks. These longer intervals (especially three days or more) are known as drug holidays. 60 The major consequence is that the action of the drug diminishes and disappears. The clinical relevance of these drug hollidays is the 'forgivingness' of the drug. (For example, oral contraceptives are very unforgiving, since if even one dose is missed, the contraceptive coverage can be lost.) Therefore, a longer-acting agent, can 'forgive' accasional or intermittent errors in compliance.

When prescribed drug therapy fails to produce the expected results, noncompliance is often the underlying reason. Drug information aimed at patients and prescribers can be improved by careful assessment of the degree fo which drug efficacy and safety depends on compliance. Therefore, in clinical practice and when conducting research, accurate knowledge of patient compliance is important for both optimising pharmacotherapy and correctly evaluating the outcome of such drugs. 161 


\section{Literature}

1. Consensus Development Conference. Prophylaxis and treatment of osteoporosis. Am I Med 1991:90:107-110.

2. Kanis $J A$, Melton $\mathrm{L} / 1 \mathrm{I}$, Christiansen $\mathrm{C}$, Johnston $\mathrm{CC}$, Khallaev $\mathrm{N}$. The diagnosis of osteoporosis. I Bone Mineral Res 1994;9:1137-1141.

3. Krolner $\mathrm{B}$, Nielsen SP. Bone Mineral Content of the lumbar spine in nomal and osteoporotic women: cross-sectional and longitudinal studies. Clinical science $1982 \cdot 62: 329-336$.

4. Riggs BL, Metton U. Involutional osteoporosis. N EnglJ Med 1986;314:1676-1684.

5. Kelepouris N, Harper KD, Gannon F, Kaplan FS, Haddad JG. Severe osteoporosis in men. Ann Int Med 1995; 23:452-460.

6. Melzer M, Lessig HI, Siegel IA. Bone Mineral Density and fracture in postmenopausal osteoporosis. Calcif Tissue int 1989:45:142-145.

7. Ross PD, Davis JW, Epstein RS, Wasnich RD. Premexisting fractures and bone mass predict vertebral fracure incidence in women. Amn Int Med 1991:114:919-923.

8. Bonjour !, Theinz $\mathrm{G}$, Buchs $\mathrm{B}$. Slosman D, Rizzoli R. Critical years and stages of puberty for spinal and femoral bone mass accumulation during adolescence. $)$ Clin Endocrinol Metab 1991;73:555-563

9. Kröger H, Kotaniemi A, Kröger L Alhava E. Development of bone mass and bone density of the spine and fernoral neck.-A prospective study of 65 children and adolescent. Bone Miner 1993;23:171-182

10. Cummings SR, Black DM, Nevilt MC, Browner WS, Cauley IA, Genant HK, Mascloli SR, Scott JC, Seeley DG, Steiger P, Vogt TM. Appendicular bone density and age predict hip fracture in women. JAMA 1990;263:665 668

11. Geusens P, Dequeker I, Verstraeten A, Nijs I. Age-, sex-, and menopausal related changes of vettebrat and peripheral bone: population study using dual photon absorptiometry and radiogrammetry. I Nucl Med 1986; 27:15:40-1549.

12. Currming RG, Nevit MC, Browner WS, Stone K, Fox KM, Fnstud KE, Cauley I, Black D, Vogt TM. Risk factors for hip fracture in white women. N Engl I Med 1995;332:767-773.

13. Ross PD, Davis IW, Epstein RS, Wasnich RD. Pre-existing fractures and bone mass predict vertebral frachure incidence in women. Ann Intern Med 1991:1 14:919-923.

14. Hui Sl. Stemenda CW, Johnston CC Ir. Age and bone mass as predictors of fracture in a prospective study. I Clin Invest 1988;81:1804-1809

15. De Laet CEDH, Van Hout BA, Burger H, Holman A, Pols HAP. Bone density and the risk of thip fractume in men and women: cross sectional analysis. BMI 1997; 315:221-225

16. Nevitt MC, Cummings SR. Type of fall and risk of hip and wrist fractures: The study of osteoporotic fractures. I Am Geriatr Soc. 1993;41:1226-1234.

17. Ruberstein LZ, Josephson KR, Robbins AS. Falls in nursing homes. Ann int Med 1994; $121: 442-451$

18. Kanis IA 1994. Osteoporosis. Blackwell, Oxford.

19. Ross PD, Davis IW, Epstein RS, Wasnich RD. Pre-existing fractures and bone mass predict vertebral fracture incidence in women. Ann Intern Med 1991;114:919-923

20. Wasnich RD, Davis IW, Epstein Ross PD. Spine fracture risk is predicted by non spine fractures. Osteoporosis Int 1994:4:1-5.

21. Cooper C. Melton LIIII Age specific incidence vates for hip, vertebral, and distal forearm fractures in men and women. Trends Endocrinology. Metab. 1992;3:224-229 
22. Lauritzen IB, Petersen MM, Lund B. The effect of external hip protectors on hip fractures. Lancet 1993; $341: 11-13$.

23. Boereboom FT, Raymakers JA, Duursma SA. Mortality and cause of death after hip Iractures in the Netherlands. Neth J Med 1992; 41:4-110.

24. Cummings SR, Black DM, Rubin SM. Lifetime risks of hip, Colles', or vertebral hracture and during coronary heart disease among white postmenopausal women. Arch Intem Med 1989;149:2445-2448.

25. Chriscilles EA, Shireman T, Wallace R. Costs and health effects of osteoporotic fractures. Bone 1994;15:377-386.

26. Melton LJ 3d, Chrischilles EA, Cooper C, Lane AW Riggs BL. How many women have osteoporosis? I Bone Miner R 1992;7: 1005-1010.

27. Pocock NA, Eisman JA, Hopper IL, Yeates MG, Sambrook PN, Eberl 5 . Genetc determinants of bone mass in adults: a twin study. I Clin Invest 1987;80:706-710.

28. Slemanda CW, Christian IC, Williams C. Norton IA Iohnston CC. Genetic delerminants of bone mass in adult women: A re-evaluation of the twin model and the potential importance of gene interaction on herilability estimates. I Bone Miner. Res.1991;6:561-567.

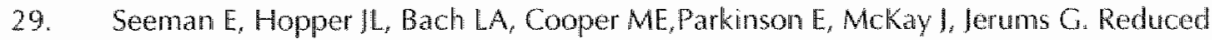
bone mass in daughters of women with osteoporosis. New Engl I of Med 1989; 320:554-558.

30. Torgesson DJ, Campell MK, Thomas RE, Reid MD. Prediction of perimenopausal fractures by bone mineral density and other risk factors. I Bone Miner Res $1996: 11: 293-297$.

31. Cummings SR, Black DM, Nevitu MC, Browner W, Cauley J, Ensrud K, Genant HK, Palermo L, Scott I, Vogt TM. Bone Density at warious sites for prediction of hip fractures. Lancet $1993 ; 341: 72-75$

32. Tromp AM, Smit JH, Deeg DJH. Predictor for falls and fractures in the Longitudinal Aging Study, Amsterdam. I Bone Miner Res 1998;13:1932-1939

33. Smeets-Goevaers CG, Leusink GL, Papapoulos SE, Maartens LW, Keyzer II, Weerdenburg JP, Beijers LM, Knotnents \A, Pols HAP, Pop VJ. The prevalence of low mineral bone density in Dutch perimenopausal women: the Eindhoven Perimenopausal Osteoporosis Study. Osteoporosis Int 1998:8:404-409.

34. Prior IC, Vigna YM, Schechter MT, Burgess AE. Spinal bone loss and ovulatory disturbances. N Engl I Med 1990;323:1221 1227.

35. Rigotti NA, Nussbaum SR, Herzog DB, Neer R. Osteoporosis in women with anorexia mervosa. N Engl I Med 1984;331:1601-1606.

36. Prior JC, Vigna YM, Barr SI, Kennedy S, Schulzer M, Li DK. Ovulatory premenopausal women lose cancellous spine bone: A five year prospective study. Bone $1996: 18: 261-267$.

37. Sowers MFR, Sapiro B, Gilbraith MA, Jannausch M. Health and hormonal characteristics of women with low premenopausal hormones. Calci Tissue Int 1990:47:130-135.

38. Cooper C. Barker DJP, Wickham C. Physical activity, muscles strength, and calcium intake in the fracture of the proximal femur in Britaim. BMI 1988;297:443-446.

39. Cumming RG, Nevitt MC. Calcium for prevention of osteoporotic fractures in postmenopausal women. I Bone Miner Res 1997;12:321-329.

40. Ranstam J, Kanis JA. Influence of age and body mass on the effects of vitamin D on hip fracture risk. Osteoporosis Int 1995; 5:450 454 . 
41. Lips, P, Van Ginkel FC, Jongen MMM, Rubertus F, Vander Viggh W, Netelenbos /C. Am I Clin Nutr $7987 ; 46: 1005-1010$

42. Sowers MR, Clark MK, Hollis B, Wallace RB. Radial bone mineral density in pre- and postmenopausal women: a prospective study of rate and risk factors for bone loss. I Bone Miner Res 1992;7:625-632.

43. Hernandez -Avila M, Colditz GA, Stampier MI, Rosner B; Speizer FE, Willet WC. Caffeine, moderate alcohol intake, and risk of fractures of the hip and forearm in middle aged women. Am / Clin Nuir 1991:54:157-163.

44. Felson DT, Kiel DP, Anderson J), Kannel WB. Alcohol consumption and hip fractures: the Framingham study. Am I Epidemiol 1988;128:1102-1110

45. Meyer HE, Henriksen C, Falch IA, Pedersen Il, Tverdal A. Risk factors for hip fracture in a high incidence area: A case control study from Oslo, Norway. Osteoporosis Int $1995: 5: 239.246$.

46. Cumming RG, Klineberg RJ. A case control study of risk factors for hip fractures in the elderly. Am / Epidemiol 1994;139:493-503.

47. Friedlander AL, Genant HK, Sadowsky S, ByI NN, Gluer CC. A two year program of aerobics and weight training, enhances bone mineral density of young women. 1 Bone Miner Res 1995; 10:574-585.

48. Kanuus P, Haapasalo $H$, Sievanen $H_{s}$ Oja P, Vuori I. The sit effects on long-term unilaterally activity on bone mineral density and content. Bone 1994;15:279-284.

49. Taaffe DR, Snow - Harter $C$, Connolly DA, Robinson TL, Brown MD, Marcus $R$. Differential effects of swimming versus weight-bearing activity on bone mineral status of eurnenorheic athletes. I Bone Miner Res 1995;10:586-593.

50. Ross PD. Prediction of fracture risk, II. Other risk factors. AM / Med Sci $1996 ; 312: 260-269$.

51. Grampp S, Genant HK, Mathur A, Lang P, Jergas M, Takada M, Gluer CC, Lu Y. Chavez $M$. Comparisons of non-invasive bone mineral measurements in assessing age related loss, fracture discrimimation and diagnostic classification. I Bone Miner Res 1997:12:697-711.

52. Cohn SH, Aloia JF, Vaswani AN, Yuen $K$, Yassamura $S$, Ellis $K$. Women at risk for developing osteoporosis: determination by body neutron activation analysis and photon absortiometry. Calcif Tissue int 1986;38:9-14.

53. Watmer HW, Dunn WL, Riggs BL. Assesment of bone mineral. Part 1. I Nud Med 1084,25:1134-1139.

54, Wahner HW, Riggs BL, Beaubout JW. Diagnosis of osteoporosis: usefulness of photon absorptionetry at the radius. I Nucl Med 1977:18:432-437.

55. Erdtsieck RI, Pols HAP. Algra A, Kooy PPm, Birkenhäger $/ C$. Bone mineral density in healthy Dutch women: spine and hip measurements using dual X-ray absorptiometry. Neth I Med 1994:45-198-205.

56. Mazess RB, Barden HS. Measurement of bone by dual photon absorptiometry (DPA) and duallenergy $X$-ray absomptionyetry. Ann Chir Cnaecol 1988;77:197-203.

57. Larcos $\mathrm{G}$. Wahner HW. An evolution of forearm bone mineral measurements with dual-energy x-ray absorptiometry. I Nucl Med 191;32:2101-06.

58. Gluer CC, Steiger P, Selvidge R, Elliesen-Kliefoth $\mathrm{K}$, Hayashi C, Genant HK. Comparative assessment of dual-photo absorptiometry and duallenergy radiography. Radiology
$1990 ; 174223-228$. 
59. Richardson ML, Genant HK. Cann CE. Ettinger BE. Assessment of metabolic bone diseases by quantitative computerized lomography. Clinn Orthop 1985; 185:224-238.

60. Genant HK, Steiger P, Block JE, Cliner CC. Ettinger B, Harris ST. Quantitative computerized tomography: update 1987. Calcif Tissue Int 1987;41:179-186.

67. Kauman 11. Einhorn TA. Ultrasound assessment of bone. I Bone Miner Res $1993 ; 8: 517-525$

62. Langton CM, Ali AV, Riggs CM, Evans GP, Bonfield W. A contactmethod tor the assessment of ultrasonic velocity and broadband attenuation in cortical and cancellous bone. Clin Phys Physiol Meas 1990; 1 1:243-249.

63. Daele van PLA, Burger H, Algra D. Hofman A, Grobbee DE, Birkenhäger JC, Pols HAP. Age-associated changes in ultrasound measurements of the calcaneus in men and women: the Rotterdam Study. \& Bone Miner Res 1994:9:1751-1757.

64. Bouxsein ML, Courtney $A C$. Hayes WC. Ultrasound and densitometry of the calcaneus correlate with the failure loads of cadaveric femurs. Calcif Tissue nt 1995;56:99-103.

65. Tuppulainen $M$, Kröger $H$, Saarikoski $S$, Honkanen $R$, Alhava $E$. The effect of gynecological risk factors on lumbar and femoral bone density in peri- and postmenopausal women. Maturitas 1995;21:137-145.

66. Johansson C, Mellestrom D, Milsom I. Reproductive factors as predictors of bone density and fractures in women at the age of 70 . Maturitas $1993: 17 \cdot 39-50$.

67. Gärdsell P. Johnell O. Nilsson B. The impact of menopausal age on future fragility fracture risk. ) Bone Miner Res 1991;6:429-433.

68. Fiders P, Van Keimpema $\mathrm{C}$. Petri H, Matser A, Pigmans. $V$, Bolhuis, A, Sips AJBI, Van Berkum H, Boukes FS, Romeijnders ACM, Wiersma Tj. NHG-Standaard Osteoporose. Huisarts Wet 1999;42:115-28.

69. The Royal College of Physicians. Osteoporosis, Clinical guidelines for prevention and treatment. 1999 Suffolk: The Lavenham Press.

70. Hirschberg $G_{G}$, Williams KA, Byrd $1 G$. Medical management of iliocostal pain. Geriatics 1992;47:62-65.

71. O'Neill T, Socrates S. Can we prevent fractures? Baillieres Clinical Rheumatology $1997 ; 115: 565 \times 582$

72. Blumsoln $A$, Herrington K, Hannon RA, Shao P', Eyre DR, Eastell R. The effect of calcium supplementation on the circadian rhythm of bone resorption. J Clin Endocrinol Metab $1994: 79: 730-735$.

73. Fujita T, Ohgitani S, Fujii Y. Overnight suppression of parathyroidhormone and bone resorption makkers by active absorbable algae calcium. A double-blind crossover study. Calcif Tissue Int 1997,60:506-512.

74. Dawson-Hughes B. The role of calcium in the treatment of osteoporosis. Osteoporosis. 1996. Academic Press, Inc. San Diego.

75. Berrard A, Bravo $G$, Gauthier P. Meta-analys is of the effectiveness of physical activity for the prevention of bone loss in postmenopausal women. Osteoporos int 1997;7:331 -337.

76. Hatori $M$, Hasagawa $A$, Adachi $H$. The effects of walking at the anaerobic theshold level on vertebralbone loss in postmenopausal women. Calcif Tissue Int 1993:52:411-414.

77. Dalsky GP, Stocke KS, Ehsani AA. Weight bearing exercise training and bone mineral content in postmenopausal women. Ann Intern Med 1997; 108:824-828.

78. Prince R, Devine A, Dick 1. The effects of calcium supplementation (millkpowder or tablets) and exercise on bone density in postmenopausal women. I Bone Miner Res $1995 ; 10: 1068-1075$. 
79. Sowden A, Sheldon T, Pahl L. Preventing falls and subsequent injury in older people. Eftective Health Care 1996:2:1-16.

80. Province MA, Hadley EC, Hombrook MC. The effect of the exercise on falls in elderly patients. A pre-planned meta-analysis of the FICSIT trials. JAMA 1995:273:1342-1347

81. Pepi Trial writing group. Effects of hormone therapy on bone mineral density. IAMA $1996,276: 1389-1396$.

82. Herd RIM, Batena R, Blake GM, Ryan Pl, Fogelman 1. Prevention of early postmenopausal bone loss. Am I of Medicine 1997; 103:92-99

83. Meunier Pl, Confavreux E, Tupinon I, Hardoin C, Delmas PD, Balena R. Prevention of early postmenopausal bone loss with cyclical etidronate therapy la double blind placebo controlled study and 1-year follow up / Clin Endocrin Meta 1997:82:2784-2791

84. Poulles IM, Tremollieres F, Roux C, Sebert IL. Alexandre C, Goldberg D, Treves $\mathbb{R}$, Khalifa P, Duntze P. Horlait S, Delmas P, Kuntz D. Effects of cyclical etidronate therapy on bone loss in early postmenopausal women who are not undergoing hormonal replacement therapy. Osteoporos Int 1997:7:213-218.

85. Hosking D, Clair ED, Chilvers D, Ravn P; Wasnich R, Ross P, McClung M; Balske A: Thompson D; Daley $M$, Yates AJ. Prevention of bone loss with alendronate in postmenopausal women under 60 years of age. N Engl J Med. 1998;338:485-492.

86. MCClung M, Clemmesen B. Daifotis A, Gilchrist NL, Eisman J, Weinstein RS et al. Alendronate prevents postmenopausal bone loss in women without osteoporosis. Ann Intern Med 1998:28:253-261.

87. Parfitt AM. Trabecular bone architecture in pathogenes is and prevention of tracture. Am J Med 1987;82:68-72.

88. Parfitt AM, Mundy GR, Roodman GD, Hughes DE, Boyce BF. A new model for the regulation of bone resorption, with particular reference to the effects of bisphosphonates. J Bone Miner Res 1996:11:150-159

89. Mamelle N, Meunier PI, Dusan R et al. Risk-benefit ratio of sodium fluoride treatment in primary wertebral osteoporosis. Lancet 1988;2:361-365.

90. Riggs BL, Hodgson SF, O Fallon WM, Chao EY, Walner HWY, Muhs JM, Cedel SL, Metron LI $3 \mathrm{~d}$. Effect of fluoride treatment on the fracture rate in the postmenopausal women with osteoporosis. N Engl I Med 1990-322:802-809.

91. Pacifici R. Postmenopausal osteoporosis: How the homonal changes of menopause Cause bone loss. Osteoporosis. San Diego, Academic Press 1996, pp $315-329$

92. Pacifici R. Cytokines, estrogen and postmenopausal osteoporosis. - the second decade. Endocrinology 1998;130:2659-2661.

93. Bilezikian IP. Oestrogen's and postmenopausal osteoporosis: was Albright right after all? I Bone Min Res 1998:13:7744-776

94. Hammar L, Lindgren $R$, Berg GE, Moller CG, Niklasson MK, Effects of hormonal replacement therapy on the postural balance among postmenopausal women. Obstet Gyneacol 1996;88:955-960.

95. Naessen T, Lindmark B, Larsen HC. Better postural balance in elderly women receiving Oestrogen's. Am J Obstet Gyneacol 1997;177:412-416

96. Lukin EG, Wahner HW, O' Fallon WM, Hodgson SF, Kotowicz MA, Lane AW, Judd HL, Caplan RH, Riggs BL. Treatment of postmenopatusal osteoporosis with transdermal Oestrogen. Ann Intern Med 1992;117:1-9. 
97. Kiel DP, Felson DT, Anderson IJ, Wilson PWF, Moskowitz MA. Hip fracture and the use of Oestrogen's in postmenopausal women. The Framingham Study. N Engl I Med $1987 ; 317: 1169-1174$

98. Maxim P. Ettinger B, Spitatny GM. Fracture protection provided by long-term Oestrogen treatment. Osteoporos int 1995:5:23-29

99. Paganini-Hill A, Ross RK, Gerkins VR, Henderson BE, Arthur M, Mack TM. Menopausal Oestrogen therapy and hip fractures. Ann Intern Med 1981;95:25-31.

100. Cauley $\mathrm{A}_{\mathrm{A}}$, Seeley DG. Ensrud K, Ettinger B, Black D, Cummings SR. Oestrogen replacement therapy and fractures in older women: Study of the Osteoporotic Fractures Research Group. Ann Intern Med 1995;122:9-16.

101. Grady D, Rubin S, Pettiti DB, Fox CS, Black D, Ettinger B, Ernster VL, Cummings SR. Hormone therapy to prevent disease and prolong lite in postmenopausal women. Ann Intern Med 1992; 117:1016-1037.

102. Michaëlsson K, BaronJA, Farahmand BV, Johnell O, Magnusson C, Persson, $P G$, Persson I. Ljunghall $\mathbf{S}$. Hormone replacement therapy and the risk of hip fracture: population based case-control study. BMII 1998;316:1858-1862.

103. Schneider DL, Barrett-Connor EL, Morton DI. Timing of postmenopausal oestrogen for optimal bone mineral density. The Rancho Bernado study. IAMA 1997:277:543-547.

104. Horsman $A_{v}$ lones $M$ Francis $R$ Nordin $C$. The effect of oestrogen doses on postmenopausal bone loss. $N$ Engl I Med 1983;309:1405-1407.

105. Felson DT, Zhang, $\gamma$, Hannan MT, Kiel DP, Wilson PWF, Anderson II. The effect of postmenopausal oestrogen therapy on bone density in elderly women. N Engl I Med 1993;329:1141-1746.

106. Beresford SAA, Weiss NS, Voigt LF, Mcknight B. Risk of endometrial cancer in relation to use of oestrogen combined with cyclic progestagen therapy in postmenopausal women. Lancet 1997;349:458-461.

107. Beral $\mathrm{V}$. Breast cancer and hormone replacenent therapy; collaboratiwe reanalysis of data from 51 epidemiological studies of 52705 women with breast cancer and 108411 without breast cancer. Lancet 1997;350:1047-1059.

108. Colditz GA, Hankinson SE, Hunter DJ, Willett WC, Manson JE, Stamprer MJ, Hennekens C. Rosner B, Speizer FE. The use of oestrogen's and progestins and the risk of breast cancer in postmenopausal women. N Engl I Med 1995;332:1589-1593

109. Grodstein F, Stampler M), Goldhaber SZ, Manson JE, Coldiz GA, Speizer FE, Willett WC. Prospective study of exogenous homones and risk of pulmonary embolism in women. Lancet 1996;348:983-987.

110. Fogelman I, Smith L, Mazess R, Wilson MA, Bevan JA. Absorption of oral diphosphonates in nomal subjects. Clin Endocrin 1986;24:57-62.

111. Papapoulos 5E. Bisphosphonates: Pharmacology and use in the treatment of osteoporosis. Osteoporosis. San Diego, Academic Press 1996, pp 1209-1229.

112. Stom T, Thamsborg G, Steiniche T, Cienant HK, Sorensen OH. Effect of intermittent cyclical etidronate therapy on bone mass and fracture rate in women with postmenopausal women. N Engl I Med 1990;322:1265-1271

113. Watts NB, Harris ST, Genant HK, Wasnich RD Intemittent cyclical etidronate therapy of postmenopausal women. N Engl I Med 1990:323:73-79.

114. Harris ST, Watts NB, Jackson RD, Gienant HK, Wasnich RD. Four years of intermittent cyclical etidronate therapy of postmenopausal women: three years of blinded therapy lollowed by one year of open therapy. Aml I Med 1993;95:557-567. 
115. Stom T, Thambborg G, Steiniche T, Genanit HK, Sorensen OH. Five years of intermittent cyclical etdronate therapy for postmenopausal women. I Rheumatology 1996;23: $1560-1564$.

116. Ott SM, Woodson GC. Huffer WE, Miller PD Watis NB. Bone histomorphometric changes after cyclic therapy with phosphate and etidronate disodium in women with postmenopausal osteoporosis. J Clin Endocrinol Metab 1994;78:968-972.

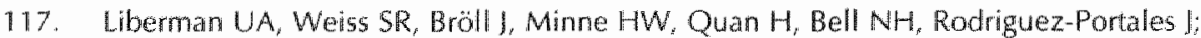
Downs RM Ir; Dequeker I; Favus M. Effect of oral alendronate on bone mineral density and the incidence of fractures in postmenopausal osteoporosis. $N$ Engl J Med $1995 ; 333: 1437-1443$

118. Black DM, Cummings SR, Karpf DB, Cauley IA, Thompson DE, Nevit MC, Bauer DC, Genant HK, Haskell WL, Marcus R, Ot SM, Torner JC, Quandi SA; Reiss TF; Ensurud KE. Randomised trial of alendronate on risk of fracture in women with existing vertebral fractures. Lancet 1996; 348:535-541.

119. Cummings SR, Black DM, Thompson DE, Applegate WB, Barrett-Connor E, Musliner TA, Palermo L, Prineas R, Rubin SM, SconIC, Vogt T, Wallace R, Yates A], LaCroix AZ. Effect of alendronate on risk of fracture in women with low bone density but without wertebral iractures. JAMA 1998;280:2077-2082.

120. Pols HA, Felsenberg D, Hanley DA, Stepan I, Munoz-Torres M, Wilkin TI, Qin-sheng G: Galich AM; Vandormael $K$, Yates AJ, Stych B. Multinational, placebo-controlled, randomised trial of the effects of alenclronate on bone density and fracture risk in postmenopausal women with low bone mass: results of the FOSIT study. Fossamax International Trial Study Group. Osteoporos Int 1999;9(5):461-468.

121. KarpfDB, Shapiro DR, Seeman E: Prevention of non-vertebral fractures by alendronatea meta-analysis. JAMA 1997:277:1159-1164.

122. Lees B, Garland SW, Walton C, Ross D. Whitehead MI, Stevenson IC. Role of oral pamidronate in preventing bone loss in postmenopausal women. Osteoporos Int $1996 ; 6: 480-485$

123. Landman JO; Hamdy NA; Pauwels EK; Papapoulos SE. Skeletal metabolism in patients with osteoporosis after discontinuation of long-term treatment with oral pamidronate. Clin Endocrinol Metath 1995;80:3465-3468.

124. Reid IR, Wattie DJ, Evans MC, Gamble GD, Stapleton IP, Cornish I. Continuous therapy with pamidronate a potent bisphosphonate in postmenopausal osteoporosis. I Clin Endocrinol Metab 1994;79:1595-1599.

125. Peretz A, Body JJ, Dumon JC, Rozenberg $S$, Hotimski A, Praet JP, Moris $M$, Ham $H$, Bergmann P. Cyclical pamidronate infusions in postmenopausal osteoporosis. Maturitas $1996: 8 ; 69-75$

126. Chapuy MC, Arlot ME, Delmas PD, Meunier PI. Effect of calcium and cholecalciferol treatment for threeyears on hip fractures in elderly women. BMI 1994;308:1081-1082

127. Lips P, Gratmans WC, Ooms ME, Bezemer PD, Bouter LM. Vitamin D supplementation and fracture incidence in elderly persons: a randomised, placebo-controlled clinical trial. Ann Intern Med 1996;124:400-406.

128. Dawson-Hughes B, Harris SS, Krall EA. Dallal GE. Effect of calcium and vitamin D supplementation on bone density in men and women 65 years of age or older. N Engl] Med 1997:337:670-676. 
129. Overgaard $\mathrm{K}$. Hansen MA, flensen SB, Christiansen $C$. Effect of salcitonine in given intranasal on bone mass and fracture rates in established osteoporosis: a dose-response study. BM 1992;305:556-561.

130. Ljunghall $S$, Gardsell $P$, johnell $O$, Larsson $K$ et al. Synthetic human calcitonin in postmenopausal osteoporosis: a placebo-controlled double bind study. Calcir tissue Inter $1991 ; 49: 17-19$

131. Punn KK, Chan MB. Analgesic effect of intranasal calcitonim in the treatment of osteoporotic vertebral fractures. Clin Ther 1989;1 1:205-209.

132. Lyritis GP, Tsakalakos N, Magiasis B, Karachalios T, Yiatzides A, Tsekoura M. Analgesic effect of salmon calcitonin in osteoporotic vertebral fractures: a double blind placebo-controlled clinical study. Calcif Tissue Int 1991;49:369-372.

133. Riggs BL, Modgson SF, O' Fallon WM etal Effect of fluoride treatment on the fracture rate in the postmenopausal women with asteoporosis. N Engl I Med 1990;322:802-809.

134. Mamelle N, Meunier PI, Dusan R, Guillaume M, Martin IL, Gaucher A, Prost A, Zeigler $G$. Netter P. Risk-benefit ratio of sodium fluoride treatment in primary vertebral osteoporosis. Lancet 1988;2:36i-365.

135. Kleerekoper M, Peterson EL, Nelson DA, Phillips E, Schork MA, Tilley BC, Parfit AM. A randomised triall of sodium fluoride as a treatment for postmenopausal osteoporosis. Osteoporosis Int 1991;1:155-167.

136. Pak CY, Sakhaee K, Adams-Huet B. Piziak V, Peterson RD, Poindexter IR Treatment of postmenopausal osteoporosis with slow-release sodium fluoride final report of a randomised controlled trial. Ann Intern Med 1995;123:401-408.

137. Pols HAP. Fluoride bij osteoporose: geen goede keus. Ned Tijolschr Geneeskd $1998 ; 142: 1902-1903$.

138. Lips P. Fluoride bij osteoporose: nog steeds experimenteel en controwersieel. Ned Tijdschr Geneeskd 1998:142:1913-1915.

139. Compstan JE. Designer oestrogen's: fact or fantasy? Lancet 1997;350:676-677.

140. Draper MW, Flowers DE, Huster WJ Neild IA, Harper KD, Amaud C. A controlled trial of raloxifere (LY 139481) HCL: impact on bone turnover and serum lipid in profile heal thy postmenopausal women. J Bone Miner Res 1996;11:835-842.

141. Ettinger B, Black DM, Mitlak BH, Knickerbocker RK, Nickelsen T, Genant HK, Christiansen C, Delmas PD, Zanchetta JR, Stakkestad), Gluer CC, Krueger K, Cohen F. Eckert S, Ensrud KE, Avioli LV, Lips P, Cummings SR, Delmas PD, Bjarnason NH, Mitlatk BH. Reduction of vertebral fracture risk in postmenopausall women with osteoporosis treated with raloxifene: results from a 3-year randomised clinical trial. Multiple Outcomes of Raloxifene valuation (MORE) Investigators. IAMA 1999:282:637-645.

142. Delmas PD, Bjarnason NH, Mitlak BH, Ravoux AC, et al. Effects of raloxilene on bone mineral density, serum cholesterol concentrations and uterine endometrium in postmenopausal women N Engl I Med 1997;337:1641-1647.

143. Cummings SR, Eckert $S$, Krueger KA et al. The effect of raloxifene on risk of breast cancer in postmenopausal women. Results from the MORE randomised irial. IAMA 1999; $281: 2189-2197$.

144. Lufkin EG, Whitaker MD, Nickelsen T, el al. Treatment of established osteoporosis with raloxifene: a randomised trial. I Bone Miner Res 1998; 13:1747-1752.

145. Lindsay R, Hart DM, Kraszewski A. Prospective double blind thal of synthetic steroid (Org OD14) for preventing postmenopausal osteoporosis. Br Med I 1980,280 : $1207-1209$. 
146. Ross LA, Ader EM. Tibolone and climacteric symptoms Maturitas 1995;21:127 136.

147. Studd 1, Arnala I, Kicovic PM, Kröger H, Holland N. A randomised study of tibolone on bone mineral density in osteoporotic postmenopausal women with previous fractures. Obstet Gyn 1998; $92: 574-579$.

148. Berning B, Kuijk CV, Kuiper JW, Coelingh Bennink HIT, Kicovic PM, Fauser BCIM. Increased loss of trabecular but not contical bone density, 1 year after discontinuation of 2 years hormone replacement therapy with tibolone. Maturitas 1999;31:151-159.

149. Geusens P, Dequeker J, Gielen I, Schot LP. Nonlineair increase in vertebral density induced by a synthetic steroid (Org ODI 4) in women with established osteoporosis. Maturitas 1991;13:155-162.

150. Rymer 1, Chapman MG, Fogelman 1. Effect of tibolone on postmenopausal bone loss. Osteoporosis Int 1994;4:3; 4; 319.

151. Hodsman AB, Fraher L, Watson PH, Ostbye T; Stitt LW; Adachil D; Taves DH, Drost D. A randomised controlled trial to compare the efficacy of cyclical parathyroid hormone versus sequential calcitonine to improve bone mass in postmenopausal women with osteoporosis. J Clin Endocrinol Metab1997:82:620-628.

152. Erdtsieck RI, Pols HA.P, Kuijk C van, Birkenhäger-Frenkel DH, Zeelenberg I, Kooy PP, Mulder P; Birkenhager JC.Course of bone mass during and after hormonal replacement therapy with and without addition of nandrolone decanoate. Bone Miner $1994: 24: 209-217$

153. Johansen 5 , Hassager C, Podenphant, Riis BJ, Hartwell D, Thomsen K, Christiansen C. Treatment of postmenopausal osteoporosis: is the anabolic steroid nandrolone decanoate a candidate. Bone Miner 1989; 6:77 86 .

154. Davis JW, Ross PD, Vogel IM, Wasnich RD. Age related changes in bone mass among Japanese-American men. Bone Mineral 1995; 15:227-236.

155. Urquhart J. Patient compliance with prescribed drug regimens: overview of the past 30 years. Clinical Measurement in drug evaluation. 1995.

156. Magometsichnigg D. Patient compliance of hypertensive patients in the physician's practice. Wien Med Wochenschr. 1995;145:360-364.

157. Cramer JA, Mattson RHA, Prevey ML, Scheyer RD, Ouellette VL. How often is medication laken as prescribed? A novel assessment technique . AMA $1989,76,3273,372 \%$.

158. Urquhart 1. Patient non-compliance with drug regimens: measurement, cinical correlates, economic impact. Eur Heart 1. 1996;17 Suppl A:8-15

159. Bond WS, Hussat DA. Detection methods and strategies for improving medication compliance. Am I Hosp Pharm. 1991:48:1978-1988

160. deklerk E. Measurement of Patient Compliance on Drug Therapy. In: Vingerhoets $A$ ed. Advances in Behavioral Medicine Asessment "Advances in Behavioral Medicine Assessment; 1998.

161. Rudd P. Partial compliance: Implications for clinical practice. S of Cardio Phar 199322 (Suppl.A;51-S5).

162. Harris ST; Watts NB; Genant HK; McKeever CD, Hangartner T, Keller M, Chesnut CH 3 rd, Brown I, Eriksen EF, Hoseyni MS, Axelrod DW, Miller PD. Effects of risedronate treatment on vertebral and nonvertebral fractures in women with postmenopausal osteoporosis: a randomised controlled trial. Vertebral Efficacy With Risedronate Therapy (VERT) Study Group. JAMA 1999:282:1344-1352.

163. de Groen PC, Lubbe DF, Hirsch L., Daifotis A, Stephenson W, Freedholm D, Pryor-Tillotson 5 , Seleznick MJ, Pinkas H, Wang KK. Esophagitis associated with the use of alendronate. N Engl I Med 1996;335:1016-1021. 
CHAPTER 3

\section{General design of the Eindhoven Perimenopausal Osteoporosis Study (EPOS)}

3.1 Introduction

3.2 Background

3.3 Design of the study

3.3.1 Screening study (full report chapter 4)

3.3.2 Intervention study (full report chapter 6) 


\subsection{Introduction}

In July 1987, the Secretary of State for Welfare, Public Health and Culture (WVC) asked the Health Council of the Netherlands (Gezondheidsraad) for advice on the prevention of osteoporosis in the Netherlands. The Health Council appointed a Committee on Osteoporosis that reported to the Secretary in 1991 with the following advice: osteoporosis is an important cause of disease, especially in elderly women, and preventative measures of a general nature are strongly recommended. ${ }^{1}$ The recommendation for prevention formed the main part of the Committee's advice, especially with respect to those women with an increased risk of osteoporosis. Furthermore, the Committee advised that bone mineral density (BMD) measurements should be carried out in women of menopausal age, in order to check their BMD and gain insight into their risk of developing osteoporosis and vertebral and hip fractures. Women at higher risk could be informed of this, and, in addition to primary prevention, could use this information in their choice of further intervention, e.g., hormone replacement therapy, for the prevention of osteoporosis. In order to establish interest in the Netherlands for the prevention of osteoporosis and the measurement of $B M D$, the Committee recommended that an exploratory study should be carried out in women of menopausal age. ${ }^{\top}$

\subsection{Background}

The advice regarding oestrogen substitution in women of menopausal age for the prevention of osteoporosis, as recommended by the Health Council Committee to the Minister of WVC in 1991, considered two options:

1. All women should be advised to start using oestrogen when they reach menopausal age (without first having measurements of $B M D$ ); or

2. All women of menopausal age should be screened for BMD using dual X-ray absorptiometry (DXA), and women with low BMD should be advised to use oestrogen.

Due to the fact that fow women were motivated to use oestrogen for the prevention of osteoporosis, without first being aware of their DXA results, the Committee chose the second of these two options. They recommended that a study be set up to gain insight into the attitude of women with regard to BMD measurements as the basis for oestrogen use, as well as into the costs of the procedure. Women with low BMD should be made aware of this fact and its consequences, and, if there were no contraindications, be advised to use oestrogen.

Although there are other therapies that can be used against osteoporosis, such as calcitonin, bisphosphonates, and anabolic steroids, the Committee did not regard the large-scale use of these medications to be warranted, since their effectiveness and safety had not yet been established in longitudinal research (1991). 
After publication of this report in 1991. Prof. Dr. V.J.M. Pop, a general practitioner from Riethoven, North Brabant, in close cooperation with Dr. J.). Keyzer, a clinical chemist and director of the Diagnostic Center of Eindhoven (DCE), took the initiative to carry out research on the basis of the above recommendation. Since this would be a general health care project, the expertise of Prof. J.A. Knottnerus (Department of General Practice, University of Maastrichn was solicited, as well as that of Prof. Dr. H.A.P. Pols (Department of Internal Medicine lll, Dijkzigt Hospital, Rotterdam) and Prof. Dr. S.A. Papapoulos (Department of Endocrinology LUMC, Leiden), inter" nists/endocrinologists in the field of osteoporosis. In January 1993, this team applied for a grant from the Prevention Fund, centred on the following aspect of research:

"A comparative study of the (secondary) preventive effects of a number of potentially relevant medication strategies in women around menopausal age with decreased bone mineral density, who are at risk for developing osteoporosis."

The Prevention Fund approved the research proposal on 8 th October, 1993 (Grant No. 28-2401), so that, on 1 January, 1994, the Eindhoven Perimenopausal Osteoporosis Study (EPOS) could get under way.

\subsection{Design of the study}

The study consisted of two parts:

1. A screening study

2. A drug intervention study, designed as a randomised clinical trial

\subsubsection{Screening study}

\section{Study population}

In the period between September 1994 and September 1995, all women in the city of Eindhoven, born between $(941$ and 1947 (aged between 46 and 54 years), were inwited by the Diagnostic Centre Eindhoven (DCE), a diagnostic centre for general practitioners, and the Department of Municipal Public Health Services, Eindhoven, to participate in the study.

The aim of the study was to assess the prevalence of low bone mass and its determinants, with special emphasis on gynaecological variables in a large cohort of perimenopausal women, using the World Health Organisation (WHO) criteriafor osteopenia and osteoporosis. A questionnaire was completed by all the women (Appendix 1), a clinical examination was performed, and BMD was measured at the lumbar spine (L.1-L4) using DXA (S.A. Hologic, Brussels). At the screening visit, the 
participants were asked if they could be contacted for a follow-up study. The results of this study are presented in Chapter 4.

\subsubsection{Intervention study}

The intervention study was designed as a randomised clinical trial (RCT), the objecfives of which were as follows:

1. To determine and compare, in a randomised study, the efficacy of wo treatment regimens compared to calcium for preventing postmenopausal bone loss in women in the lowest tertile of the DXA measurements after screening. The following regimens were compared:

a. calcium $400 \mathrm{mg} / \mathrm{day}$

b. calcium $400 \mathrm{mg} / \mathrm{day}+$ oestradiol $2 \mathrm{mg}$ continuously, combined with dydrogesteron $10 \mathrm{mg}$ in the second half of the cycle

c. calcium $400 \mathrm{mg} / \mathrm{day}+\mathrm{APD}$ (= pamidronate), $100 \mathrm{mg} / \mathrm{day}$

2. To determine the rate of change in $\mathrm{BMD}$ one year after cessation of treatrment

3. To determine the compliance for each treatment regimen

The results of the above issues are presented in Chapters 6 and 7 , respectively.

\section{Design of the drug intervention study}

The study was designed as a single open-label, controlled, randomised study. It had to be an open study because blinding was not possible in the oestrogen/progestogen group. In this group, the women received cyclically oestrogen/progestogen and would therefore have had monthly withdrawal bleedings. The relatively low close of calcium was selected to ensure that the women would not in fact have calcium deficiency. The participants were allocated to one of the treatment protocols for a period of wo years, followed by a washout period of one year. No reallocation was offered to a different reatment group, based on individual preferences. The women were seen every three months during their participation in the study, and DXA measurements of the lumbar spine and hip were performed on four occasions during the study.

In all groups, compliance was measured based on counting by hand, and, in addition, in the group of women receiving pamidronate, it was also measured using the Medication Event Monitoring System (MEMS, Aardex Ltd., Switzerland). This system consists of a normal pill container with a special cap that contains electronic microcircuitry to record the time and date of each opening of the container. Throughout the analysis, we assumed that one tablet was actually ingested each time the container was opened. 


\section{Study population}

The study population consisted of healthy perimenopausal women who met the selection criteria and who were willing to participate in the study. The inclusion criteria were:

- women born between 1941 and 1947 and living in the city of Eindhoven

- a period of amenorhea of a maximum of three vears

- a changed menstrual pattern, with less than five bleedings in the past welve months

- BMD in the lower tertile $\left(<0.998 \mathrm{~g} / \mathrm{cm}^{2}\right)$

The following cases were excluded:

- women who had undergone hysterectomy and/or ovariectomy

- women with a history and/or presence of a metabolic bone disease other than osteoporosis

- women with rheumatoid arthritis, or a history of serious cardiovascular disease

- women with uncontrolled hypertension

- women with diabetes mellitus or other endocrine diseases, such as pituitary, thyroid or parathyroid dysfunction

- women with a history and/or presence of malignancies

- women who had used bisphosphonates, fluoride, calcitonin, anabolic steroids glucocorticoids, or other medications that might interfere with calcium and bone metabolism, in the twelve months prior to the intervention study

- no use of systemic oestrogen's/progestogens was permitted in the three months prior to the trial

\section{Randomisation}

Women who were eligible were randomised over one of the treatment groups. When a woman announced her willingness to participate, a central registration office was contacted, which had a list of the random treatment assignments. 2 The treatment assignment could be read off the randomisation list and was supplied to the investigator by telephone. No reallocation to a different treatment group was offered. Women who decided not to participate in the study after randomisation, because they had not received the medication they had requested, were regarded as dropouts immediately after randomisation.

BMD of the lumbar spine (L. 1 - 4 4) and hip was measured at baseline and after one and two years of treatment with DXA model QDR-1000 (S.A. Hologic Europe, Brussels).

\section{Study size}

The aim was to detect an difference of $5 \%$ in $B M D$ between the calcium group and the other intervention groups. Using Pocock's formula (1993) ${ }^{2}$, it could be calculated 
that, each group should consist of 150 participants $\left(=0.05,=0.90,500.1 \mathrm{~g} / \mathrm{cm}^{2}\right)$. An estimated 300 participants were required as a minimum. Women discontinuing the study after having been included would be regarded as dropouts. Early discontinuation of the study could take place at the request of either the participant or the investigator. A participant could discontinue the study at any time, without explanation. Exclusion of participants from the study by the investigator was due to either exclusion criteria developing during the course of the study, serious adverse events, or emergence of a severe concurrent disease.

\section{Data handling and statistical analysis}

All the data from the study, both those collected during visits as well as the results of the laboratory analysis, were transferred to the Case Records Form (CRF) of the investigator. Statistical analysis was performed using the Statistical Products and Service Solution (SPSS).

The primary outcome, the percentage of change in lumbar spine BMD, was compared between the wo treatment groups and the calcium-only group using the t-test for independent observations, adjusted for multiple comparisons with a Scheffe correction. Statistical significance was defined as $p<0.05$, two-sided. The secondary outcome, the percentage of change in BMD at the different measurement sites in the proximal femur, was analysed accordingly. Analyses were made by intention to treat, including those women in whom lumbar spine BMD was measured at baseline and at least once during treatment.

The individual prognostic value of each variable was estimated using multiple linear regression analysis, with the percentage of change in lumbar spine BMD as. dependent variable with adjustment for relevant covariables, such as $\mathrm{BMI}$, age, duration of amenorhoea, and smoking status (baseline data).

\section{Literature}

1. Osteoporosis Commitee: Preventie van osteoporose. The Hague. Health Council of the Netherlands 1991 ; publication No. $91 / 21$

2. Procock S1. Clinical Trials. A practical Approach. UK: John Wiley \& Sons l.td. 1993. 


\section{The prevalence of low bone mineral density in Dutch perimenopausal women: The Eindhoven Perimenopausal Osteoporosis Study}

C.G. Smeets-Coevaers', G.L. Leusink" S.E. Papapoulos², L.W. Maartens', 1.1. Keyzer" I.P. Weerdenburg ${ }^{3}$, L.M. Beijers' A.H. Zwinderman' ${ }^{2}$, J.A. Knottnerus" H.A. Pols ${ }^{6}$, V.I. Pop ${ }^{1}$

Diagnostic Centre Eindhoven, ${ }^{2}$ Department of Endocrinology and Metabolic Diseases, University of Leiden Medical Centre, "3i. Joseph Hospital Veldhoven, ${ }^{4}$ Department of Medical Statistics, University of Leiden Medical Centre, 5 Department of Fannily Medicine, University of Maastricht, ${ }^{6}$ Department of Internal Medicine III, University Hospital Dijkzicht Rotterdam, The Netherlands

Published Osteoporosis International 1998;8:404-409 


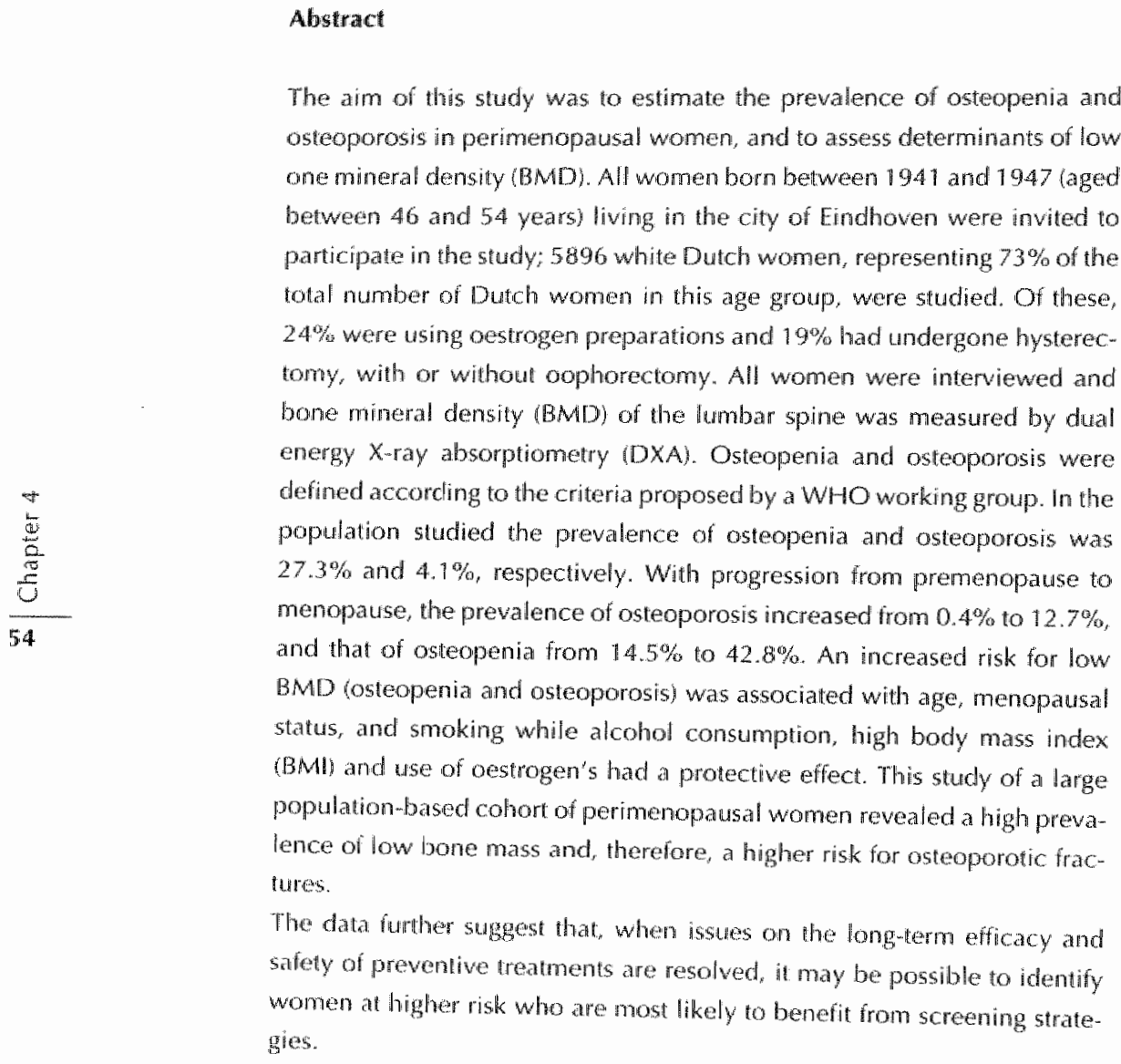

Key Words: Bone mineral clensity; Oestrogen's: Hysterectomy; Menopause: Osteopenia; Osteoporosis; Prevalence; Risk factors; Screening 


\section{Introduction}

Osteoporosis, currenty defined as a systemic skeletal disease characterised by low bone mass and microanchitectural deterioration of bone tissue with a consequent: increase of bone fragility and susceptibility to fracture, "is recognised as a major health problem. Bone mass in later life is determined by the peak mass attained during growth and early adulthood and the rate of subsequent bone loss. In women, the period of accelerated bone loss following the loss of ovarian function is theoretically the best time for treatments aimed at preserving bone mass, provided that effective, safe and generally acceptable means are available. Therefore it is important to identify those women around the menopause who are at risk of developing asteoporosis and are most likely to benefit from such treatments. Screening of all women for low bone mineral density (BMD) around the menopause, as proposed by some authors ${ }_{f}^{2,3}$ is debatable and certainly not justified by the available data. Altermative approaches are therefore needed. However, for the design of optimal strategies to prevent osteoporotic fractures, adequate knowledge of the problem around the menopause is essential. Prospective studies have shown bone mass measurements to be strong predictors of fractures, 5,6 and a WHO working party has proposed an operational definition for osteoporosis and diagnostic criteria based on BMD measurements. ${ }^{7}$ In the present study we used these criteria to assess the prevalence of low bone mass and its determinants with special emphasis on gynaecologic variables in a large cohort of perimenopausal women.

\section{Subjects and methods}

\section{Study Design}

Between September 1994 and September 1995, all women born between 1941 and $1947(n=8503)$ who were living in the city of Eindhoven, The Netherlands, were invited to participate in the study by the Diagnostic Centre Eindhoven (DCE), a diagnostic centre for general practitioners, and the Department of Municipal Public Health Services, Eindhowen. Of the 8503 women, 8098 of whom were Dutch, 6846 $(81 \%)$ responded to the invitation and $6648(78 \%)$ agreed to participate in the study. In order to obtain homogeneous data comparable with other studies, the present analysis includes only white Dutch women, $6262(77 \%)$ of whom agreed to participate in the study. Of these, 31 women who falled to provide relevant information and 3 in whom (BMD) could not be measured, were excluded from the analysis. Three hundred and thirty-two women were evaluated in a pilot, feasibility study and these results are not included either. Their mean BMD was $1.015 \pm 0.138 \mathrm{~g} / \mathrm{cm}^{2}$, while that of the remainder of the cohort $\left(n=5896\right.$ ) was $1.013 \pm 0.145 \mathrm{~g} / \mathrm{cm}^{2}$. A questionnaire was completed by all wonnen, medical history was taken, clinical exami- 


\begin{tabular}{|c|c|c|}
\hline Chardrorisues & Mean $=S D$ & Ho $(\%$ of 5896$)$ \\
\hline Age (wears) & $500+2$ & \\
\hline Height om & $1.65=0.06$ & \\
\hline weight kg) & $69,92+12.49$ & \\
\hline BN1 $\mathrm{kg} / \mathrm{m}$ ) & $25.46 \div 4.47$ & \\
\hline Age at nonarche $(y e a r s)$ & $13,301 \%$ & \\
\hline Nonbler of pregnarncies & $2,20 \pm 1,31$ & \\
\hline Current use of Gitrogen & & $1433(243)$ \\
\hline Hysterectony & & $771(13,2)$ \\
\hline Hysterestony and bophorectoiny & & $340(5,8)$ \\
\hline Oophorectomy & & $(141,24$ \\
\hline
\end{tabular}

nation was performed and lumbar spine BMD was measured. Evaluation and measurements were performed at two centres: the DCE and St. Joseph Hospital, Veldhoven, a suburb of Eindhoven. All responders gave their written informed consent and the study was approved by two medical ethics committees. The charac. teristics of all women studied are shown in Table 1.

\section{Menstrual status}

The following definitions were used:

1. Premenopausal: Women with regular menstrual periods, or those who had stopped using hormone replacement therapy HRT) or oral contraceptives in the 3 months prilon to screening, followed by a regular menstruation pattern.

2. Perimenopausal: (a) Women with irregular menses (at least one menstruat period in the preceding year). (b) Women who had stopped using HRT or oral contraceplives 3 months to 1 year prior to screening, followed by irregular menses. (c) Women who had slopped using HRT or oral contraceptives during the year before screening, followed by amenorhoea.

3. Menopausal: Women with amenorhoea for 1 year or longer before screening.

\section{Bone Mineral Density}

BMD was measured a the lumbar spine (L1-4) by dual energy $X$-ray absorptiometry (DXA; S.A. Hologic Europe, Brussels). At the DCE, DXA model QDR-1000 S/N 291 was used, at St. Joseph Hospital, model QDR-2000 S/N 2260. Cross-calibration of the two densitometers was performed in nine volunteers. The Pearson correlation coefficient of these measurements was $0.9862, p<0.0001$. For quality control, wo 


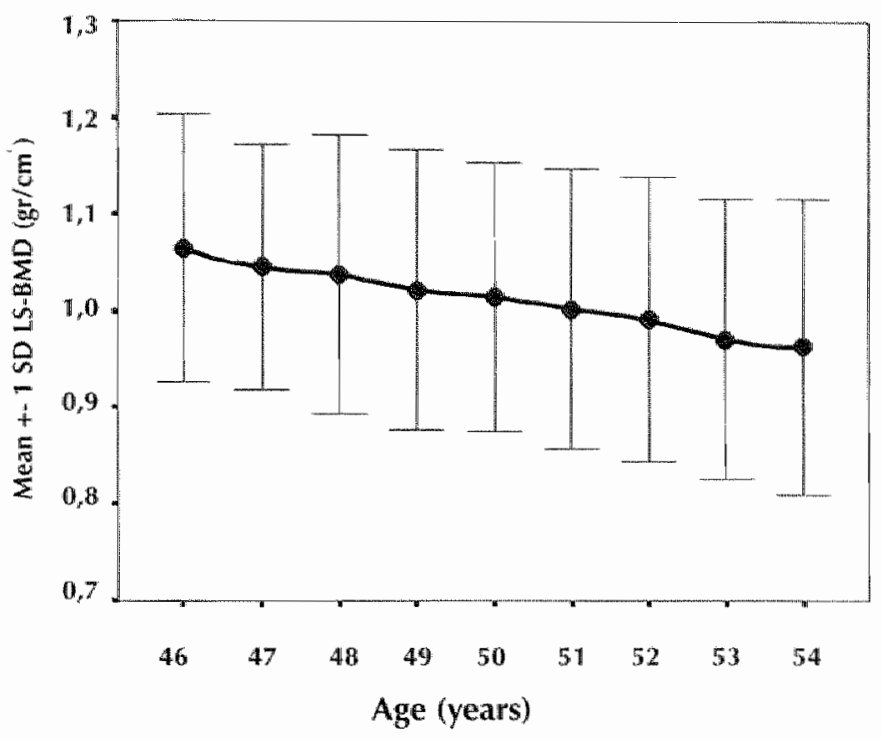

Figure 1. Bone mineral density of the lumbar spine (LS-BMD) in 5896 white Dutch women aged between 46 and 54 years (means and SDs).

calibrations were performed daily using a spine phantom. The coefficient of variation for the DCE densitometer for the duration of the study was $0.54 \%$, calculated using a spine phantom with a value of $1.0354 \mathrm{~g} / \mathrm{cm}^{2}$. For the St. Joseph Hospital densitometer this was $0.41 \%$, calculated using a different spine phantom with a value of $1.0409 \mathrm{~g} / \mathrm{cm}^{2}$. Vertebrae that could not be evaluated (due to calcification, operations, etc.), were not included in the calculation of BMD.

According to the diagnostic criteria proposed by a WHO working parly ${ }^{6}$ osteopenia is defined as a BMD between 1 and 2.5 standard deviations (SD) below the young adult mean (the $T$-score). $T$-score values below 2.5 are defined as osteoporosis. According to the reference data obtained by Hologic, the mean $( \pm S D)$ BMD of the spines (L1.4) of 650 healthy women studied at the University of San Diego, California, was $1.047 \pm 0.110 \mathrm{~g} / \mathrm{cm}^{2}$. Osteopenia is therefore defined as a value between 0.937 and $0.772 \mathrm{~g} / \mathrm{cm}^{2}$, and osteoporosis as a value below $0.772 \mathrm{~g} / \mathrm{cm}^{2}$. The mean BMD value of the premenopausal women in the present study was $1.069 \pm 0.129$ $\mathrm{g} / \mathrm{cm}^{2}$ (mean \pm SD). The BMD equivalent to -1 and $-2.5 \mathrm{SD}$ was therefore 0.940 and $0.747 \mathrm{~g} / \mathrm{cm}^{2}$, respectively. Both thresholds were used for the calculation of the prevalence of osteopenia and osteoporosis in the whole cohort. The Hologic thresholds. were used in the further analysis of the data. 


\section{Statistics}

The statistics were performed with the use of the Statistical Products and Service Solutions (SPSS). To correct for confounding factors the relationship (odds ratio (OR) between low bone mass (osteopenia and osteoporosis) and potential determinants of BMD was examined by multivariate logistic regression analysis. The variables were hormonal use (use of HRT or oral contraceptives), age at screening and body mass index (BNA), gynaecological operations (hysterectomy, unilateral and bilateral oophorectomy), gynaecological parameters (menopausall status, age at menarche and previous pregnancies, smoking (current or past smokers), drinking current alcohol consumption, and milk consumption before and after the age of 25 years.

\section{Results}

The mean ( 1 SD) BMD of the 5896 women studied was $1.013 \pm 0.145 \mathrm{~g} / \mathrm{cm}^{2}$ and, of these, $4.1 \%$ had osteoporosis and $27.3 \%$ osteopenia, according to the BMD thresholds provided by Hologic. When the BMD threshold obtained in our premenopausal women was used, the prevallence of osteoporosis and osteopenia was $2.7 \%$ and $29.5 \%$, respectively; similar thus to that estimated with the use of the Hologic thresholds. As expected, there was a progressive decline in lumbar spine BMD with increasing age (Figure 1), due to the increasing presence of menopausal women in the higher age groups.

Separate analysis of perimenopausal women according to age showed that the prevalence of osteoporosis was $1.4 \%$ at 48 years and $1.3 \%$ at 53 years. The corresponding values for menopausal women of the same ages were $13.4 \%$ and $14.1 \%$, respectively. The prevalence of low bone mass tosteopenia and osteoporosis) in the postmenopausal women was related to the number of years since menopause fper year $O R=1.12, p<0.001$ ).

The $\mathrm{BMD}$ values and the prevalence of osteoporosis and osteopenia in the 3681 women in whom menstrual status could be determined are shown in Table 2. In 2215 women, the menopausal status could not be determined due to hysterectomy, oophorectomy, use of HRT or oral contraceptives. Of these, 782 women did not use oestrogen $(580$ had undergone hysterectomy, 195 hysterectomy and oophorectomy, and 7 bilateral oophorectomy). Their mean BMD was $1.008 \pm 0.149$ $\mathrm{g} / \mathrm{cm}^{2}$ and $5.0 \%$ had osteoporosis, whille $27.9 \%$ had osteopenia (Table 2 ). The prevalence of osteoporosis in women who had had a hysterectomy was $4.3 \%$, and this rose to $11.1 \%$ in those who had had hysterectomy and bilateral oophorectomy and to $28.6 \%$ in those who had had bilateral oophorectomy only. However, the number 
Table 2 bone mineral density in Butch worren aged between 46 and 54 years

\begin{tabular}{|c|c|c|c|c|c|}
\hline Menstrual status & No & $\begin{array}{l}\text { Mean are } \\
\text { (years) }\end{array}$ & $\begin{array}{l}\text { Mean BMD } \\
\text { (gron) }\end{array}$ & Psteoporosis & $\begin{array}{l}\text { Osteppenia } \\
\text { (\%) }\end{array}$ \\
\hline Premenopausall & 760 & 488 & 11069 & $3(0.4)$ & $110(14.5)$ \\
\hline Perimenopausal & 1842 & 49.6 & 1,032 & 2811.5 & 450124.11 \\
\hline Menopausal & 1079 & 513 & 0.930 & $137(127)$ & $462(42,8$ \\
\hline Hysterectomy & & & & & \\
\hline oophorectomy & 78 & 50.2 & 1008 & $39(501$ & $218,27,9$ \\
\hline Estrogen/use & 143 & 499 & 1,022 & 352,4 & $371(25.9)$ \\
\hline
\end{tabular}

With progression from premenopause to menopause, here was an micrease in the prevalence of osteoporos is fron $0.4 \%$ to $12.7 \%$ within a narrow age range, the corresponding prevalence of osteopenla was $145 \%$ and $428 \%$, respectively

Table 3 . Bone mineral density of women using aestrogen $(n-1433)$

\begin{tabular}{|c|c|c|c|c|c|}
\hline Stans: & No & $\begin{array}{l}\text { Mean age } \\
\text { (years) }\end{array}$ & $\begin{array}{l}\text { Mean BMD } \\
\text { g/(am) }\end{array}$ & $\begin{array}{l}\text { Osteeporosis } \\
(\%)\end{array}$ & $\begin{array}{l}\text { Osteopenia } \\
(\%)\end{array}$ \\
\hline No hysterectomy andior & & & & & \\
\hline oophorectomy & 1049 & 498 & 1.020 & $26(2,3)$ & $267(25.2)$ \\
\hline Aysteredomy alone & 197 & $50 \%$ & 4045 & $2(1,0)$ & $47(299)$ \\
\hline Hysterectony with & & & & & \\
\hline unilateral oophorecrony & Y 83 & 50.5 & 1.015 & $3(3,6)$ & $23(27,1)$ \\
\hline Bulateral ogphorestony & 62 & 301 & 0.994 & $2(3,2)$ & $23(171)$ \\
\hline Oophorgetiony & & & & & \\
\hline unilateral & 38 & 498 & 1007 & $2(53)$ & $9(2) 7)$ \\
\hline bilateral & 4 & 486 & 1060 & 0 & 2500 \\
\hline
\end{tabular}

of women in the last group was too small to allow any definite conclusions. The mean BMD and prevalence of osteoporosis and osteopenia in the remaining 1433 women who used HRT or oral contraceptives are shown in Table 2, and the respecive values in subgroups of these hormone users in Table 3.

In these women, the prevalence of osteoporosis and osteopenia was also highest in those with bilateral oophorectomies with or withoul hysterectomies.

The results of the multivariate analysis of the risk factors for low bone mass (osteopenia and osteoporosis) are shown in Table 4.

An increased risk for low BMD was associated with age, peri- and postmenopausal status, bilateral oophorectomy and smoking, while alcohol consumption, high BMI and use of oestrogen's had a protective effect. To obtain more insight into the rela- 
Table 4. Determinants of low bone nineral density $T$ score -1 so in permenopausal women

\begin{tabular}{|c|c|c|}
\hline Variable & $\mathrm{OR}$ & $95 \% \mathrm{Cl}$ \\
\hline Esrogen use: & 0.81 & 0,001111 \\
\hline age? & 112 & $1,091,17$ \\
\hline $\mathrm{BM}$ & 030 & 0089092 \\
\hline Hystereciomy & 0.93 & $0.681,27$ \\
\hline Unilatral ooplyorrectomy & 121 & $0.92-1.58$ \\
\hline Bilakeral ooplorectoryy & 2.25 & 1.443 .52 \\
\hline Premenopause (indicaton) & 100 & \\
\hline Perimenopause & 1,72 & 134,19 \\
\hline Menoprase & 4.91 & $3,77-6,40$ \\
\hline Undeternined menstrual slatiss & 2.28 & $75,3,40$ \\
\hline Apedthenarche & 1.03 & $0,991,07$ \\
\hline Provious pregiancies (f) & 0.95 & 0911,00 \\
\hline smoking & 125 & $1,081,44$ \\
\hline Alen holl Consumption & 071 & $0,61-0,83$ \\
\hline Muk consumpiron & & \\
\hline Berbre 25 year & 0,86 & $0,0.6134$ \\
\hline After 25 years & 0.92 & 0.58145 \\
\hline
\end{tabular}

BM, body nass undex. mever snoked, past or current smoker 2 no use and current use

Table 5 . Nisk for low hone mass nirelation lo grnacecological variables

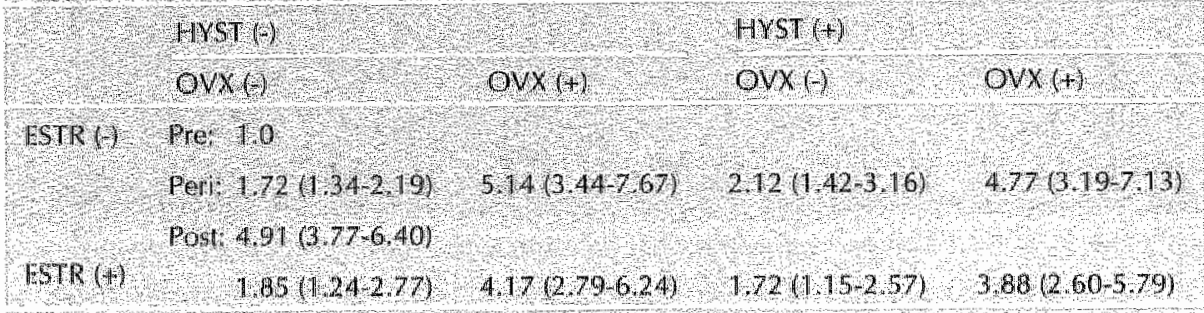

Odds raties and confidence intervals are shown 1 V ST, hysterectony, OVX, oophorectomy. ESTR, nestrogen's, Pre prenenopasal, Pert, peimenopausal, Post, postmenopausal

tion between gynaecological parameters and bone mass we further estimated the risks of the various subgroups (Table 5).

In general, gynaecological operations (hysterectomy, oophorectomy) increased the risk for low $\mathrm{BMD}$, relative to premenopausal women, and the risk was always reduced by the concurrent use of oestrogen's. It should be noted, however, that the prevalence of low bone mass corrected for age, was related to the number of years since the operation (hysterectomy, OR 1.04 per year, $p=0.001$, bilateral oophorectomy, OR 1.05 per year, $p=0.07$ ). 


\section{Discussion}

The present study of a large population-based cohort of perimenopausal women, revealed the presence of osteoporosis and osteopenia of the axial skeleton in $4.1 \%$ and $27.3 \%$ of the women, respectively. For this classification, the defintions for osteoporosis and osteopenia proposed by a WHO study group were used, logether with threshold values of BMD provided by the manufacturer of the bone densitometer. These values were obtained in young healthy American women and are comparable to those reported in the $U^{9}$ and Germany ${ }^{10}$, as well as to those obtained in the premenopausal women in our study (mear BMD $1.047 \pm 0.110$ $\mathrm{g} / \mathrm{cm}^{2}$ and $1.069 \pm 0.129 \mathrm{~g} / \mathrm{cm}^{2}$, respectively). However, although the mean $\mathrm{BMD}$ of our premenopausal group is slighty higher than that of the American population, the SD is larger, accounting for a lower BMD threshold for defining osteoporosis: 0.747 $\mathrm{g} / \mathrm{cm}^{2}$ compared with $0.772 \mathrm{~g} / \mathrm{cm}^{2}$ using the manufacturer's data. Using this threshold, we diagnosed osteoporosis and osteopenia in $2.7 \%$ and $29.5 \%$ of the women, respectively. It should be mentioned that these reference values were obtained in an unselected group of premenopausal women who were, however, older than 45 years. Bone mass in such women may not be representative of the peak bone mass, as some bone loss may occur even before the menopause. ${ }^{11}$ Furthermore, the present estimates of osteoporosis and osteopenia are based on BMD measurements at a single skeletal site, the humbar spine, which may be an underestimation of the general risk for osteoporotic fractures. We chose to measure this site because trabecular bone is more sensitive to changes in oestrogen status which are likely to occur in this narrow age-range group of women.

Our findings, therefore, while emphasising the need for obtaining well-defined nomal ranges for BMD, underline the high risk for osteoporotic fractures in relatively young women, even using the most conservative criteria for diagnosis. Our data, which were obtained in an unselected population cohort, cannot be compared directly with those obtained in other studies, mainly due to different study designs and subject selection characteristics. They are, however, generally in agreement with the results of studies of women of similar ages in the UK ${ }^{12}$ and France ${ }^{13}$ evaluated in menopause clinics and of a select Finnish population cohor of 1600 women. ${ }^{1.4}$

Even within the narrow age-range of the women in our study, there was a clear age-related decrease in BMD of the lumbar spine. This was due more to the increased representation of menopausal women in the higher age groups than 10 an effect of chronological age per se. Separate analysis of perimenopausal women according to age showed that the prevalence of osteoporosis was $1.4 \%$ at 48 years and $1.3 \%$ at 53 years. The corresponding values for menopausal women were $13.4 \%$ and $14.1 \%$, respectively. Indeed, menopause was found to be a very strong risk factor for low $\mathrm{BMD}$ which was also related to years since menopause. On the other hand, a high $B M l$ and use of oestrogen had a protective effect on the skeleton, 
as commonly reported. 15 From our data it appeared initially that hysterectomy was associated with an increased risk of low bone mass when this group was compared with premenopausal women. Caution is needed however, in interpreting this result, as the prevalence for low bone mass adjusted for age was also related to the years since the operation in these women, which might have accounted for a higher representation of menopausal women. Nevertheless, the use of oestrogen's decreased this risk. The number of hysterectomies varies greatly in different countries 16.17 reflecting local gynaecological practices rather than absolute indications for performing the operation. 18 Our findings, though not definite, suggest that an increased risk of osteoporosis may be considered a potential complication of this operation in young women, which can be, however, reduced by oestrogen use. of the other commonly assessed risk factors for osteoporosis, smoking had a negative effect on BMD, while alcohol consumption had a protective one.

The question arising from the present study is whether the results of this large unselected cohort of perimenopausal women can help in the design of preventive strategies, a subject that is currently under debate ${ }^{19-22}$. Twenty-four percent of the women studied were using oestrogen preparations and, in these cases, BMD measurements are not indicated. 22 Premenopausal women, representing $13 \%$ of our population, can also be excluded from screening due to the lack of an effective treatment in this group. This leaves $63 \%$ as potential candidates for BMD screening. As shown here, however, the greatest differences in BMD occur between the perimenopause and the menopause and more than half of the total number of the menopausal women of this age group, not using oestrogen, had either osteoporosis or osteopenia. Thus, screening of these women (18.3\% of the total population) is likely to reveal low bone mass in $55 \%$. The chances of detecting a low bone mass are highest in this group of women. When th can be shown prospectively that safe and effective treatments that preserve or increase bone mass at the menopause, protect against fractures later in life, screening of these women might be realistic. However, until the above-mentioned requirements are fulfilled, we do not feel that screening is indicated around the menopause, and BMD measurements should only be performed in this age group according to specific indications. ${ }^{2}$

\section{Acknowledgements}

This sudy was supported by a grant from the Dutch Praeventiefonds (project no. 0028240 . 0). We thank P. V. Nierop, epidemiologist of the Department of Municipal Public teath Services Eindhoven, for his help in the recruitment of the participants and 1.H. Komproe (Free University of Amsterdam) for his help in the statistical evaluation of the data. 


\section{Literature}

1. Consensus development conference: diagnosis, prophylaxis, and treatment of osteoporasis. Am J Med 1993;94:646-50.

2. Johnston CC, Melton LU, Lindsay $R$, ell al. Clinical indications for bone mass measurements: a report from the scientific advisory board of the National Osteoporosis Foundation. I Bone Min Res 1989;4:1-28.

3. National Health Technology Advisory Panel. Bone mimeral assessment: an update. Cambera: Australlian Institute of Heath, 1989.

4. Kanis IA, Delmas P, Burckhardt P, Cooper C, Torgerson D. Guidelines for diagnosis and management of asteoporosis. Osteoporos Int 1997;7:390-406.

5. Cummings SR, Black DM, Nevitt MC, et al. Bone density at various sites for prediction of hip fractures. Lancet $1993 ; 341: 72 \times 5$.

6. Melton LI, Atkinson EJ, Fallon WM, Wahner HW, Riggs BL. Long-term fracture prediction by bone mineral assessed at different skeletal sites. J. Bone Miner Res 1993;8:1227-33.

7. Kanis JA, Melton LI, Christiansen $C$, Johnston $C C$, Khaltaev $N$. The diagnosis of osteoporosis. I Bone Min Res 1994:9:1137-41.

8. Algra A, Tijssen JPG, Roelandt JRTC, Pool ], Lubsen I. Contribution of the 24 hour electrocardiogram to the prediction of sudden coronary death. $\mathrm{Br}$ Heart I 1993:70:421-27.

9. Ryan PI, Spector TP, Blake GM, Doyle DV, Fogelman I. A comparison of reference bone mineral density measurements derived from two sources: referred and population based. Br J Radiol 1993;66:1138-41.

10. Lehmann $R$, Wapniarz $M$, Randerath $O$, et al. Dual-energy $X$-ray absorptiometry at he lumbar spine in German men and women: a cross-sectional study. Calcif Tissue Int $1995 ; 56: 350-354$.

11. Citron IT, Ettinger B, Genant HK Spinal bone mineral loss in oestrogen-replete, calcium-replete premenopausal women. Osteoporosis $\| n t ~ 1995 ; 5: 228-233$.

12. Compston JE, Cooper $\mathrm{C}$, Kanis $\mathbb{I A}$. Bone densitometry in clinical practice. BMJ 1995;310:1507-10.

13. Poulles IM, Tremolliers F, Ribot C. Spine and femur desitometry at the menopause: are botth sites necessary in the assessment of the risk of osteoporosis? Calcif Tissue Int $1993 ; 52: 344-7$.

14. Kröger $H$, Tuppuramen $M$, Honkanen R, Alhava E, Saarikoski S. Bone mineral density and risk factors for osteoporosis: a population-based study of 7600 perimenopatssal women. Calcif Tissue int 1994;55:1-7.

15. Michaëlsson K, Bergström, Mallmin H, Hohmberg L, Wolk $\mathrm{A}_{,}$Ljunghall S. Screening Ior osteopenia and osteoporosis: selection by body composition. Osteoporos int $1996 ; 6: 120-6$.

16. McPherson $K$, Strong $B$, Epstein $A$, Jones $L$. Regional varialions in the use of common surgical procedures: within and between England and Wales, Canada and the United States of America. Soc Sci Med 1981;15A:273-88.

17. Coulter A, MCPherson K, Vessey M. Do British women undergo too many or too few hysterectomies? Soc Sci Med 1988;27:987-94.

18. Lifford RI. Hysterectomy: will it pay the bills in 2007? Treatment of choice for cancer, but a choice of treatment for menorhagia. BMI 1997;13:160-1. 
19. Law M, Wald M. Meade TW. Strategies for the prevention of osteoporosis and hip fracure. BM/ 1991;303:453-9.

20. Ringa $V$, Durieux $P$, Bréart $G$. Bone mass measurements around menopause and prevention of osfeoportic fractures. Eur Obstet Gynecol Reprod Biol 1994;54:205-3.

21. Black DM. Why elderly women should be screened and treated to prevent osteoporosis. Am l Med 1995;98:67-75.

22. Mcknight A, Steele K, Milis K, Gillchrust C, Taggart H. Bone mineral density in relation to medical and lifestyle risk factors for osteoporosis in premenopausal, menopausal and postmenopausal women in general practice. Br I Gen Pract 1995;45:317-20.

Received for publication 2 lune 1997

Accepted in revised form 21 fanuary 1998 


\section{Is depressed mood a risk factor for low bone mineral density in perimenopausal women?}

Geraline L. Leusink 1, 1. Andre Knotnerus 4, Luc W.F. Maartens 1, Huibert A.P. Pols ${ }^{3}$, Victor I.M. Pop ${ }^{2}$

'Diagnostic Center Eindhoven, ${ }^{2}$ Department of Clinical Health Psychology, University of Tilburg, 3 Department of Internal Medicine III, Erasmus University Rotterdam ${ }^{4}$ Department of Family Medicine, University of Maastricht

Manuscript submitted for pubication 


\begin{abstract}
Previous studies showed an association between depression and decreased bone mineral density (BMD) suggesting that homone levels could play an important role. We examined the relationship between depression and BMD in a large population-based colrot of healthy women around menopausal age. The study population consisted of 4944 healthy women, aged betwen 47 and 53 years. These women completed a questionnaire about their lifestyle habits, such as smoking, alcohol intake, medication intake, and physical activity, and completed a depression sell-rating scale. Moreover, BMD of the lumbar spine was measured with dual energy $X$-ray absorptiometry (DXA)

One thousand and fourteen $(20.5 \%)$ of the women were depressed, according to a cut off score of $\geq 12$ on the Edinburgh Depression Scale (EDS). Excluding lifestyle habits, the characteristics of the depressed and non-depressed women were rather similar. The women with depressed mood had a significantly lower BMD compared to the non-depressed women
\end{abstract}

This study confirmed the relationship between depressed mood and decreased BMD at a univariate level. However, after adjustment for several important determinants of bone mass related to hiestyle habits, depressed mood showed no relation to decreased BMD. These findings suggest that the relationship between depressed mood and low BMD is inlluenced by lifestyle habits

Keywards: depression, osteoporosis, bone mineral density women, perimenopausal, Edinburgh Depression Scale (EDS) 


\section{Introduction}

Depression is a common and often chronic disease. A recent report by the WHO estimates that, within 30 years, over 300 million people throughout the world will be suffering from depression ${ }^{1}$ Apart from its negative impact on quality of life in general - depression being the major cause of suicide 2.3 - depression has also been associated with an increased risk of chronic diseases 4 The association between depression and the subsequent development of cardiovascular diseases is well known. 5,6 Depression has been shown to increase the risk of auto-immune syndromes, 7,8 and an association between chronic depression and an increased risk of cancer has been suggested 9,10 Recently, several studies have shown an association between depression and decreased bone mineral density (BMD) or osteoporosis 11-14,15 However, the number of subjects involved in these studies was rather small, which might explain why only tentative theories were formulated to explain this finding. Another study in a large cohort of older women with established osteoporosis found no differences between depressed and non-depressed women. 16

In order to achieve appropriate epidemiological power, the assessment of depressed mood (or high depressive symptomatology) in large samples, by means of depression self-rating scales, is a good approach, a high score on this self-rating scale being the strongest predictor of the presence of a depressive syndrome. ${ }^{17}$

The present study investigates the relationship between depressed mood and BMD in a large (5000) population-based cohort of healthy women around menopausal age $^{18}$ Although no established osteoporosis would be expected within this population, a substantial variation - because of the declining oestrogen production in menopausal women - of BMD was found. Moneover, previous research within this sample has shown that up to $23 \%$ of these women suffer from high depressive symptomatology. ${ }^{19}$

\section{Methods}

\section{Subjects}

The initial study population consisted of 8503 women, aged $47-54$ years, living in the city of Eindhoven, the Netherlands. Between December 1994 and November 1995, these women were invited to take part in a BMD assessment. A total of 6846 women responded (response rate, $81 \%$, of whom $6648(78 \%$ ) actually had their BMD measured. Moreover, they completed a questionnaire in connection with their lifestyle (smoking habits, alcohol intake, medication intake, physical activity) and underwent a physical examination (blood pressure, pulse, weight, height). Poor physical activity was defined by less than wo hours a week of physical exercise 
(during daly life, such as walking and sports). Data regarding these baseline measurements have been published in detail elsewhere. 18

Subsequently, the women were asked to complete a depression self-rating scalle at home and to return it within one week of screening. Because of possible language problems, only Dutch Caucasian women 15896 in totall were included, of whom $5655(95.6 \%)$ completed the depression self-rating scale correctly. Of these women, 711 falled to complete questions concerning lifesiyle habits accurately. Therefore, the analysis refers to the remaining $4944183.8 \%$ women. This group did not differ in baseline characteristics from the original study population. All women provided informed written consent, and the study was approved by an Independent Medical Ethical Committee.

\section{Assessments}

Bone mineral density

BMD of the lumbar spine (L1-L4) was measured with dual energy X-ray absotptiometry (DXA, model QDR-1000, S.A. Hologic Europe, Brussels). Callibration of the densitometer, scan quality control and scan performance were carried out by one qualified operator. The daily spine phantom quality controls were within $1.5 \%$ of the reference value. The coefficient of variation for the anatomical phantom $\left(1.0354 \mathrm{~g} / \mathrm{cm}^{2}\right)$ for the duration of the study was $0.54 \%$. All scans were performed in the supine position. Vertebrae that could not be evaluated (due to calcification, operation, etc.) were not included in the calculation of BMD.

\section{Edinburgh Depression Scale}

Depressive symptoms were assessed using the Edinburgh Depression Scale (EDS), a ten-item self-rating scale originally designed for use in postpartum women, and recently validated in non-childbearing women. 20,21 The EDS has already been validated in the Nethertands in the postpartum period ${ }^{22}$, and recently in women of menopausal age 31 Scores vary between 0 and 30 (with higher scores indicating more depressive symptomatology), with a commonly used cut off score of $\geq 12.20,21$ According to their EDS scores, the women were divided into five categories: those with hardly any depressive symptomalology (EDS $<7$ ); those with moderate depressive symptomatology ( $7 \leq \mathrm{EDS}<12$ ); those with clear depressive symptomatology (12 $\leq$ DDS < 16): those with high depressive symptomatology (16 $\leq$ EDS $<21$ ); and finally those with EDS $\geq 22$, a score generally referring to severe depression. 21

\section{Statistics}

Statistics tests were pertormed with the use of Statistical Products and Service Solutions (SPSS). Mean scores of BMD between the depressed (EDS $\geq 12$ ) and non-depressed women ware compared with Student's t-test. Differences between 
proportional were assessed using the chi-square test for independent proportions. The effect of the severity of depressed mood on BMD was investigated by means of multiple logistic regression analysis, with low $\mathrm{BMD}(\mathrm{BMD}<0.869$, osteopenia and osteoporosis) as the dependent variable and depressive mood, age, smoking body mass index (BMl, $\mathrm{kg} / \mathrm{m}^{2}$ ), and physical activity as independent variables. A two-tailed significance level of 0.05 was used.

\section{Results}

The mean BMD was $1.008 \mathrm{~g} / \mathrm{cm}^{2}(S D \pm 1.440)$. One thousand and fourteen $(20.5 \%)$ of all women were depressed according to a cut of scone of $\geq 12$ on the EDS. The characteristics of the depressed and non-depressed women are presented in Table 1. Except for their lifestyle habits, the two groups were rather similar. However, depressed women had poorer lifestyle habits, as far as smoking and physical activity were concerned. Also, depressed women used antidepressant drugs and tranquillisers significantly more often. The number of women in this study who used other medications that could contribute to a dectine in bone mass, such as corticosteroids, anticonvulsant, or heparin, was small, and did not differ between the two groups (data not shown).

The women with depressed mood (EDS $\geq 12$ ) had a significantly lower BMD of the lumbar spine (mean: $0.998 \mathrm{~g} / \mathrm{cm}^{2} ; \mathrm{SD} \pm 0.143$ ), compared to the non-depressed women (mean: $1.018 \mathrm{~g} / \mathrm{cm}^{2} ; S D \pm 0.144 ; t$ test,$p<0.00$ ). This relationship was seen in the group as a whole, in those using oestrogen's, and in those not using oestrogen's.

In order to investigate the effect of an increasing EDS score on BMD, Table 2 shows the mean BMD scores in the five different EDS groups: the higher the EDS score, the lower the mean BMD. Subsequently, the severity of depressed mood was related to BMD, adjusted for age, BMl, smoking habirs and physical activity, all of which are determinants of BMD (Table 3). In multiple logistic regression analysis, these indem pendent factors substantially still affected BMD, white the influence of depressed mood disappeared. When menopausal state was included in the model instead of age, similar results were found. In women with an EDS scone of $\geq 12(n=1014)$, the mean $B M D$ in those using antidepressant drugs $(n=69)$ was compared to those with an EDS score of $\geq 12$ not undergoing antidepressant therapy: the values were rather similar, 0.988 and $0.989 \mathrm{~g} / \mathrm{cm}^{2}$, respectively. 
Table 1. Baseline character stics of he 4944 nenopausal women aged $(47.53$ years)

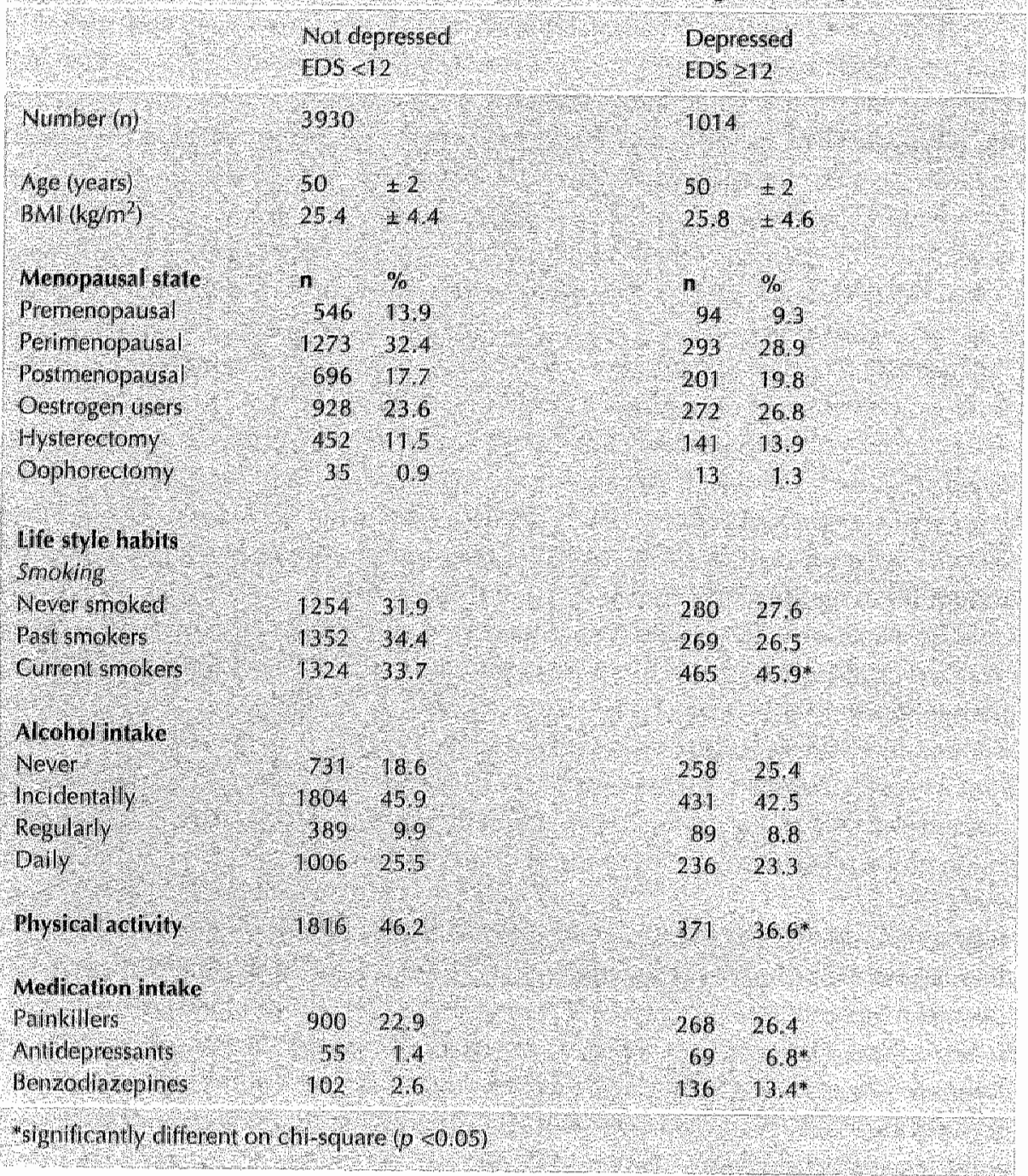


Table 2. LDS scores compared to mean BMD

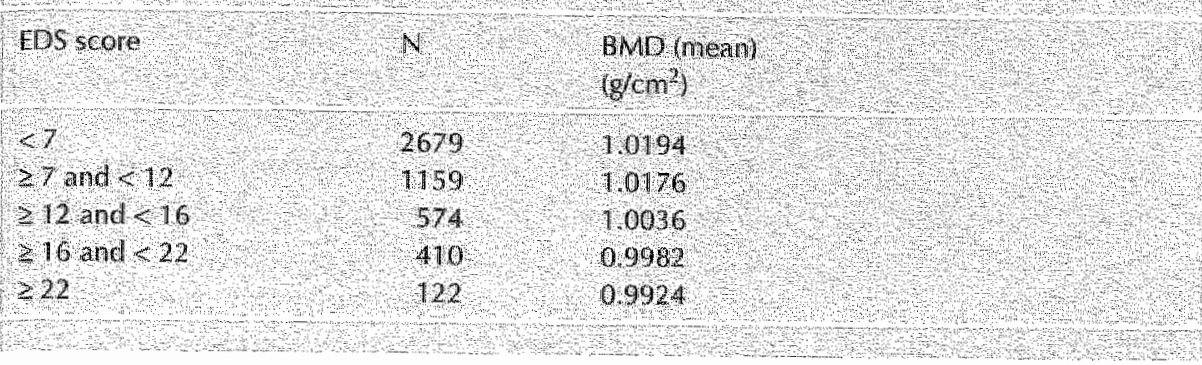

Table 3 . Determinants of bone mineral density of the lumbar spine in perimenopausal women: Legistic regression a nalysis. Dependeni variable: 10W BMD detined as osteopena and osteoporosis)

\begin{tabular}{|c|c|c|}
\hline Varable & $\mathrm{OR}$ & $95 \% \mathrm{C}$ \\
\hline Age & 1.25 & $1.20-1,30$ \\
\hline BMI & 0.90 & $0.60-0.9$ \\
\hline Snoking & 1,15 & 1,094122 \\
\hline Pliysical activity & 0.70 & 0.620 .86 \\
\hline Depressive syriptomatoligy & 110 & $0.98-122$ \\
\hline
\end{tabular}

\section{Discussion}

While this study investigated the occurrence of high depressive symptomatology rather than syndromal depression, the relationship between depression and decreased $B M D$, as shown in several other studies $11,12,13,15$ was confirmed at an uni-variate level. It is the first study in which such a relationship has been demonstrated in a large healthy community-based population consisting of 5000 perimenopausal women. Contrary to other studies, hospitalised patients were excluded from this study. Moreover, it showed a linear association: the higher the score on a depression self-rating scale, the lower the bone mass. However, after adjustment for several important determinants of bone mass (mostly related to life style habits), depressed mood showed no relation to decreased BMD.

The first study to question whether subjects with depression are at risk for low BMD investigated a rather small sample of 80 severely depressed inpatients (both men and women) ${ }^{11}$ Each patient was matched with five controls for several other determinants of bone mass \{age, sex, BMI, and menopausal state\}.

Hypercorticoidism was suggested as an explanation for this finding. "In the study by Halbreich et al. ${ }^{12}$, the effect of several psychiatric disorders (mania, depression, schizophrenia, adjustment disorder) on bone mass in hospitalised medicated male patients was mainly explained by hypogonadism, which questions the possible role 
of neuroleptics. Michelson et al. ${ }^{13}$ found lower BMD in 24 women with past or current depression. A decrease in bone turnover (as reflected by a decrease in osteocalcine and urinary deoxypyridinoline) and higher cortisol levels, in depressed women versus controls, was hypothesised to explain the lower bone mass Another population based study in 7414 older women, in whom decreased bone mass had aready been established, could not find a difference in BMD between depressed and non-depressed women 16. Finally, a small community sample study of 102 older women, with a rather similar design as the present study, also found a higher prevalence of osteoporosis in women with high scores on a depression self-rating scale. 15

From a conceptual point of view, the finding in the present study that higher scores for depressive symptoms in 'healthy' women (no psychiatric inpatients, and a high response rate, $81 \%$, of all women of menopausal age from the city of Eindhoven) are related to decreased $\mathrm{BMD}$, is rather intriguing. Contrary to what has been suggested so far, it might be hypothesised that - alleast in a healthy (non-hospitalised) population - a possible explanation for this finding is more likely to be found in the differences in lifestyle habits between depressed and non-depressed subjects (which are strongly related to BMDy, rather than in primarily endocrinological factors directly related to depressed mood and bone mass (such as differences in cortisol levels). Previous studies have shown that depression - particulally major depression - is significantly associated with poorer lifestyle habits: high alcohol intake, 23,24 high tobacco consumption, 25,26 and decreased physical activity. 27,28

The latter wo have also been shown to be related to decreased BMD 29,30 The almost linear association between scores on the depression scale (EDS) and bone mass the higher the score, the lower the BMDican also be explained by the association with these lifestyle habits. It has been shown that very high scores $(\geq 17)$ on the EDS are commonly associated with the occurrence of severe (major) depression. 31 Clinical studies have shown that severely depressed patients do indeed present with low physical achivity, ${ }^{32}$ the latter being a major deteminant of low bone mass. The stuggestion that the use of antidepressant drugs might influence BMD was not supported by the present study: depressed women with and without the use of antidepressants showed similar bone mass. Although the odds ratio in this study is rather low, from a conceptual point of view, it is important to realise that the possible relalionship berween depressed mood and low BMD might be influenced by other factors.

As shown in the EDS walidation study, scores abovel 6 are highly suspicious of the existence of major depression (positive predictive value, $75 \%$ ) 31

A limitation of the study was the assessment of depressive mood by self-rating scales, rather than by making a syndromal diagnosis of depression in a semi-structured interwiew. However, as pointed out earlier, the assessment of depressed mood cor high depressive symptomatology) in large samples by means of depression self-rating scales is a good altemative, a high scone on this self-rating scale being the 
strongest predictor of the presence of a depressive syndrome. 17 Another limitation is the fact that this study used a cross-sectional rather than a prospective design, which made it impossible to evaluate the effect of the duration of depression on BND. However, repeated assessments of depressed mood in large samples have shown that markedly elevated scores on the self-rating scale are highly suspicious of the occurrence of chronic depression.

The finding that depressed mood (undirectly rather than directly) negatively affects bone mass, might be regarded as another argument for treating depression. Major problems of depression are its high incidence, the small proportion of subjects who seek professional help, 32 the high number of depressed patients seeking help in whom the diagnosis is missed by the physician, ${ }^{33}$ the high number of depressed patients who - once they receive pharmaceutical intervention - are treated with inadequately low levels of antidepressants, 34 and, finally the poor compliance to drug therapy. 35 All these factors are thought to contribute to the chronicity of depression and the high rate of recurrence. In turn, this chronicity may increase the risk of concomitant chronic diseases, such as cardiovascular and auto-immune syndromes, cancer and osteopenia or osteoporosis.

\section{Literature}

1. WHO report on Depression and Resource Utilization. Harvard Universily 1998.

2. Angst 1, Angst F, Stassen HH. 1999 Suicide risk in patients with major depressive disorder. J Clin Psychiatry, 60, Suppl 2:57-62.

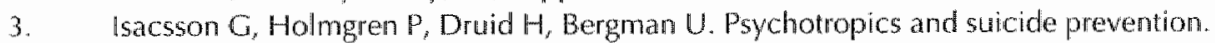
Implications from toxicological screening of 5281 suicides in Sweden 1992-1994. Br J Psychiatry Mar 1999; 174:259-265.

4. Stoltz CM, Baime MJ, Yaffe K.. Depression in the patient with theumatologic disease. Rheurm Dis Cin North Am. 1999;25:687-702.

5. Glassman HD, Shapiro PA. Depression and the course of cononary artery disease. Am I Psychiatry 1998; 155:4-11.

6. Musselman DC, Evanc DC, Nemeroff CB. The relationship of depression and cardiovascular disease. Arch of Gen Psychiatry 1998,55:580-592

7. Pop VI, Maartens LH, Leusink GL, Son MJ wan, Knotnerus AA, Ward AM, Metcalle R, Weetman AP. Are autoimmune thyroid dysfunction and depression related? I Clin Endocrinol Metab 1998;83:3194 3197.

8. Leonard BE Miller K. Stress and the immune system; inmunological aspects of depressive illness. John Wiley \& Sons Lid., 1995;113-136.

9. Penninx BW, Guralnik IM, Pahor $M$, Ferrucci $L$, Cerhan IR, Wallace RB, Havlik RJ. Chronically depressed mood and cancer risk in older persons I Natl Cancer Inst 1998,90:1888-93.

10. Penninx BW, Geerlings SW, Deeg DI, van Eijk JT, van Tilburg W, Beekman AT. Minor and major depression and the risk of death in older persons. Arch Gen Psychiatry 1999; $56: 889-95$ 
11. Schweiger U, Deuschle M, Korner A, Lammers CH, Schmider J, Gothandt U, HolsboerF, Heuser I. Low lumbar bone mineral density in patients with major depression. Am I Psychiatry 1994:151:1691-1693.

12. Halbreich U, Rojansky N, Palter S, Hreshchyshyn M, Kreeger J, Bakhai Y, Rosan R. Decreased bone mineral density in medicated psychiatric patients. Psychosom Med 8995:57:485-491.

13. Michelson D, Stratakis C, Hill L, Reynolds J. Galliven E, Chrousos G, Gold Ph. Bone mineral density in women with depression. N Eng I of Med 1996;335:1176-1181.

14. Amsterdam JD, Hooper MB. Bone density measurement in major depression. Prog Neuropsychopharmacol Biol Psychiatry 1998;22:267-277.

15. Coelho R, Silva C, Maia A, Prata) Barros H. Bone mineral density and depression: a community study in women. I Psychosom Res 1999;461:29-35

16. Whooley MA, Kip KE, Cauley IA, Ensrud KE, Neviu MC, Browner WS. Depression, falls, and risk of fracture in older women. Study of Osteoporotic Fractures Research Group. Arch Intem Med 1999; 159:484-490.

17. Gelder M, Mayou R, Geddes I. Oxford Textbook of Psychiatry. Second edition Oxford University Press. 1999

18. Smeets-Govaers CG, Leusink GI., Papapoulos SE, Maartens LW, Keyzer IJ, Weerdenburg IP, Beijers L.M Zwinderman AH, Knotmerus J.A, Pols HA., Pop, VI. The prevalence of low bone mineral density in Dutch perimenopausal women: The Eindhoven Perimenopausal Ostteoporose Study. Osteoporos Int 1998;8:404-409

19. Maartens LH, Leusink GL, Knottnerus JA, Pop VI. Hormonal substitution what are we treating? Maturitas 1999;34:113-118.

20. Cox IL. Chapman G, Murray D, Jones, P. Validation of the Edinburgh Posmatal Depression scale (FPDS) in nom-postnatal women. I Aftect Disord 1996; 39:185 189.

21. Cox J., Holden JM, Sagovsky R. (1987) Detection of postnatal depression: Development of the 10-item Edinburgh Postnatal Depression Scale. Br. Psychiatry 150: 782-786.

22. Pop VI, Komproe $I H$, wan Son MI. Characteristics of the Edinburgh Post Natal Depression scale in The Netherlands. I Affect Disord 1992;26:105 110.

23. Mulsant BH, Ganguli M. Epidemiology and diagnosis of depression in late life. I Clin Tsycritaliry 19y2y; bu suppl $20: y-13$.

24. Hasin DS, Tsai WY, Endicott J, Mueller TI, Coryell W, Keller M. Five-year course of major depression: effects of comorbid alcoholism. I Affect Disond 1999,41:63-70

25. Black DW, Zimmerman $M$, Coryell WH. Cigarette smoking and psychiatric disorder in a community sample. Ann Clin Psychiatry 1999;11:129.136.

26. Brestau $N$, Peterson EL, Schultz LR, Chilcoat HD, Andreski P. Major depression and stages of smoking. A longitudinal investigation. Arch Gen Psychiatry 1998;55:161-166.

27. Pennirx BW, Leveille S, Ferrucci L., van Eijk IT, Guralnik IM. Exploning the effect of depression on physical disability: longitudinal evidence from the established populations for epidemiologic studies of the elderly. Am / Public Health 1999;89:1346-1352.

28. Stewart AL, Hays RD, Wells KB, Rogers WH, Spritzer KL, Greenfield S. Long-term functioning and well-being outcomes associated with physical activity and exercise in patients with chronic conditions in the Medical Outcomes Study. I Clin Epidemiol $1994: 47: 719-730$

29. Kall EA; Dawson-Hughes B. Smoking increases bone loss and decreases intestinal calcium absorption. 1 Bone Miner Res 1999;14:215-220. 
30. Wolff I, van Croonenborg II. Kemper HC, Kostense PI, Twisk IW. The elfect of exercise training programs on bone mass: a meta ana ysis of published controlled trialls in preand postmenopausal women. Osteoporos Int 1999;9:1-12.

31. Becht MC, Van Erp CF, Teeuwisse TM, Van Son M, Van Heck GL, Pop VI Measuring depression in women around menopausal age validation of the Edinburgh Depression Scale. I Affect Dis 2000 in press

32. Lin E, Parikh SV. Sociodemographic, clinical, and attitudinal characteristics of the untreated depressed in Ontario. I Affect Disond 1999;53:153-162.

33. Tylee A. Depression in the community: physician and patient perspective. 1 Clin Psychiatry 1999;60:Suppl 7:12-16; discussion 17-18 [Reviewl.

34. Dunn RL, Donoghue IM, Ozminkowski RI, Stephenson D. Longitudinal patterns of antidepressant prescribing in primary care in the UK: comparison with treatment guidelines. I Psychopharmacol 1999;13:136-143.

35. Demyttenaere $K$, Van Ganse E, Gregoire I, Gaens E, Mesters P. Compliance in depressed patients treated with Iluoxetine or amitriptyline. Belgian Compliance Study Group. Mesters P Int Clin Psychopharmacol 1998; 13:11-17. 



\section{Prevention of early postmenopausal bone} loss: A randomised trial of calcium, HRT and pamidronate in women with low bone mass selected from a population-based cohort and one-year follow-up

Geraline L. Leusink, LuC W.F. Maartens, Victor J.M. Pop, Jules J. Keyzer, J. Andre Knottnerus, Huibert A.P. Pols, Socrates E. Papapoulos

Diagnostic Centre Eindhoven (GLL, LWFM, لlK); Department of Social and Behavioral Science, University of Tilburg (VIMP); Department of Family Medicine, University of Maastricht UAK); Department of Endocrinology and Metabolic Diseases, Leiden University Medical Centre (SEP); Department of Internal Medicine III, Erasmus University Rotterdam (HAPP); the Netherlands

Submitted for publication 


\begin{abstract}
Objectives: The objective of this study was to compare the effect of calcium supplementation (te $400 \mathrm{mg}$ d) alone, calcium with HRT loestradiol 2 mg/dydrogesterone $10 \mathrm{mg}$, and calcium with pamidronate $(100 \mathrm{mg} / \mathrm{d}$ ) on early postmenopausal bone loss in women with low bone mass and to evalwate the rate of change in (BMD) one year after medication withdrawal.
\end{abstract}

Design: A randomised clinical trial.

Setting: A collaborative primary care centre in Eindhoven, the Netherlands.

Subjects: From a population-based cohort of 8503 women aged 47-54 years, 649 fulfilled the study criteria, and of these, 392 were randomised to. receive calcium $(n=129)$, calcium and HRT $(n=133)$, or calcium and pamidronate $(n=130)$, for two years and were followed one year after the completion af treatment:

Outcome measurements: BMD of the lumbar spine and the hip were assessed at baseline and atter one, two and three years.

Resullts: Three hundred and four women $(77.6 \%)$ completed the two-year study. At one and wo years, the mean increases in lumbar spine BMD were significantly higher in the HRT group $14.5 \%$ and $5.2 \%$, respectively) and the panvidronate group $(1.4 \%$ and $0.5 \%$, respectively) compared to the calcium-cnly group $(-1.1 \%$ and $-2.3 \%$, respectively; $p<0.001$ for all comparisons). During treatment, no bone loss was observed att the proximal femur or fiemoral neck in any of the treatment groups. In the 302 women $(77 \%$ ) who were studied in the third year, but who were no longer undergoing treatment, spinal BMD decreased by $-4.5 \%$ in the HRT group, by $-2.6 \%$ in the pamidronate group, and by $-1.6 \%$ in the calcium group. There was also a decrease of BMD in the proximal femur (HIRT $-3.3 \%$, pamidronate $-2.6 \%$, and callcium $-2.0 \%$, and a decrease was observed at the femoral neck in all three groups (HRT $-2.9 \%$, pamidronate $-2.0 \%$, and calcium $-1.2 \%$.

Conclusions: In early postmenopausal women with a low bone mass, bone loss can be prevented by HRT and pamidronate. One year after the completion of treatment, lumbar and fennoral BMD was still increased in the HRT group compared to baseline measurements, while BMD in the pamidronate group was slightly decreased. The highest decrease in spinal BMD was observed in the calcium group.

Key words: osteoporosis, prevention, permenopause, Hormone Replacement Therapy $(\mathrm{HRT})$, calcium, bisphosphonates 


\section{Introduction}

The loss of ovarian hormones in the menopause is a major risk factor for osteoporosis. 1,2 The rate of bone loss is accelerated for approximately five to ten years after the menopause. It has been estimated that the risk of a women developing fractures later in life is as great as that of cardiovascular diseases and six times higher than that of breast cancer. ${ }^{3}$ Prevention of bone loss with hormonal replacement therapy (HRT) is associated with a reduced incidence of vertebral and hip fractures, and is considered to be the primary intervention for prevention of the disease. 4-6 However, long-term compliance with HRT is low, ${ }^{7}$ necessitating the development of effective alternative interventions. Bisphosphonates, which suppress bone resorption and reduce bone turnover, have been shown to decrease postmenopausal bone $\operatorname{los}^{8-1} 11$ and, when given to women with osteoporosis, to decrease the risk of new osteoporotic fractures. $12,13,14$ Hosking et al ${ }^{15}$ reported that oral alendronate was as effective as HRT in preventing bone loss in postmenopausal women younger than 60 years. However, studies assessing the efficacy and safety profiles of HRT and bisphosphonates in a population-based cohort of women, particularly those at higher risk for osteoporosis, have not yet been undertaken. Moreover, the effect of the discontinuation of these interventions in this group has not yet been studied in a randomised clinical trial.

In the present study we reported the results of a randomised clinical trial comparing the effects of HRT, the bisphosphonate, pamidronate (APD), and calcium, in early postmenopausal bone loss in women with low BMD selected from a population-based cohort and and to evaluate the rate of change in (BMD) one year after medication withdrawal.

\section{Material and methods}

The initial study population consisted of 8503 women, aged from $47-54$ years, living in the city of Eindhoven, the Netherlands. Bewween December 1994 and November 1995, a total of 6846 women responded to a postal questionnaire fresponse rate $81 \%) ; 6648$ women (78\%) consented to having their BMD measured, completed a questionnaire, and had a physical examination. Details of the characteristics of this population have been reported previously. ${ }^{16}$

Six hundred and forty-nine women $(7.6 \%)$ fulfilled the inclusion criteria for the study, as follows: amenorhoea for up to three years, altered menstrual pattern with less than five bleedings in the past 12 months, and $\mathrm{BMD}$ of the lumbar spine in the lowest tertile of premenopausal women $\left(<0.998 \mathrm{~g} / \mathrm{cm}^{2}\right)$. Of those eligible, 56 women did not wish to participate in the study, and 201 were excluded. Exclusion criteria included: hystereclomy and/or ovariectomy, history and/or presence of a metabolic bone disease, rheumatoid arthritis, history of serious cardiovascular 
diseases, endocrine diseases such as pituitary, thyroid or parathyroid dysfunction, history and/or presence of malignancies, and use of bisphosponates or medications that could interfere with calcium and bone metabolism in the 12 months prior to the intervention study. The use of systemic oestrogens/progestagens was not permitted in the three months prior to the trial.

The final study population consisting of 392 women, who were randomly assigned to the three different ireatment modalities (see below). All women provided informed written consent, and the study was approved by two medical ethical committees.

\section{Treatment}

All the women were given a calcium carbonate tablet (1000 mg Davitamon $(B)$, providing $400 \mathrm{mg}$ elementary calcium. One group received no additional treatment; the second received continuous $2 \mathrm{mg}$ oestradiol tablets, combined with $10 \mathrm{mg}$ dydrogesterome in the second half of the cycle (Femoston(1), Solvay Pharmaceuticals, the Netherlands); the third group received pamidronate (gelatin capsule) 100 mg/day, (Aminomux(B), Gador, Argentina). The women were instructed to take the pamidronate on an empty stomach, half an hour to one hour before breakfast or dinner, with two glasses of water. The calcium was to be taken at bedtime. The women were randomly assigned to one of the treatment groups by computer, and no reallocation to another treatment group was offered. The total duration of the intervention was two years. The follow-up was an one year open study, women who had completed the two-year study received no medication and no calcium supplementation.

\section{Bone mineral density measurements}

BMD of the lumbar spine (1.1-1.4) and hip was measured at baseline during the subsequent three years with dual energy $X$-ray absorptiometry (DXA, model QDR- 1000 S.A. Hologic Europe, Brussels). Calibration of the densitometer, scan quality control, and scan performance were carried out by one qualified operator. The daily spine phanton quality controls were within $1.5 \%$ of the reference value. The coeficient of variation for the anatomical phantom $\left(1.0354 \mathrm{~g} / \mathrm{cm}^{2}\right)$ for the duration of the study was $0.54 \%$. All the scans were performed in the supine position. The following sites were measured at the left proximal femur: total hip, femoral neck, and trochanter.

\section{Assessment of safety of the treatment}

The participants were seen every three months during the first two years, and every six months during the third year of treatment. 
The following items were evaluated at each visit: any symptoms reported, occurrence of vaginal bleeding, medication used, adverse events, pill counting blood pressure, weight, and pulse rate. Laboratory analyses, namely haematology, renal function and liver function tests, were performed every six months, for safety reasons. Mammograms were performed at the start and after wo years of intevention. Women with abnormalities (suspected lesions) ${ }^{17}$ on mammography were care. fully followed throughout the trial, and mammography was performed yearly.

\section{Statistical analysis}

The primary outcome, the percentage change in lumbar spine BMD, was compared between the wo treatment groups and the calcium-only group using the t-test for independent observations, adjusted for multiple comparisons with a Scheffe correction. Statistical significance was defined as $p<0.05$, two-sided. The secondary outcome, the percentage change in BMD at the different measurement sites at the proximal femur, was analysed accordingly. Analyses were by intention to treat, including those women in whom lumbar spine BMD was measured at baseline and at least once during treatment. The statistical analysis was performed with the use of the Statistical Products and Service Solutions (SPSS).

Using multiple linear regression analysis with the percentage change in lumbar spine BMD as the dependent variable, the effect of each treatment was compared, adjusted for relevant covariables such as $\mathrm{BMI}$, age, duration of amenorthoea, and smoking status (baseline data).

\section{Results}

The baseline characteristics of the 392 women randomised to the three treatment groups are shown in Table 1. The mean age of the participants in the study was 51.6 years, and there were no significant differences in any of the baseline characteristics between the three groups. Twenty women $(5.1 \%)$ declined further participation in the study immediately after randomisation, and 42 women $(17.3 \%)$ did not complete the study. The reasons for discontinuation are shown in Figure 1 for each treatment group. Eighteen percent of the women in the HRT group willdrew from the study because of menstrual disturbances (withdrawal bleedings, menomagia) and mastopathy; $11 \%$ of the women in the pamidronate group discontinued reat ment because of gastrointestinal complaints, namely nausea and voniting. The other main reason in the calcium and pamidronate groups for discontinuation of the study was the occurrence of climacteric complaints. After two years, 304 women had completed the study (77.6\%): there were no significant diferences in any of the baseline characteristics between those women who did or did not drop out. Compli- 


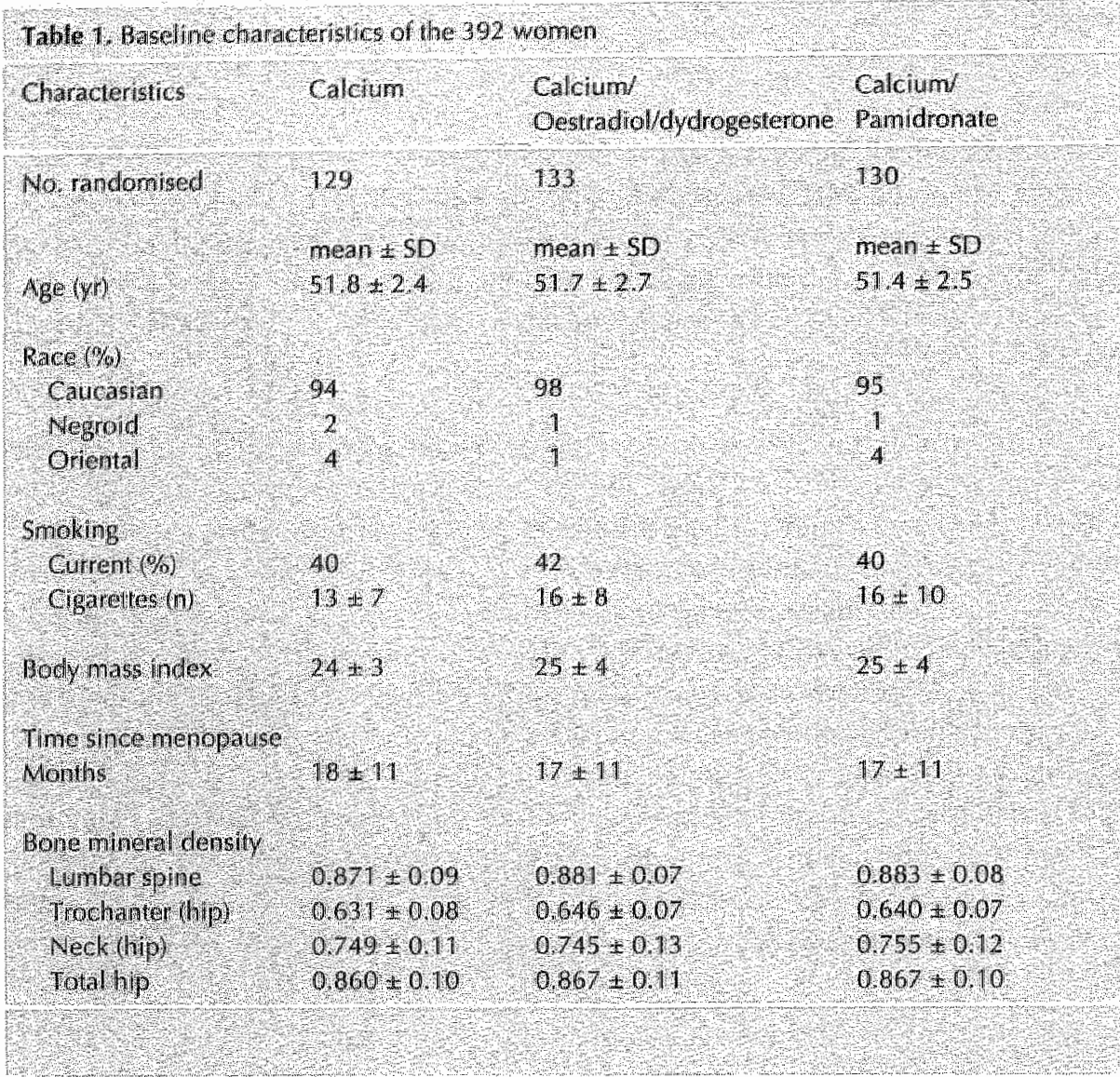

ance to treatment, assessed by pill counts, was high throughout the trial: the mean compliance in all the treatment groups was $86.3 \%$.

Three hundred and two women entered the follow-up study; wo subjects withdrew because they chose to stay on homone therapy due to the possible recurrence of hot flushes. Three hundred women completed the study, while wo withdrew lone in the pamidronate group because of a pancreas carcinoma, and one woman in the calloium group was lost to tollow-up).

\section{Lumbar spine bone mineral density}

Two years of treatment

Lumbar spine BMD steadily decreased in the calcium-treated women, while it clearly increased in both the pamidronate and HRT treated women Table 2 , Figure 2. This increase in BMD was most prominent in the HRT group lafter one year, $4.5 \%$; 


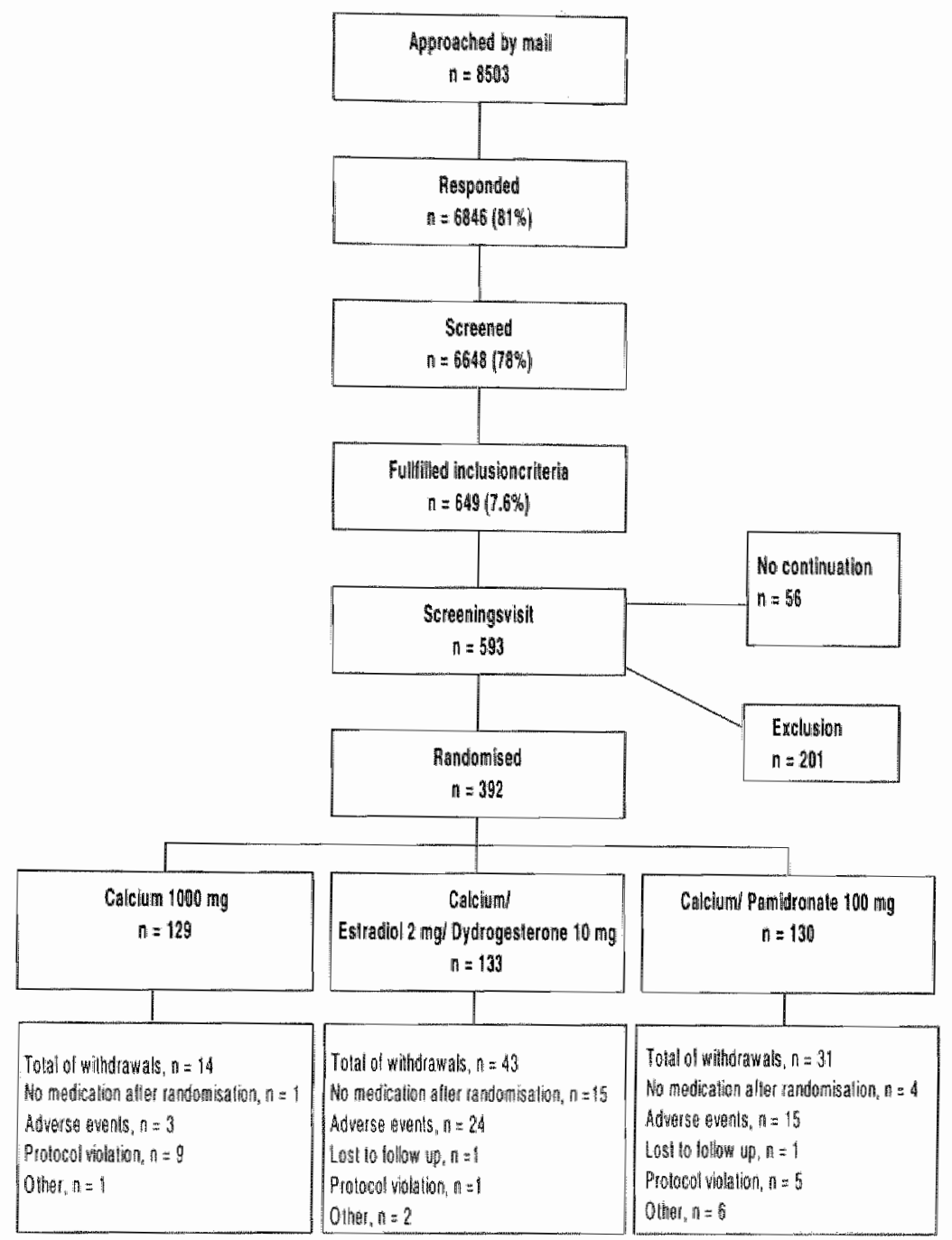

Figume 1. Study profile and patient disposition

after wo years, $5.2 \%$. Compared to the calcium group, both HRT and pamidronate significantly prevented bone loss. However, the BMD response to HRT was significantly higher than that to pamidronate $(p<0.001)$.

Follow up year

After withdrawal of treatment, there was a significant decrease of BMD in all groups (HRT $-4.5 \%$, pamidronate $-2.6 \%$, calcium $-1.6 \%$, Table 2 , Figure 2 . The mean 


\begin{tabular}{|c|c|c|c|c|}
\hline indecrease & $\begin{array}{l}\text { Year } 10 \\
\text { /o }\end{array}$ & $\begin{array}{l}\text { Year } 2 \\
\text { \% }\end{array}$ & $\begin{array}{l}\text { Years } \\
\text { of SEM }\end{array}$ & Ooltal \\
\hline Cakrun & & & & \\
\hline Lunbar spince & $111 \div 0.3$ & 2310.3 & $-16+0$. & $40+0.3$ \\
\hline Prennoral ned & $10 ? 0$. & $0.4+0.4$ & $12+0.3$ & $1-10+0.5$ \\
\hline Total hip & $1.5+02$ & $0.2 \pm 0.2$ & $718 \pm 0.3$ & $1,8+03$ \\
\hline Calciumpess & erone. & & & \\
\hline Mumber spine & $4.5+0.3$ & $5,2+0.7$ & $45 \pm 0.4$ & $1,3 \pm 0,4$ \\
\hline Temorit hed & $3,940,5 \%$ & $50+0,5^{*}$ & $2,9+0,3$ & 2.8407 \\
\hline & $3.5+0.2$ & & $-30 \pm 03$ & $1,4=0.3$ \\
\hline Calcium Pami & & l) & & \\
\hline Lumber spine & $1.4 \pm 0.3$ & $0.5 \pm 0.4^{*}$ & $2.6+03$ & $-2.9+0.3$ \\
\hline Hemoral neck & $1.5+0.4$ & $1,7 \pm 0.4$ & $2.0 \pm 0.4$ & $1,0 \pm 0,3$ \\
\hline Tolalitio & $12+0.2$ & $07=0.3$ & $2.6 \pm 0.2$ & $4-18+0.4$ \\
\hline
\end{tabular}

percentage change in BMD versus baseline was significantly increased in the HRT group $(1.3 \%)$, and significantly decreased in both the pamidronate and calcium groups $(-2.0 \%$ and $-4.0 \%$, respectively).

\section{Bone minerall density of the femur}

\section{Two years of treatment}

There was no significant decrease in mean $B M D$, as measured at the different sites of the proximal femur in any of the treatment groups, Table 2, Figure 3 . There was a significant increase in BMD in the HRT-treated women, compared to both the calcium. and pamidronate-treated women. The major increase in BMD occurred after one year.

Follow up year

After the withdrawal of treatment, there was a significant decrease of BMD in all groups (HRT $-3.3 \%$ and pamidronate $-2.6 \%$, calcium $1.8 \%$ ), Table 2 , figure 3 . The mean percentage change in BMD from baseline was significantly increased in the HRT group (2.8\%) and significantly decreased in both the pamidronate and calcium groups $(-1.0 \%$ and $-1.0 \%$, respectively). 


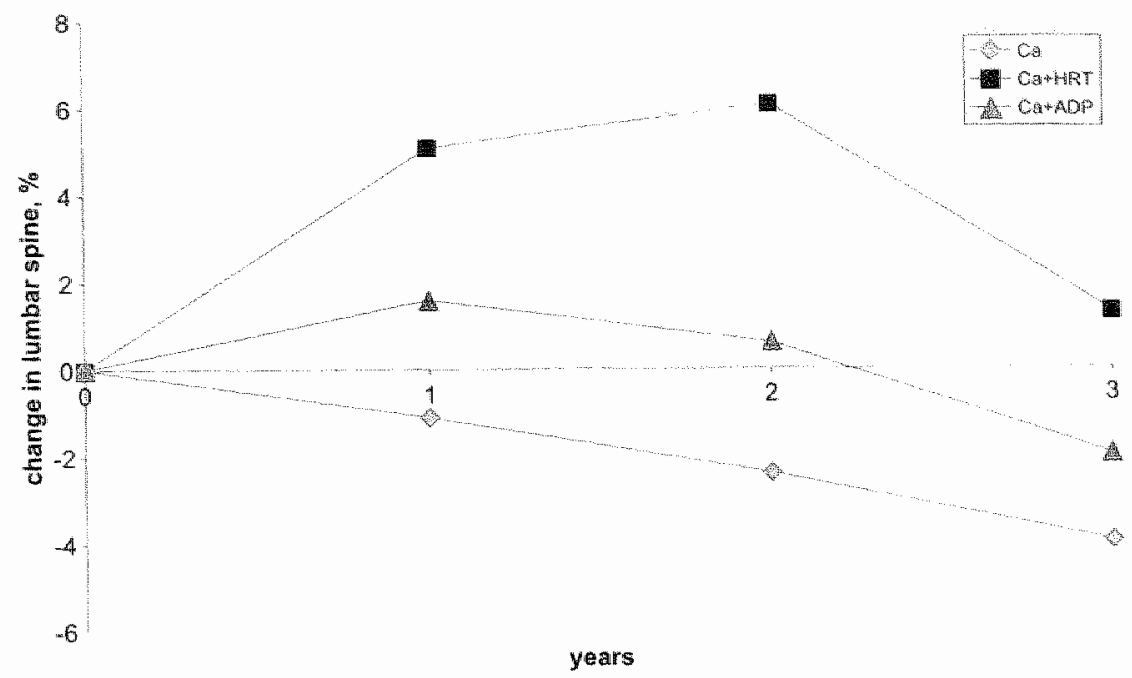

Figure 2. $\mathrm{BMD}$ of the lumbar spine during two years of intervention and 1 year follow up.

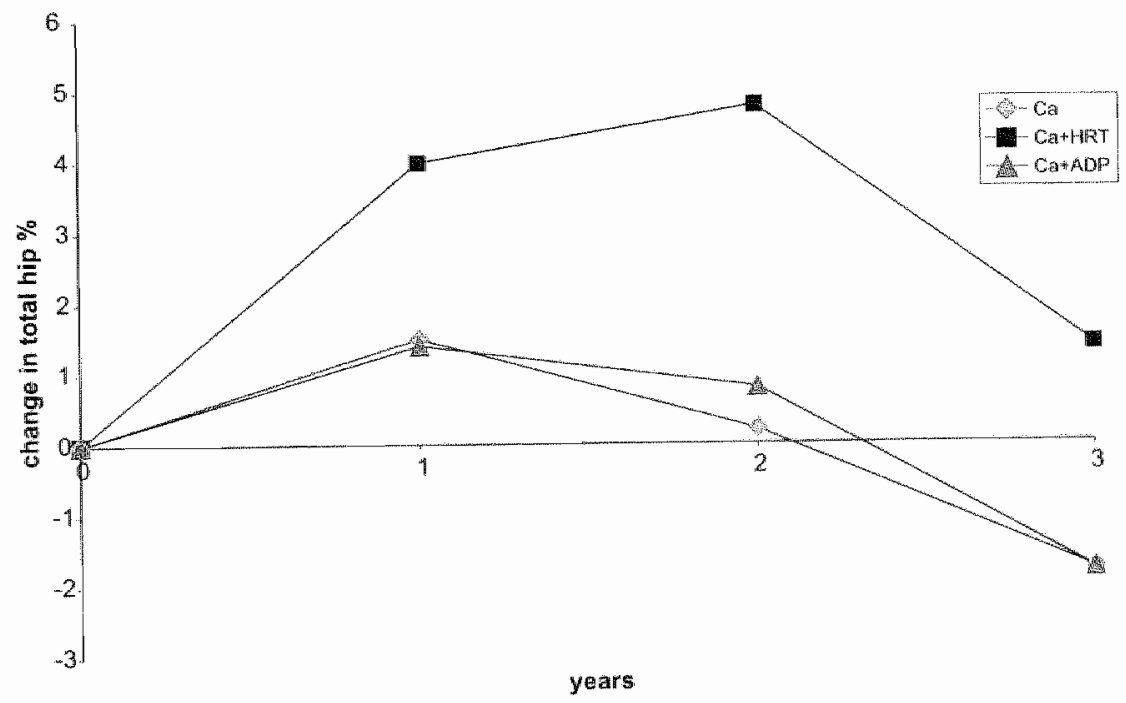

Figure 3. BMD of the total hip cluring two years of intervention and 1 year follow up. 


\section{Subgroup analysis}

This analysis was limited to those women who adhered to treatment regimen for the entire study pueriod of two years (Table 2). Age and smoking were not significantly related to changes in lumbar spine BMD over the two years, in all the treatment groups combined. Women with a longer duration of amenorhoea gained slightly, but significantly, more bone: calcium group, $7.1 \%$; HRT group, $12.9 \%$; and pamidronate group, $0.2 \%$. In the HRT group, women with a higher body mass index gained less bone $(-3.7 \%)$, and those who smoked more than ten cigarettes a day gained significantly less bone $(-7.8 \%)$ at the lumbar spine than smokers in the pamidronate $(-1.4 \%)$ and calcium $(-0.8 \%)$ groups. It should be emphasized that the effects of the covariables examined contributed very little to the overall effect of the intervention.

\section{Adverse events}

Overall safety was comparable between the three treatment groups. A high percentage of participants reported adverse events: calcium-only group, $90 \% ; H R T$ group, $97 \%$; and pamidronate group, $89 \%$. Gastrointestinal complaints were equally frequent in all three groups (calcium, $22 \%$, pamidronate, $25 \%$; and HRT, $21 \%$.

As expected, the typical HRT-related adverse events were significantly more frequent in this group, including breast tenderness (15\%) and dysmenorhoea $(12 \%)$. Interestingly, musculoskeletal complaints, such as arthralgia, myalgia and tenosynovitis, were significantly less frequent in the HRT group $(33 \%)$ compared to the calcium and pamidronate groups (48\% and $50 \%$, respectively; $p<0.05$ ). During the third year, $50 \%$ of the woman on HRT treatment reported the recurrence of hot flushes. Serious adverse events occurred in all three groups. In the calcium group, one woman developed an endometrial carcinoma, while, in the pamidronate group, one case of severe endocarditis and one of vaginal postmenopausal blood loss requiring a hysterectomy, occurned. In the HRT group, three women with breast cancer ware detected during follow-up: one tumour appeared after one year and two carcinomas after wo years of treatment. During the third year, one woman developed a pancreas carcinoma, (pamidronate group), and at the last visit, a woman was diagnosed with an inoperable brain tumour (calcium group).

\section{Discussion}

Bone loss occurring after the menopause is accelerated in the early postmenopausal period, making this a popular period for administering interventions aimed at reducing bone loss and preserving bone mass. This is particularly important in 
women who already have a low BMD. We focused on a group of peri- or early postmenopausal women who already had a low BMD. Consistent with the anti-resorptive action of HRT and pamidronate, our results demonstrated that both treatments given together with calcium prevented bone loss.

Usually, women included in osteoporosis prevention studies are selected from postmenopausal clinics, advertisements or personal invitation and, therefore, may not be representative of the population as a whole. In the present study, we selected a group of peri- and early postmenopausal women with BMD at the lowest tertile of premenopausal women, from a population-based cohort of women aged between 47 and 54 years. In this way, we did not only study those women at greatest risk for osteoporosis in the community. Individual preferences, which might indicate selection bias, were also noted in the present study: $5.1 \%$ declined participation immediately after randomization, due to preference for another intervention than the one assigned. The majority of these women had been allocated to the HRT group. Reallocation to another treatment group, as had occurred in the only published study of similar design 15 was not offered.

Consistent with the anti-resorptive action of HRT and pamidronate, our results demonstrated that both treatments given together with calcium prevented bone loss. The response to HRT was significantly better than that induced by pamidronate. At first sight, the effects of pamidronate on postmenopausal bone loss appeared to be less favourable than those recently observed by Hosking et al., 15 using another aminobisphosphonate, alendronate. In contrast to this study, we focused on a younger group of peri- or early postmenopausal women with an already low BMD, and used the lowest effective dose of pamidronate, since our aim was to prevent bone loss rather than to increase bone mass. In the treatment of patients with established osteoporosis, pamidronate $150 \mathrm{mg} / \mathrm{d}$ has been shown to induce changes in BMD similar to those ascribed to alencronate in a similar patient population. 8,18 As already observed in other studies, ${ }^{19}$ smoking interacted with the gain in BMD in HRT-treated women. Furthermore, the most prominent effect of HRT appeaned to occur in women with a relatively low BMII and in those with a longer duration of amenorrhoea. Nevertheless, we wish to emphasize that the overall effect of these factors was limited, and did not essentially intluence the final responses to interven. tion.

During our study of women using pamidronate and HRT, BMD gain was observed to slow up in the second year of treatment, and a significant loss of BMD following the withdrawal of treatment was noted. These data are consistent with the anti-resorptive action of these drugs, leading to filling in the remodelling space rather than to permanently resetting the balance befween formation and resorption. The response of BMD induced by HRT, observed after wo years and one year after withdrawal, was significantly better than that induced by pamidronate. BMD showed a significant increase from baseline in the spine and the hip, while pamidronate produced a decrease in BMD at both sites compared to baseline 
measurements. However, we used the lowest effective dose of pamidronate, since our aim was to prevent bone loss raher than to increase bone mass. This dose does not seem to be sufficient to reach a similar effect as HRT.

HRT and pamidronate were well tolerated in the present study, and any reported adverse events were very mild or irrelewant. The proportion of women who discontinued the study due to an adverse event was higher in the HRT group than in the pamidronate group, but the incidence of gastrointestinal complaints did not differ between the three groups. The occurrence of three cases of breast cancer in the HRT-treated women, compared to none in the other two groups, is worrying. However, the period of exposure to oestrogen's was too short to account for this, and perhaps it was a chance finding 30 rather than a drug-related event.

\section{Oestrogens}

The mechanisms of the anti-resorptive action underlying the effect of oestrogen treatment on the bone is not clearly understood. It is thought to involve the inhibition of osteoclasts, 20,21 which reduces bone turnover and improves the balance between bone formation and resorption. 21,22 un addition, oestrogen improves calcium retention through increased testinal calcium absorption and renal calcium reabsorption. ${ }^{23}$ The bone loss 'catcin up' effect following the termination of treatment has a negative effect on the efficacy of short-term and early-applied treatment. Therefore, the bone loss catch up effect favours long-term treatment, or treating women at the age when fractures occur (i.e., around the age of 75 years for hip fractures, and around the age of 65 years for vertebral and wrist fracturesi.

Recently, Le Pen et al.24 described a computer-based stimulation model which compared the long-term effectiveness of difierent preventive strategies. In this model, strategies combining both early (starting at menopausal age) and later treatment (at the age that fractures occur) are shown to be the most effective.

The Framingham study round a relative risk of $0.3469 \%$ confidence interval 0.11 .1 .09 after mulliwariate adjustment) among current or recent users of pestrogen and of $0.70(0.45-1.08)$ in former users for the protection of fractures. ${ }^{25} \mathrm{Als}$, significant protection from hip fractures in women who began HRT within five years of the menopause was seen in a study of osteoporotic fractures, but not in woman who started treatment later. 26 However, in a cross-sectional study of bone density, a nearly equal bone conserving benefit was seen for oestrogen therapy, starting before or after the age of 60 years, if the treatment was continued. 27 Several studies have suggested that oestrogen therapy only taken at the time of the menopause preserves bone during use, but may not preserve bone density later in life 28,39 or protect against osteoponotic fractures. 26, 29-31 The above-mentioned studies show that the timing of starting HRT and its optimal duration are still matters for discussion. From a skeletal perspective, very long-term HRT reatment appears to carry the greatest chance of preventing clinical osteoporosis, although this will be influenced by the 
weight given to non-skeletal issues, including other benefits and the risk of side-effects.

\section{Pamidronate}

The findings in our study are consistent with those of Meunier et al, 32 using the bisphosphonate etidronate in the prevention of early postmenopausal bone loss: a marginal increase in BMD of the lumbar spine after two years of treatment, and a significant decrease in the following year wilhout treatment.

Orr-Walker et al. 33 observed in women with a mean age of 66 years and established osteoporosis, an increase in BMD during three years of treatment, but also a decline in BMD after discontinuation of pamidronate $(150 \mathrm{mg} / \mathrm{day})$. Consistent with the concept of the mechanism of action of an anti-resorptive agent, the increase in lumbar spine BMD occurred wholly during the first year of treatment. Pamidronate inhibits bone resorption with a consistent increase in bone mass until a new steady state is reached. At steady state, the decrease in bone resorption is matched by a decrease in bone formation and bone mass is maintained, and therefore, withdrawal of treatment induces a rapid decrease of BMD.

Landman et al. ${ }^{34}$ described a cohort of 30 patients with established osteoporosis who had been treated with pamidronate $(150 \mathrm{mg} / \mathrm{day}$ ) for an average of 6.5 years. BMD of the lumbar spine and femoral neck did not change during two years of follow-up, despite biochemical evidence of the reversal of the suppression of bone turnover within six months of the discontinuation of treatment. In this study, a quarter of the patients was male, and one-third was taking vitamin D supplements or thiazides for the duration of the study. However, the effect of the longer duration of treatment with the greater skeletal accumulation of bisphosphonates may explain the apparently more persistent of treatment.

Ourfindings imply that pamidronate treatment for the prevention of osteoporosis in a dose of $100 \mathrm{mg} / \mathrm{day}$ may be insufficient to result in a substantial increase in bone mass, and will not affect bone loss after the cessation of treatment.

\section{Calcium}

An interesting observation was the lack of any significant bone loss at the proximal femur in the calcium-treated women for two years, and a decrease in BMD during the third year, following the withdrawal of calcium supplementation. This increase apparently contrasts with findings from other studies. 15,35 An explanation for this might be that the calcium supplement added to the already high calcium inlake of Dutch women (1000-1200 $\mathrm{mg} /$ day) provided a total, pharmacological amount of calcium ${ }^{36}$ sufficient to decrease bone turnover at cortical sites, while this treatment is insufficient to decrease bone turnover at sites containing more trabecular bone, where the bone turnover is higher. Therefore, the subsequent bone losses at all sites measured, after the cessation of calcium supplementation, might be explained by a higher bone turnover, resulting in a loss at both the hip and lumbar spine. 


\section{Conclusions}

This randomised clinical trial indicates that HRT is preferable for the prevention of BMD in women with early postmenopausal osteoporosis, but must be continued for a long period of time, taking other non-skeletal benefits and the risk of side-effects into consideration. Secondly, calcium supplementation may play a role in the prevention of cortical bone loss in women with early postmenopausal osteoporosis.

\section{Acknowledgments}

This study was kindly supported by a grant from the Dutch Preventiefonds (Project Na. 002824010). We would like to thank I. Komproe, statistician, for his help and critical view of the statistical analysis. The medlications used in this study were kindly provided by Solvay Pharmaceuticals, the Netherlands and Gador, Argentina.

\section{Literature}

1. Lindsay R. The menopause and osteoporosis. Obstet Gynecol (Suppl Ii) 1996; 87:165-195.

2. McGowan JA. Osteoporosis: assessment of boneloss and remodelling. Ageing Clin Exp Res 1993; 5:81-93.

3. Compston JE, Cooper C., Kanis JA. Bone densitometry in clinical practice. BMI 1995; 310:1507-1510.

4. Christiansen $C$. The different routes of administration and the effect of hormone replacement therapy on osteoporosis. Fertil Steril 1994; 62:152S-1565.

5. Sagraves $R$. oestrogen therapy for postmenopausal symptoms and prevention of osteoporosis. I Clin Pharmacol 1995; 35:2-10.

6. Michaelsson K, Baron JA, Farahmand FA, Johnell O, Magnusson C, Persson PG, Persson 1. L.junghall S., the Swedish Hip Fracture Study Group. Hormone replacement therapy and the risk of hip fracture. BMl 1998; $316: 1858 * 1863$.

7. Ryan Pl, Harrison R, Blake GM, Fogelman 1. Compliance with homone replacement therapy (HRT) after screening for postmenopausal osteoporosis. BrJ Obstet Gymaecol $1992 ; 99: 325-328$.

8. ReidIR, Wattie DJ, Evans MC, Gamble GD, Stapleton JP, Comish I. Continuous therapy with pamidronate a potent bisphosphonate in postmenopausal osteoporosis. J Clin Endocrinol Metab 1994; 79:1595-1599.

9. Meunier P|, Confavreux E, Tupinon $I_{*}$ Hardoin C. Delmas PD, Balena R. Prevention of early postmenopausal bone loss with cyclical etidronate therapy (a double blind placebo-controlled study and 1-year follow uph I Clin Endacrin Metab 1997; 82:2784-2791.

10. Pouilles IM, Tremollieres. F, Roux C, Sebert L, Alexandie C, Goldberg D, Treves R, Khalifa P, Duntze P, Horlait S, Delmas P, Kuntz D. Effects of cyclical etidronate therapy on bone loss in early postmenopausal women who are not undergoing hormonal replacement therapy, Osteoporosis Int 1997; 7:213-218. 
11. Herd RIM, Balena R, Blake $G M_{z}$ Ryan PJ, Fogelman I. Prevention of early postmenopausal bone loss. Am I Med 1997; 103:92-99.

12. Liberman UA, Weiss SR, Bröll 1, Minne HW, Quan H, Bell NH et al. Eltect of oral alendronate on bone mineral density and the incidence of fractures in postmenopausal osteoporosis. N Engl I Med 1995: 333:1437-1443.

13. Black DM, Cummings SR, Karpf DB, Cauley IA, Thompson DE, Nevitt MC el al. Randomised trial of alendronate on risk of fracture in women with existing vertebral ractures. Lancet 1996; 348:1535-1541.

14. Cummings SR, Black DM. Thompson, Applegate WB, Barrett-Connor E, Musliner TA et al. Effect of alendronate on risk of fracture in women with low bone density but without vertebral fractures: results from the Fracture Intervention Trial. IAMA 1998; 280:24:2077-2082.

15. Hosking D, Clair ED, Chilvers D, Ravn P, Wasnich R, Ross P, McClung $M$, Balske $A$, Thompson D, Daley $M$, Yates $A$. Prevention of bone loss with alendronate in postmenopausal women under 60 years of age. $N$ Engl I Med 1998; 338:485-492.

16. Smeets-Goevaers CG, Leusink GL, Papapoulos SE, Maartens LW, Keyzer II. Weerdenburg IP, Beijers L.M, Zwindermann AH, Knottnerus JA, Pols HA, Pop VI. The prevalence of low mineral bone density in Dutch perimenopausal women: the Eindhoven Perimenopausal Osteoporosis Study. Osteoporosis Int 1998; 8:404 409.

17. Duijm EM, Guit GL, Zaat JOM, Koomen AR, Willebrand D. Sensitivity, specificity and predictive values of breast imaging in the detection of cancer. Br / Cancer 1997; $76: 377-381$.

18. Valkema $R$, Vismans F-JFE, Papapoulos SE, Pauwels EKJ, Bijvoet OLM. Maintained improvement in calcium balance and bone mineral content in patients with osteoporosis treated with the bisphosphonate APD. I Bone Miner Res 1989; 5:183-192.

19. Jensen : Christiansen $C_{x}$ Rotbro P. Cigarette smoking, serum estragens and bone loss during hormone replacement therapy early after menopause. N Engl I Med 1985; 313:973-975.

20. Hillard TC, Stevenson IC. Role of oestrogen in the development of osteoporosis. Calcif Tissue Int 1991: 49:55-59.

21. Rizzoli R, Bonjour I-P. Hormones and bones. Lancel 1997: 349(Suppl 1):20-26.

22. Christiansen C, Lindsay R. oestrogen's, bone loss and preserwation. Osteoporos Int 1990; $1: 7+13$

23. Heany RP. Calcium in the prevention and reatment of osteoporosis. I Intern Med 1992; 231:169-180

24. Le Pen $C_{r}$ Maurel F, Breart $G_{x}$ Lopes P, Plouin PF, Allicar MP, Roux $C$. The long term effectiveness of preventive strategies for osteoporosis in postmenopausal women: a modeling approach. Osteoporos Int 2000; 1:524.532.

25. Kiel DP, Felson DT, Anderson II. Wilson PWF, Moskowitz MA. Hip fracture and the use oestrogen's in postmenopausal women. N Engl I Med 1987; 317:1169-1174.

26. Catuley JA, Seeley DG, Ensrud K, Ettinger B, Black D, Cummings SR. Oestrogen replacement therapy and fractures in older women. study of Osteoporotic Fractures Research Group. Ann Intern Med 1995; 122:9-16.

27. Schneider DL, Barrett-Connor EL, Morton DJ. Timing of postmenopausal oestrogen for optimal bone mineral density: the Rancho Bermardostudy. IAMA 1997;227:543-547. 
28. Felson DT, Zhang $Y$, Hannan MT, Kiel DP. Wilson PWF, Anderson IJ. The effect of postmenopausal oestrogen therapy on bone density in elderly woman. N Engl 1 Med 1993:329:1141-1146.

29. Nyugen TV, Jones G, Sambrook PN, White CP, Kelly PI, Eisman IA. Effect of cestrogen exposure and reproductive factors on bone mineral density and ostoporotic fractures. J Clin Endocrinol Metab 1995; 80:2709-2714.

30. Ettinger $B$, Genant $H K$, Cann CE. Long term oestrogen replacement therapy prevents bone loss and fractures. Ann Intern Med 1985; 102:319-324.

31. Maxim P, Ettinger B, Spitnaly GM, Fracture protection provided by long-term oestrogen therapy. Osteoporos Int 1995; 5:23-29.

32. Meunier PI, Confavreux E, Tupinon I, Hardoin C, Delmas PD, Balena R. Prevention of early postmenopausal bone loss with cyclical etidronate therapy ca double blind placebo-controlled study and 1-year follow uph. I Clin Endocrin Metab 1997; $82: 2784-2791$.

33. Orr-Walker B, Wattie Dy, Evans MC et al. Effect of prolonged bisphosphonate therapy and its discontinuation on bone mineral density in post-menopausal osteoporosis. Clin Endocrinol 1997; 46:87-92.

34. Landman $J O$, Hamdy NAT, Pauwels EKJ, Papapoulos SE. Skeletal metabolism in patients with osteoporosis after discontinuation of long term treatment with oral pamidronate. I Clin End Metab 1995; 80:3465-3468.

35. MoClung $M$, Clemmesen B, Daifotis A, Gilchrist NL. Eisman I, Weinstein RS et al. Alendronate prevents postmenopausal bone loss in women without osteoporosis. Ann Intern Med 1998; 28:253-261.

36. Elders PJM. Perimenopausal bone loss. Thesis University of Amsterdam. VU University Press, 1991. 


\section{Compliance to an oral bisphosphonate therapy in women with early postmenopausal bone loss}

Geraline L. Leusink", Erik De Klerk2, Victor J.M. Pop ${ }^{3}$, Desiree M.F.H. Van der Heijde $^{2}$, Socrates E. Papapoulos ${ }^{5}$, Huib A.P. Pols ${ }^{6}$ and I. Andre Knotnerus ${ }^{4}$

Diagnostic Centre Eindhoven; ${ }^{2}$ Department of Rheumatology, University Hospital Maastricht; ${ }^{3}$ Department of Social and Behavioral Science, University of Tilburg: ${ }^{4}$ Department of Family Medicine, University of Maastricht; 5 Department of Endocrinology and Metabolic Diseases, Leiden University Medical Centre; GDepartment of Internal Medicine, Erasmus University Rotterdam; the Netherlands

Manuscript: Submitted for publication 


\begin{abstract}
In order to achieve optimal beneit from the treatment of postmenopausal bone loss, strict compliance with bisphosphonate ingestion instructions is required. Low absorption $(<2 \%)$ and significant food-drug interaction make it necessary for the drug to be ingested at least 30 minutes before a meal. We examined the compliance of a cohort of early postmenopausal women to oral pamictronate (Aminomux(B), prescribed for the prevention of bone loss. Patient compliance was measured using: MEMS (Medication Event Monitoring System, AARDEX Lttl., Switzerland). This consists of a special, microprocessor-equipped pill-phialcap that records the time and date of opening the cap. The women were instructed to take the pamidronate half an hour before breakfast or dinner. Eighty-six women were followed for a mean duration of 38,268 days (104 patient years).

Overall, compliance was high: $90 \pm 13 \%$ (range, 20-101) of all tablets were ingested. Seventy-eight percent of patients took the capsules within a $25 \%$ time window around the prescribed dosing intervals (uming compliance). There were 133 periods of three or more days without drug intake d drug holidays), with large inter-individual variation. Overall compliance for the time of day was consistent: $33.1 \%$ of the women took the pamidronate capsule in the morning and $58.4 \%$ took it in the evening. However, $50 \%$ of all patients showed a significant variation in the time of ingestion of capsules (standard deviation for time of ingestion $>2$ houry, making it probable that food-drug interaction could have occurred. No relationship between the time of capsule ingestion and changes in lumbar spine bone mineral density (BMO) was observed.

Overall, taking and liming compliance was high. This was surprising because of the asymptomatic nature of low BMD. No difference was found in BMD response between women who took pamidronate in the mornings and those who took it in the evenings.
\end{abstract}

Key Words: compliance, osteoporosis, bisphosphonate, bone mineral density, pamidronate 


\section{Introduction}

Osteoporosis is a common and important cause of mobidity and mortality among postmenopausal women. It arises as a consequence of progressive loss of bone, and results in an increased risk of fractures. Four in about ten white women currently at the age of 50 years will sustain one or more osteoporotic fractures in their remaining lifetime. ${ }^{1-6}$ As the elderly population grows, the worldwide annual incidence of hip fractures is projected to increase from 1.7 million in 1990 to 6.3 million by 2050 , obviously placing great economic strain on health care systems. ${ }^{7}$

There are several strategies to reduce the incidence of tractures in postmenopausal women. Among these, bisphosphonates which can reduce the incidence of osteoporotic fractures by about $50 \%$ are used in the prevention and treatment of osteoporosis. $8-12$ Specific pharmacological properties of bisphosphonates include very low intestinal absorption and significant drug-food interactions, most notably with calcium. ${ }^{13}$ These properties necessitate specific instructions about the timing and conditions of the administration of these drugs. For example, for alendronate, the manufacturer recommends taking the bisphosphonates in the morning 301060 minutes before breakfast with water only. ${ }^{14}$ if such instructions are not carefully followed, it is assumed that the full efficacy of treatment will not be achieved. In addition, such strict instructions may reduce patient compliance over longer periods.

Patient compliance to a prescribed drug regimen can be accurately measured using electronic monitoring of the opening of medication phials. Although an indirect measurement, as there is no proof of drug intake, this method has many advantages over other techniques for measuring compliance and is currently considered the gold standard. 19 The advantages and disadvantages of other methods of measuring compliance have been described in detail elsewhere. 17,18

Surprisingly, data on patient compliance with bisphosphonates are not available. In the present study. we examined the compliance to once daily administration of the aminobisphosphonate pamidronate in asymptomatic early postmenopausal women with low bone mineral density (BMD), selected from a population-based cohort, who participated in a trial of the effects of various interventions for the prevention of bone loss. For this, electronic monitoring instruments capable of recording the time and date of removing tablets from a container were used.

The objectives of the study were, firstly, assessment of the overall compliance rate to treatment and to specific instructions about the timing of drug intake and, secondly, the relationship between compliance to these instructions and changes in $B M D$ after two years. 


\section{Methods}

In a population-based cohort of 8503 women aged from $47-54$ years, 15649 fulfilled the following criteria: menopause for up to three years and BMD of the lumbar spine in the lower tertile of premenopausal women $<0.998 \mathrm{~g} / \mathrm{cm}^{2}$ (DXA Hologic). All patients were given calcium carbonate $1000 \mathrm{mg}$ (Davitamon ${ }^{(B)}$ ), which consists of $400 \mathrm{mg}$ elementary calcium. Of these, 392 women were randomised to the following groups: the first group $(n=129)$ received no additional treatment; the second group ( $n=133$ ) received oestradiol $2 \mathrm{mg}$ continuously combined with dydrogesterone $10 \mathrm{mg}$ in the second half of the cycle (Femoston ${ }^{8}$ ); and the third group $\left(n=130\right.$ ) received oral pamidronate (APD) $100 \mathrm{mg} / \mathrm{day}$, (Aminomux ${ }^{B}$, Gador, Argentina). The duration of treatment was two years. BMD was assessed at baseline, and after one and two years.

In the group receiving pamidronate, compliance was measured using the Medication Event Monitoring System (MEMS, Aardex Ltd., Switzerland). This system consists of a normal pill container with a special cap that contains electronic microcircuitry to record the time and date of every opening. Throughout the analysis, we assumed that with every opening a tablet was actually taken. The data from the monitors were downloaded to an IBM compatible personal computer, using a dedicated modem and CSS software version 2.1 (AARDEX Ltd, Switzerland), which was also used for the calculation of the compliance variables.

Patients were instructed to take the pamidronate capsule 30-60 minutes before breakfast or dinner, with two glasses of water, and not together with food or calcium tablets. All patients had given their written informed consent and were told that the cap was capable of 'counting pills'. We did not use electronic monitoring in the calcium and hormone replacement therapy (HRT) group, because the calcium tablets did not fit into the special boxes and HRT is accompanied by special dose-organizers with instructions to take the dydrogesterone in the second half of the cycle.

In addition to the electronic data in the pamidronate group, we counted the number of returned lablets in all three groups. Monitoring was applied for at least six months after the initiation of treatment, and patients were followed until two years after baseline.

Compliance was calculated as

Taking compliance $=($ total number of doses taken/number of days monitored $) \times$ $100 \%$

Timing compliance $=$ (number of doses taken at $24 \pm 6$ hourly intervals/number of days monitored $\times 100 \%$

The response to treatment was assessed by the changes of the BMD in the lumbar spine, measured by dual energy $X$-ray absorptiometry (DXA, model QDR-1000 S.A. 
Hologic Europe, Brussels). Callibration of densitometers, scan quality control, and scan performance were carried out by one qualified densitometry operator. All daily spine phantom quality controls were within $1.5 \%$ of the reference value. The coeffcient of variation for the anatomical phantom $\left(1.0354 \mathrm{~g} / \mathrm{cm}^{2}\right)$ for the duration of the study was $0.54 \%$. All scans were performed in the supine position. BMD of the lumbar spine was measured at baseline, and at 12 and 24 month of follow-up. Treatment success was defined as an increase in $B A D$, expressed as the percentage change score between BMD at two years and baseline BMD. A positive change rincrease in $B M D$ or no change) was labelled 'responder', while a negative change (decrease in BMD) was labelled 'non-responder'.

Data are expressed as mean \pm standard deviation. Correlation's are estimated using Pearson's correlation coefficient. The relationship between compliance and change in BMD was investigated with the $\chi^{2}$ test and by linear regression analysis, and by when compliance was related to success of treatment. All calculations were performed in SPSS version 7.5 for Windows 95.

\section{Results}

The data from four caps could not be retrieved: two had been lost, and two were not readable. Nine women had almost finished the study by the time the electronic monitors became available and therefore did not participate in this arm of the study. Thirty-one women dropped out of the study for several reasons, for example, adverse events such as epigastric pain and nausea, protocol violation, and motivation problems. Therefore, compliance data were available for 86 women. Table 1 shows the patients' characteristics and demographic data.

A total of 38,268 days (105 patient-years) were monitored in 86 patients (average $450 \pm 93$ days of follow-upl. Taking compliance was high: $90.4 \%$ of all lablets were taken, of which $86.3 \%$ were taken as prescribed (once daily), whereas on $11.7 \%$ of the days, no medication was taken, and on $1.9 \%$ of the days, extra medication was taken. Figure 1 shows a histogram of the distribution of taking compliance. Analysis of timing compliance showed that the majority of the prescribed doses $(77.7 \%)$ were

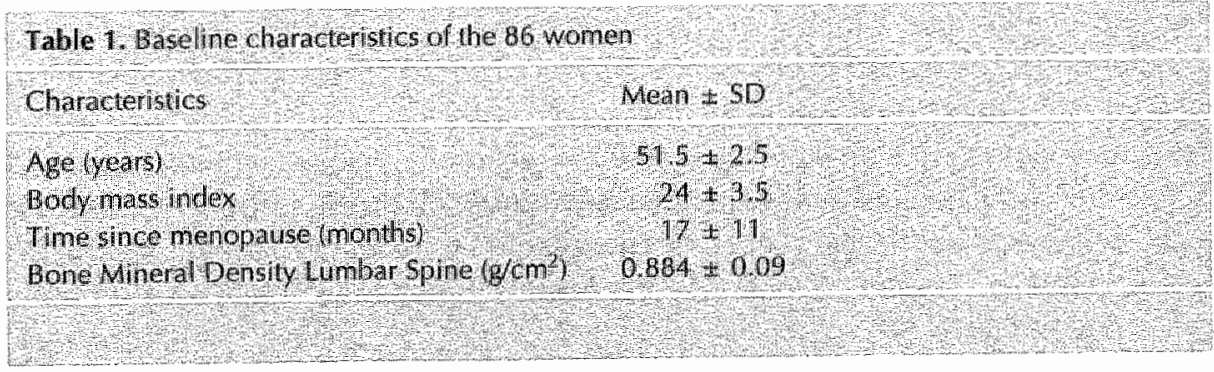




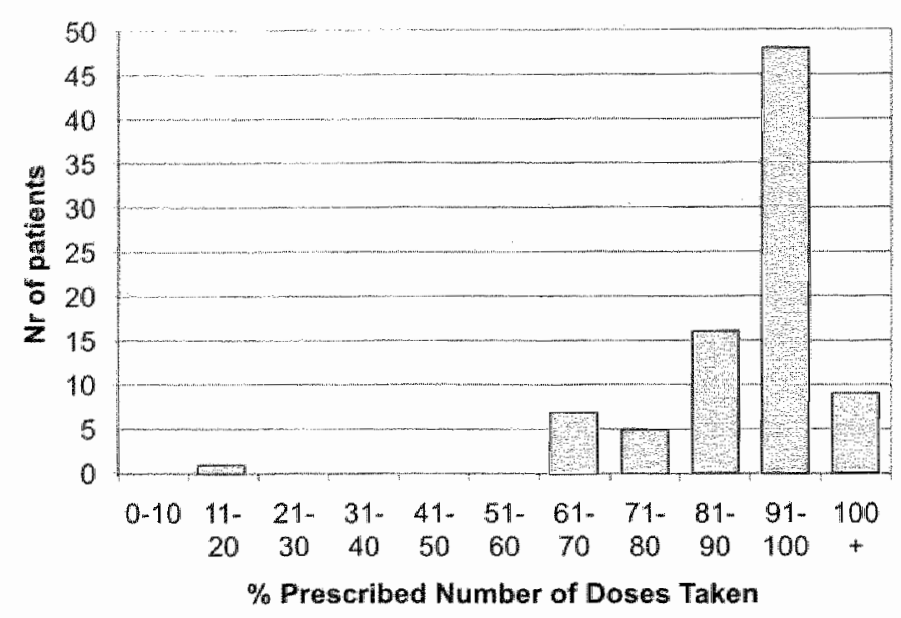

Figure 1. Taking compliance of pamidronate

taken at $24 \pm 6$ hourly intervals. However, $4.4 \%$ were taken too early and $8.2 \%$ too late. Since timing compliance uses the prescribed number of doses as its denominator, which is higher than the number of recorded openings, these do not add up to 100\%

Distribution of the timing of drug intake revealed that $24.8 \%$ of all doses were taken in the morning (arbitrarily defined as between 6.00 and 10.00 a.m., average 7.45 a.m.) whille $55.6 \%$ were taken in the evening (arbitrarily defined as between 15.00 p.m. and 19.00 p.m., average 16.45 p.m.). Figure 2 shows the distribution of the timing of drug intake.

Drug holidays, defined as three or more consecutive days without evidence of dosing, 20,21 were not uncommon: 47 of 86 patients (55\%) had at least one holiday, and overall there were 216 drug holidays $(55 \%$ of all dose-free days), with an average duration of eight days. There were eight exceptionally long drug holidays (>30 days), the longest of which lasted for 89 days.

The correlation coefficient between the returned tablet count and taking compliance was low (0.52.). Figure 3 shows that returned tablet counts led to the overestimation of compliance in the majority of patients.

We specifically studied patients with correct timing of drug intake, defined as $>30$ minutes and $<120$ minutes before breakfast or dinner, in order to test whether there was a relationship between time of drug intake and change in lumbar spine BMD. Forty-nine women had an increase in BMD of the lumbar spine after two years, and 37 women had a decline in their lumbar spine BMD. Of the 49 responders, 24 took their medication within the predefined time window, while 25 did not. Of the 37 non-responders, 24 women took their the medication on time, while $13 \mathrm{did}$ not $\left(x^{2}=2.16, p=0.14\right)$. 


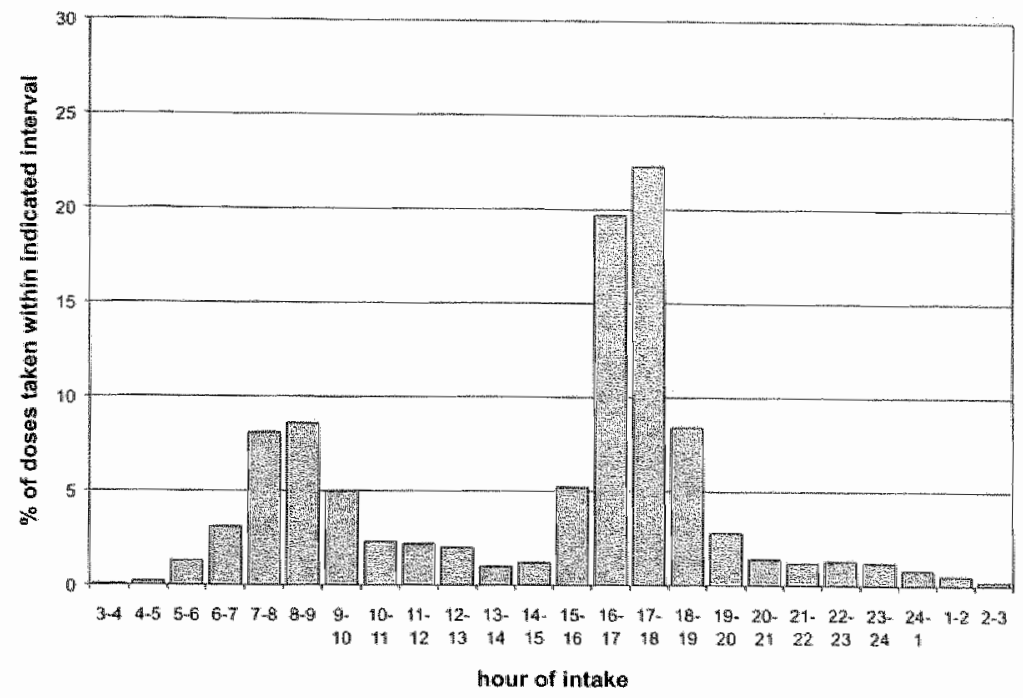

Figure 2. Tirne distribution of drug intake

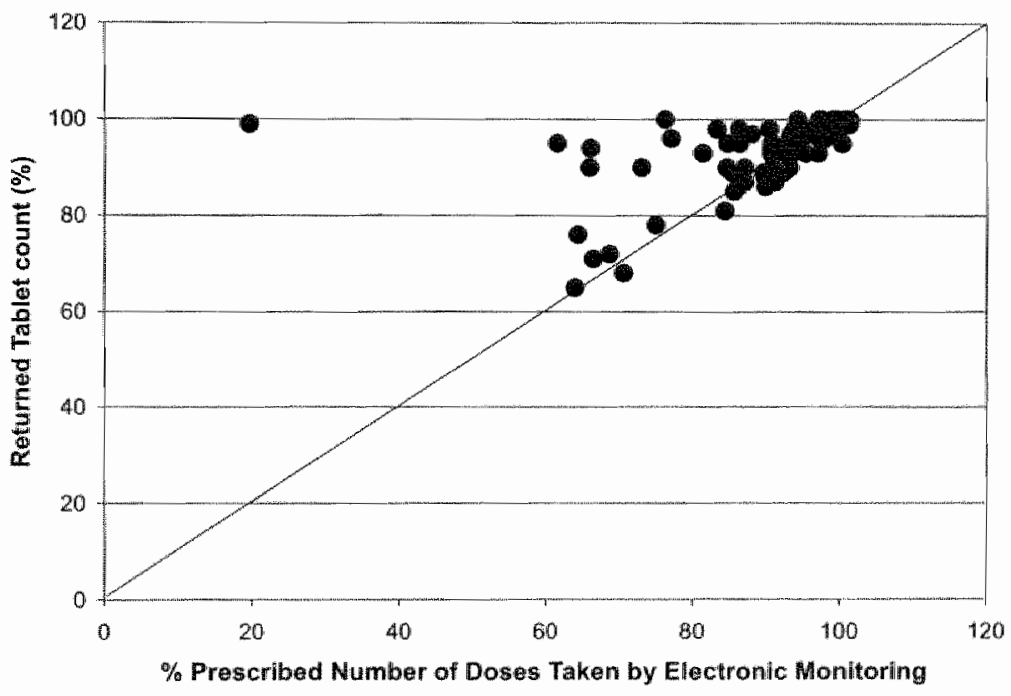

Figure 3. Compliance of Returned Tablet Count wersus Electronic Monitoring 


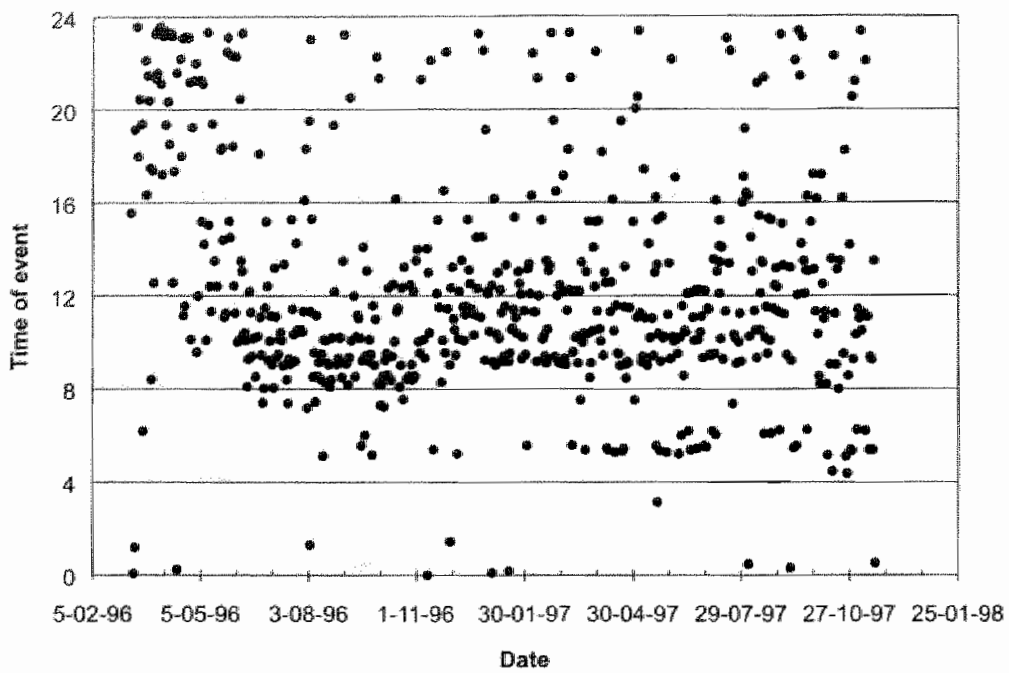

Figure 4a. Chronology plot of a responder

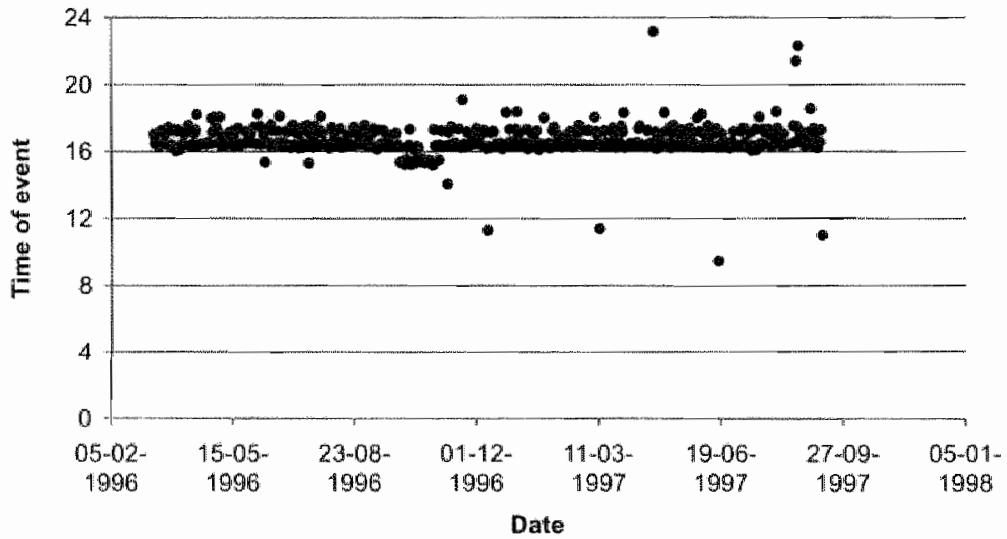

Figure $4 \mathrm{~b}$. Chronology plot of a mon responder 
Linear regression analysis showed a positive but weak association between taking compliance and percentage change in BMD. However, this association was not statistically significant.

\section{Discussion}

In general, no drug can work if it is not taken, and it is reasonable to assume that large deviations from the prescribed dosing regimen result in sub optimal results. A general property of all bisphosphonates is their low absorption (usually $<2 \%$ ) and significant food-drug interactions, ${ }^{13}$ necessitating attention to the timing of their intake. This is the first study in which an electronic instrument has recorded the time and date of the opening of medication phials. This manoeuvre allowed detailed investigation of patient compliance and of the relationship between the intake of pamidronate and the change in BMD of the lumbar spine.

Overall, the taking and timing compliance were high compared to studies with a variety of other drugs, such as antihypertensives, cholesterol lowering and non-steroid anti-inflammatory drugs, antimepileptics, migraine and anti-AIDS drugs. 16,22-27 This was surprising because of the asynptomatic nature of low BMD. Several factors may have contributed to the high compliance in this population. including the selection procedure utilised in the enrolment the relatively high visit frequency, and the fact that patients were aware of the monitoring capacity of the caps.

Study enrolment comprised a three-step selection process. Participating women were selected from the lowest tertile for lumbar BMD of a population-based cohort of 8,000 women (step 1); they were invited by telephone to visit the doctor and were informed of their low BMD (step 2); and finally made a conscious decision, in a consultation with the physician lasting approximately one hour, to participate in the study (step 3). Since each of these steps requires the active co-operation of the patients, it is possible that these steps resulted in a relatively compliant population.

After inclusion in the study, the women were seen by the same physician every three months for two years. This is more frequent than the usual follow-up of patients who are at risk for osteoporosis, and a more frequent follow-up may result in better patient compliance.

Although all patients in the pamidronate group were informed that compliance was measured electronically, this seems an unlikely explanation for the good compliance rate observed, because compliance was also high in the other study groups, based on tablet counting (calcium, $82.1 \%$; HRT, 90.5\%). Furthermore, during the study, no feedback was given on compliance measurements. Finally, the monitoring technique used in this study has been used in many other fields, such as hypertension 16 and epilepsy, ${ }^{24}$ where compliance was much lower, making it unlikely that knowledge of electronic monitoring is commonplace. 
Bisphosphonates such as pamidronate and alendronate are given with instructions regarding the time of ingestion, because of the above-mentioned low gastrointestinal absorption and drug-food interaction. Therefore, we evaluated the relationship beween time of ingestion during the day (morning or evening) and time of meals (breakfast or dinner) to changes in BMD. Given the design of our study, it was possible to evaluate the relationship between the time of bisphosphonate intake and changes in lumbar spine BMD. Surprisingly, there was no difference in BMD response between women who took pamidronate correctly (more than 30 and less. than 120 minutes before breakfast or dinner) and those who took it at other times intervals. In addition, there was no difference in $B M D$ response between the women who took the bisphosphonate in the morning and those who took it in the evening. Of particular practical significance was the much higher preference for taking pamidronate in the evening, which underscores the inconvenience of currently recommended regimens. These results suggest that the instructions regarding medication ingestion, as given for the bisphosphonates, may perhaps be too stringent and need to be further evaluated.

The current study had a high rate of compliance, making it impossible to draw any conclusions on factors regarding non-compliance. Furthermore, the study was population-based and the results cannot be extrapolated to patient populations attending hospitals or those with secondary osteoporosis. Therefore, further reseanch is needed to evaluate the validity of stringent instructions for the ingestion of bisphosphonates, as well as other determinants of compliance efficacy, and to study the relationship with drug exposure more closely.

\section{References}

1. Cummings SR, Black DM, Nevilt MC, el al. Bone mineral density at various for prediction of hip fractures. Lancel 1993; 341:72-75.

2. Murshall $\mathrm{D}$, Johnell $\mathrm{O}$. Wedell $H$. Mela-analysis of how well measures of bone mineral densify predic the occurrence of osteoporotic fractures. BMJ 1996; 312:1254-1259.

3. Melton LJ. Atkinson EI, OFallon WM Wahner HW, Riggs BL. Long-term fracture prediction by bone mineral assessed at different skeletal sites. J Bone Mineral Res 1993; 8:1227-1233.

4. Looker AC, Johnston CCIR, Wahner HW, et al. Prevalence of femoral bone density in older U.S. women from NHANES III. I Bone Mineral Res 1995; 10:796-B02.

5. Melton L..J III. How many women have osteoporosis now? I Bone Mineral Res 1995; 10:175-177.

6. Black DM, Cummings SR, Melton LIIII. Appendicular bone mineral and a women's lifetime risk of hip fracture. I Bone Mineral Res 1992; 7:639-646.

7. Cooper C, Campion C, Melton LIIIL. Hip fractures in the elderly: a world wide projection. Osteoporosis Int 1992;2:285-289. 
8. Reid IR, Wattie Dl, Evans MC, Camble GD, Stapleton IP, Comish J. Continuous therapy with pamidronate a potent bisphosphonate in postmenopausal osteoporosis. I Clin Endocrinol Metab 1994; 79:1595-1599.

9. Herd RIM, Balena R, Blake GM, Ryan PJ, Fogelman I. Prevention of early postmenopausal bone loss. Am I Med 1997; 103.92-99.

10. Liberman UA, Weiss $\$ \mathrm{R}$, Bröll], et al. Effect of oral alendronate on bone mineral density and the incidence of fractures in postmenopausal osteoporosis. N Engl / Med 1995; $333: 1437-1443$.

11. Black $D M_{,}$Cummings SR, Karpf $\mathrm{DB}$, ef al. Randomised trial of alendronate on risk of fracture in women with existing vertebral fractures. Lancet 1996; 348:1535-1541

12. Hosking D, Clair ED, Chilvers D, et al. Prevention of bone loss with alendronate in postmenopausal women under 60 years of age. N Engl I Med 1998; 338:485-492.

13. Bisphosphonates pharmacology and use in the treatment of osteoporosis. In: Osteoporosis Academic Press, Inc 1996.

14. Gertz B1, King WF, Matuszewski BK, Sacco IF, Lasseter KC, Porras AG. Oral bioavailability and dose proportionality of alendronate in postmenpausal women. I Bone Mineral Res 1991; Suppl1, 5281 .

15. Smeets-Goevaers CG, Leusink GL, Papapoulos SE, Maartens IW. Keyzer If, Weerdenburg IP, et al. The prevalence of low mineral bone density in Dutch perimenopausal women: the Eindhoven Perimenopausal Osteoporosis Study. Osteoporosis Int 1998; 8:404-409.

16. Magometschnigg D. Patient compliance of hypertensive patients in the physician's practice. Wien Med Wochenschr 1995; 145:360-364.

17. Bond WS, Hussar DA. Detection methods and strategies for improving medication compliance. Am J Hosp Pharm 1991; 48:1978-1988.

18. De Klerk E. Measurement of patient compliance on drug therapy. In: Vingerhoets A Cedi Advances in Behavioral Medicine Assessment/Advances in Behavioral Medicine Assessment; 1998.

19. Urquhart 1. Patient non-compliance with drug regimens: measurement, clinical correlates, economic impact. Eur Heart I 1996; 17 Suppl A:8-15.

20. Urquhart, Chevalley C. Impact of unrecognized dosing errors on the cost and effectiveness of pharmaceuticals. Drug inf | 1988; 22:363-378.

21. DeKlerk E, Vander Linden S, Vander Heijcle D, UnquhartJ. Facilitatedanalysis of daten on drug regimen compliance. Statist Med 1997; 16:1653-1664.

22. Kruse W, Nikolaus T, Rampmaier, Weber E, Schliert G. Actual versus prescrilbed timing of lovastatin doses assessed by electronic compliance monitoring. Eur / Clin Pharmacol $1993 ; 45: 211-215$.

23. De Klerk E, Van der Linden S1. Compliance monitoring of NSAD drug therapy in ankylosing spondylitis, experiences with an electronic monitoring device. Br I Rheumatol 1996; 35:60-65.

24. Cramer JA, Mattson RH, Prevey ML, Scheyer RD, Ouellette VL. How often is medication taken as prescribed? A novel assessment technique. IAMA 1989;261:3273-3277.

25. Cramer A. Medication compliance in epilepsy. Arch Intern Med 1991; 151:1236-1237.

26. Steiner T], Catarci $T$, Hering R, Whitmarsh T, Couturier EG. If migraine prophylaxis does not work, think about compliance. Cephalalgia 1994; 14:463-464.

27. Vanhove GF, Schapiro IM, Winters MA, Merigan TC, Blaschke TF. Patient compliance and drug failure in protease inhibitor monotherapy. JAMA 1996; 276:1955-1956. 
CHAPTER 8

General discussion 


\title{
Introduction
}

The central theme of this thesis is the question of whether or not an intervention with anti-resorptive drugs (oestrogen or pamidronate) is useful in the prevention of further bone loss in early postmenopausal women with low bone mass. Other questions of major importance are: do women with low bone mineral densify (BMD), and therefore at risk of developing osteoporosis, want to take medication to prevent osteoporosis, and what is the compliance rate regarding the medication taken. The results of the randomised clinical trial and the compliance study, which are presented in full in chapters 6 and 7 , are discussed below. The relevance and implications for population-based screening of BMD in early menopausal women will be outlined. The results of the data obtained in the screening study and the intervention study will be estimated in a population of 100,000 women, in order to show how many women. can be reached regarding the prevention of osteoporosis. Finally, the relevance for future research of the results presented in this thesis will be discussed.

\section{Developments over time}

After the Health Council of the Netherlands (Gezondheidsraad) published the report Prevention of osteoporosis in 1991, ${ }^{1}$ a second report, The prevention of osteoporosis-related fractures, appeared in $1998 .{ }^{2}$ This second report was written due to the rapidly increasing knowledge on osteoporosis, new epidemiological insights, and new ways of treatment. An important difference between the two reports is the approach to the screening of BMD in women around the menopause. In the first report, the committee advised the Minister of Health to study the need for screening, while in the second report, the committee made the following recommendation:

\begin{abstract}
"Osteoporosis-related fractures make osteoporosis an important health problem. In its considerations, the committee has attached prime importance to the effects on the risk of fractures of various ways of prevention. The committee notes that the effect of many interventions on the fracture risk has not been established. This is one of the reasons why the committee rejects a screening study."
\end{abstract}

In this report, osteoporosis is characterised as a public health problem. Apart from promotion of a healthy lifestyle, including exercise, and attention to a healthy diet, it is important to recognise those who are at increased risk for fractures, in other words, case finding is advocated. This advice contradicts the osteoporosis guidelines for general practitioners published by the Dutch College of General Practitioners in 1999, ${ }^{3}$ which rejects case finding on the basis that many risk factors for bone density have not yet been fully clarified. ${ }^{4}$ 


\section{Implications of the findings}

\section{Screening study}

The definition of osteoporosis implies that low bone mass is an important deteminant of the risk of fracture, and that other factors such as falls are also important. The clinical significance of osteoporosis lies in the fractures that occur. BMD measurement by dual-energy X-ray absorptiometry (DXA) provides us with relevant information for clinical management. Many prospective studies have shown that the risk of fractures increases approximately two-to-three-fold for each standard deviation (SD) decrease in BMD. ${ }^{5}$ BMD measurement predicts fractures as well as blood pressure predicts strokes, and significantly better than serum cholesterol predicts myocardial infarction. ${ }^{6}$ By themselves, BMD measurements have a high specificity, but a lower sensitivity. This means that a negative test (the absence of osteoporosis) indicates a very low risk of future fractures. However, moderate sensitivity (approximately $50 \%$ ) means that half af all osteoporotic fractures will occur in a population not defined as having osteoporosis. ${ }^{7}$ For this reason, it has been suggested that this test is more useful in the context of a case finding strategy than for screening at a population level. ${ }^{8}$ Case finding is focused on those subjects with the highest risk of fractures, and BMD measurements are indicated in those subjects. Risk factors that are an ind cation for BMD measurements are listed in Table 1.

Case finding for the prevention of osteoporosis is advised by the Health Council of the Netherlands ${ }^{3}$ and the Clinical Guidelines for the Prevention and Treatment (Royal College of Physicians, UK), ${ }^{7}$ but this is in contrast to the guidelines of the Dutch College of General Practitioners. These guidelines do not advise an active policy for a particular section of the population at possible risk for osteoporosis. The policy is based on a lack of evidence of risk factors which, in the long-term, contribute to low bone mass, and a lack of evidence regarding the medical prevention and treatment of osteoporosis in the long-term. Our population-based study showed that, according to the World Health Organisation (WHO) criteria, 4.1\% of the nearly 6000 women studied in the age group from 46-54 years, had osteoporosis, and $27.3 \%$ osteopenia. An important subgroup $(n=1079$ ) of this population were menopausal women with a mean age of 51 years. The prevalence of osteopenia and osteoporosis was $42.8 \%$ and $12.7 \%$, respectively, and none of these women used hormone replacement therapy (HRT). If we follow the Guidelines of the Dutch College of Ceneral Practitioners in this population, this would imply that a substantial portion of these women would not have their BMD measured, although they already have osteoporosis and are at risk for fractures.

When considering the Guidelines for General Practitioners, it might be possible to agree on whether factors that contribute to the risk of fractures can improve prediction and detection in patients in whom long-term treatment might be useful. 9 
Table 1. Risk tactors tor dentify ing patients th a case finding strateby

- Early menopause

Amenor hoea for mote than a year

Primary bypogonadism

long tern use of conticasteroids, $7.5 \mathrm{mg}$ or nore daly

Maternal ramily hision of hip liacture

Cinical nerease of thoracic kyphosis

- Drior frasility fractiols

BWl lawer than $19 \mathrm{~kg} / \mathrm{m}^{2}$

Anorexia, malabsorption syndrome, primary hyperparathyroidism, hyperthy ridism, renal osteodystrophy, or Cushing's syndrone

- Status a tret organ Lainsplarilation, status after Billinoth il resection

- Inmobilisation for several months.

- Xray with an indication of low bone nass

\section{Intervention study}

The intervention study described in Chapter 6 compared the effect of calcium supplementation ( $1400 \mathrm{mg} / \mathrm{d}$ ) alone, or together with HRT (oestradiol $2 \mathrm{mg} /$ dydrogesterone $10 \mathrm{mg}$ ) or pamidronate $(100 \mathrm{mg} / \mathrm{d}$ ), on early postmenopausal bone loss in women with low bone mass. The conclusion from this study was that women at around menopausal age with low bone mass have a substantial increase in BMD when taking HRT, and have a marginal increase of BMD when taking pamidronate. Women in the calcium group had a significant decrease in the lumbar spine (compared to HRT and pamidronate), but a marginal increase of BMD at the hip. During the third year, all groups showed significant bone loss, although in the HRT group, BMD remained above baseline levels.

\section{Oestrogens}

From other studies we know that if HRT is initiated at the start of the menopause it will prevent bone loss for the duration of therapy. ${ }^{10}$ In contrast, to our study, a significant increase in BMD from the baseline measurement was observed one year after withdrawal of medication. The extent to which the benefit of the BMD gain is sustained atter the cessation of HRT is still a matter of debate. There is some evidence of this in observational studies that show fewer fractures in wonan who have used HRT.11-13 Also, the timing of starting HRT and the optimal duration of substitution are points of discussion and will be influenced by other factors, including other benefits and the risk of side-effects in women using HRT.

From a skeletal perspective, long-term HRT treatment appears to provide the greatest chance of preventing clinical osteoporosis. The possibility that long-term use of HRT 
may increase the risk of breast cancer is a serious concem. There is various epidemiological literature on this topic, which has been reviewed in meta-analyses. 4-18 The overall conclusion of these meta-analyses is that the shont-term use of HRT does not increase the risk of breast cancer, but that long-term use (possibly after five years, but most probably after more than ten years) may be associated with an increased risk. This has been confirmed in a systemic reanalysis of the epidemiological literature, covering 160,000 women world-wide, by the Collaborative Group on Hormonal Factors in Cancer (CGHFC) ${ }^{19}$ In women using HRT for less than five years, no increase in the risk of breast cancer was observed, while the use of HRT for more than five years resulted in an increased risk of breast carcinoma (RR 1.35 ). This risk appears to decrease after termination of HRT, and there was no detectable risk five years after the cessation of treatment.

It should be mentioned that the above clata refer to the incidence of breast cancer; not to mortality. This reanalysis of the CGHFC study ${ }^{19}$ stated that the effect of HRT on mortalify from breast cancer remains unknown. Several other studies 20,21 reported a reduction in the death rate due to breast cancer in HRT users. Two possible mechanisms have been reported:

1. La Croix 22 reported that $81 \%$ of hormone users underwent at least one mammography, while this occurred in only $53 \%$ of non-users.

2. The use of HRT was associated with a reduced rate of axillary lymph node and metastatic spread. 19

The possible association between the use of HRT and the risk of breast cancer hinders its use by some women and doctors. Therefore, more data on incidence and mortality are needed with regard to the type of HRT, dosages, and the definition of subgroups of women most at risk.

The occurrence of three cases of breast cancer in the HRT-treated women in our trial, compared to none in the other two groups, seems worrying. However, the period of exposure to oestrogen's was short, and supported by data from the meta-analysis, it may be a chance finding rather than a drug-related event.

A long-term effect of HRT use could be the prevention of cardiovascular disease, ${ }^{23}$ although the mechanism of overall cardiovascular prevention is not exactly known. Another possible mechanism is that oestrogen's beneficially influence the lipid and lipoprotein profile (increase of high density lipoprotein and decrease of low density lipoprotein). ${ }^{24}$ However, in the Heart Oestrogen Replacement Study (HERS) 25 the first placebo-controlled RCT in this field, the HRT group showed an increase in cardiovascular mortality in the first year, followed by a (non-significant) progressive fall in mortality over the next two to four years. This report may indicate that the use of HRT may have an initial adverse thrombogenic effect, but also in the long-term, a more beneficial effect. Further research is centainly needed to define the role of HRT in the prevention of cardiovascular disease in postmenopausal women. 


\section{Pamidronate}

The most widely used regimen for pamidronate in the treatment of osteoporosis is $150 \mathrm{mg}$ daily. Previous open and control led studies with oral pamidronate $150 \mathrm{mg}$ in patients with established osteoporosis showed significant increases of BMD in the lumbar spine and hip. 27,28 The doses of pamidronate used in the study of Halminn et al. ${ }^{29}$ were $150 \mathrm{mg} /$ day, which was fully effective in the treatment of osteoporosis, and $75 \mathrm{mg} / \mathrm{dlay}$, which caused significant suppression of bone resorption. The 100 mg/day of pamidronate used in our study falls between the doses used in the above-mentioned study, and was used on the assumption that it would be effective in the prevention of osteoporosis compared to 75 or $150 \mathrm{mg}$, which are both effective in the treatment of osteoporosis. The moderate increase during the two years of intervention and the significant decrease after withdrawal of treatment, both suggest that the close of pamidronate (100 mg/day) was not enough to prevent further bone loss in menopausal women who already had a low bone mass.

The increase of BMD in the treatment of osteoporosis with pamidronate is the effect of a reduction in the remodelling space induced by the primary anti-resorptive action of the bisphosphonates. Therefore, inhibition of bone turnover by bisphosphonates is probably responsible for the early increase of BMD. In our study, it is a point of discussion as to whether, due to the low dose, during the one year of treatment, the reduction in remodelling space reached a plateau phase by the filling of this space. Landman et al. 27 described a cohort of 30 patients with established osteoporosis who had been treated with pamidonate (150 $\mathrm{mg} / \mathrm{day})$ for an average of 6.5 years, in which $\mathrm{BMD}$ of the lumbar spine and femoral neck did not change during two years of follow-up. However, more research is needed regarding the optimal dose and the duration of bisphosphonates.

\section{Calcium}

Women in the calcium group had a slight increase in BMD, but only in the cortical bone. After cessation of treatment, the BMD decreased significantly. At the lumbar spine (trabecular bone), a slight but significant decrease was observed during the two years of treatment and atter withdrawal. It may be that the calcium supplement added to the already high calcium intake of Dutch women (1000-1200 $\mathrm{mg} / \mathrm{day})$ provided a total, pharmacological amount of calcium, sufficient to slow down bone loss in the femur, but clearly insufficient to thave the same effect in the spine, where bone turnover is higher. This finding is consistent with other studies that indicate that supplements of calcium salts (generally exceeding $1 \mathrm{~g}$ daily) are capable of slowing down the rate of bone loss in women around the menopause with or without fractures at various skeletal sites. ${ }^{30-32}$ 


\section{Long-term effectiveness of different preventive strategies}

Recently, Pen et al..$^{35}$ described a computer-based stimulation model to compare the long-term effectiveness of different preventative strategies for osteoporotic fractures. These strategies were compared with the no treatment' strategy. The results showed that early intervention (ten years of HRT in 50-year-old women), followed by a five-year course of bisphosphonates starting from the age of 65 years, is the most effective strategy. Strategies applied later, and dealing exclusively with women at risk (i.e. osteopenic and osteoporotic) are the least effective. Combined short-term intervention (i.e., five years of HRT from the age of 50 years) with later intervention in women at risk only, is effective to a certain extent. There are several limitations to this study, for example, the model concentrated on the prevention of fractures and did not consider the other effects of hormone treatment, such as cardiovascular diseases and cancer, especially breast cancer.

The authors stated in their article that modelling is an appropriate way to assess the long-term benefits of various therapeutic or preventive strategies and to incorporate various hypotheses concerning the duration of treatment effect. Furthermore, there are no randomised urials of anti-osteoporotic drugs which are capable of assessing the 20-30-year impact of such treatment. Therefore, is it interesting to see what a computer-based model regarding the prevention of fractures can calculate. Although this model has several limitations, it presents us in a model long-term data on the prevention of fractures.

\section{Compliance}

In all groups, compliance was measured based on pill counts during the follow-up wisits and, in addition, in the group of women receiving pamidronate compliance, using the Medication Event Monitoring System (MEMS, Aardex Ltd., Switzerland). This system consists of a normal pill container with a special cap that contains dectronic microcircuitry for recording the time and date of each time the container is opened. Throughout the analysis, we assumed that one tablet was actually ingested each tume the container was opened. This is the first study in the field of osteoporosis prevention in which an electronic instrument is used that records the time and date of opening of medication bottles. It enabled a detailed investigation of patient compliance and of the relationship between the intake of pamidronate and the change in $B M D$ of the lumbar spine.

Overall, ingestion and timing compliance was high. This was surprising because of the asymptotic nature of low BMD. Bisphosphonates such as pamidronate and alendronate are given with instructions regarding the fime of ingestion, because of the earlier mentioned low gastrointestinal absorption and drug-food interaction (paragraph 1.7). We evaluated the relationship between the time of ingestion during the day (morning or evening and the time to the nexi meal (breakfast or dinner) to 
changes in BMD. Surprisingly, there was no difference in BMD response between women who took pamidronate correclly (more than 30 and less than 120 minutes before breakfast or dinner) and those who took it at other times intervals. In addition, there was no difference in $B M D$ response between the women who took pamidronate in the moming and those who took it in the evening. Of particular practical significance was the much higher preference for taking pamidronate in the evening, which underscores the inconvenience of currently recommended regimens. These results suggest that the instructions regarding the ingestion of bisphosphonates, may perhaps be too strict and need further evaluation.

\section{Acceptance of screening}

In the decision as to whether active screening around the menopause should be promoted , there are general considerations to be taken into account, such as:

- Are women willing to have their bone mass measured?

- How many women diagnosed with low bone mass wish to have information about the prevention of osteoporosis?

- How many women diagnosed with low bone mass will take medication for the prevention of further bone loss and the prevention of fractures?

When screening bone mass for the prevention of osteoporosis, $19 \%$ of our population did not respond to the invitation to participate in our study, and $3 \%$ did not agree to having their BMD measured by DXA. In total, $78 \%$ of women participated in our screening study for the prevention of osteoporosis.

We divided the bone mass into tertiles, and 649 women with their bone mass in the lowest tertile were invited to participate in the intervention study. Fifty-six of these women $(8.6 \%)$ did not want any further information on osteoporosis, even though they had been informed of their low BMD and therefore that they were at risk for developing osteoporosis.

Of the 392 women who were included in the wo-year intervemtion study, $22.4 \%$ (88 women) prematurely stopped taking medication. However, $77,6 \%$ of the women took the medication, with a compliance rate of almost $90 \%$, wanted to continue after the wo years of the intervention study, which suggests a high motivation for treatment.

Although the above numbers have been estimated from a population-based cohort in a specific region, they give augh rostimation of the population at llarge. 
Table 2. Flow chart Bala from the screening and intervention sh wy extra polhted to a population of 100000 wonen. Wh an indication how many women will be readned for the prevention of os leoporosis

Population based screening: Whis flow chart indicates which women liave osteoporosis is $2,5 \mathrm{SB}$ below the enean in a Durch population based cohor and how nany of these women will lake medication lor the prevention of fractures

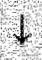

100,000 women in the study population, $19 \%$ of his poplilition did hor respond to the invitation

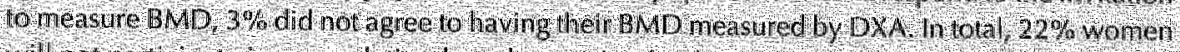
will not participate in a population based screening for the prevention of osteoporosis

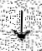

78,000 women will have a measurenent of BVD Of these, 19,000 woner $(243 \%$ ) are dready users of MRT or oral contraceptives (OC) and will be excluded.

\section{9,000 women}

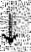

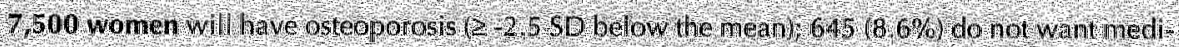

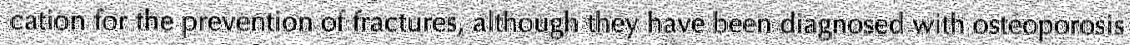

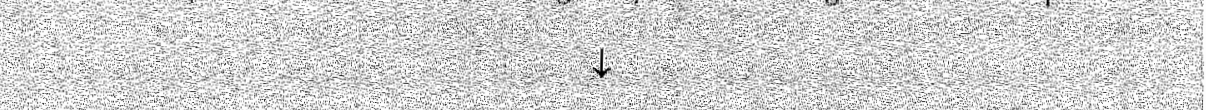

6,855 women will take nedication for the prevention of tractures, $1508.22 \%$ or these willake the medication for less than wo years, hecause of unwanted side eflects

\section{4}

5, 347 women $5.3 \%$ of the orignal 100,000 who are diagnosed will os reoporosis will be nnat vated lo take their medication for longer than two years, neans $430 \%$ of the women diagnosed With osteoporosis 


\section{Methodological reflections and limitations}

There are several methodological issues that should be considered when interpreting the results of the present study, which was designed as a single-centre open-label, controlled, randomised clinical trial. It had to be an open study because blinding was not possible in the oestrogen/progestagen group. In this group, women received oestrogen/progesterone cyclically, and had monthly withdrawal bleedings. In an open study, possible biases can occur because everyone involved in the trial is aware of the treatment each patient is receiving. In this respect, there are three main actors to consider: the patient, the doctor, and the DXA operator. The bias is minimal if the treatments being compared are rather similar to each other and the end points of the study are clear. ${ }^{33}$ In our clinical trial, the treatment evaluation was clear and the BMD measurements were evaluated blindly. Moreover, the women were randomly assigned to one of the treatment groups by computer, and no reallocation to another treatment group was offered, so neither the patient nor investigators could choose a preferred treatment. This procedure optimised the quality of the trial and avoided any selection bias. The relatively low dose of $400 \mathrm{mg}$ calcium was selected to ensure that the women would not, in fact, have calcium deficiency. However, the calcium dose used seems to prevent bone loss at the hip. The hypothesis was that calcium would be much less effective on BMD compared to HRT and pamidronate. HRT and pamidronate had to be more effective in order to demonstrate any significant increase in BMD. A study design including a fourth arm, women not undergoing any treatment, would have offered the possibility of adjusting for a placebo effect. However for such a fourth arm we did not expect enough women willing to be included.

Another limitation was that compliance in those women who remained on treatment during the study was very high, which made it difficult to evaluate the effect of non-compliance.

Finally, the effect of treatment measured as the percentage change of BMD has no clinical impact per se with regard to the long-term fracture rate. However, although no fractures were observed during three years of follow-up based on evidence from other sources, it may be assumed that women with low BMD are at high risk for developing fractures. ${ }^{34}$

\section{Recommendations and conclusions}

\section{Recommendations}

Based on the results of our study, a number of conclusions and recommendations can be made: 
- The prevalence of osteoporosis in the screenings study (total cohort) was 4.1\%, and of osteopenia $27.3 \%$. The prevalence of osteoporosis and osteopenia in a subgroup of this total cohort, postmenopausal women, was $12.7 \%$ and $42.8 \%$, respectively.

- Population-based screening in early postmenopausal women seems to be of limited value. $5,3 \%$ of the women are diagnosed with osteoporosis.

- Case-finding for the prevention of osteoporosis is indicated because $\pm 80 \%$ of the women who are diagnosed with osteoporosis will take medication for the prevention of osteoporosis with a compliance rate of almost $90 \%$.

- The most effective preventive treatment for perimenopausal and early postmenopausal women with low BMD, and therefore potentially at risk for future fractures, is HRT, bearing in mind the contraindications.

- If HRT treatment is to be continued for many years, starting in the early postmenopausal period, the patient could eventually switch to another treatment, e.g.", bisphosphonates.

- With regard to the development of fractures in this cohort, it is important that these women are monitored for a longer period of time, e.g., at least 30 years. This might provide an insight into the risk factors and causes of fractures in this population.

- The compliance study suggests that, perhaps, the instructions regarding the ingestion the time of bisphosphonates are too strict and need to be further evaluated.

\section{Conclusions}

This thes is evaluates three different ways in which the prevention of perimenopausal and early postmenopausal osteoporosis can be managed: treatment with HRT, pamidronate, or calcium alone or in combination with the other treatments. The available evidence does not allow us to choose an optimal treatment plan, which will be adequate for the long-term prevention of osteoporotic fractures. However, based on our results, HRT seems to be the most effective treatment in women around the menopause. Not only does it prevent bone loss, but it also results in a significant gain of BMD. Moreover, calcium supplementation should be considered in women of menopausal age.

\section{References}

1. Health Council: Osteoporosis Committee: Preventie van asteoporose. Health Council of the Netherlands 1991; Publication No. 91/21.

2. Health Council: Osteoporosis Committee. Preventie van an osteoporose gerelateerde fracturen. Rijswijk: Health Council of the Netherlands 1998 ; Publication No. $1998 / 05$. 
3. Elders P, Van Keimpena IC, Petri H, Matser A, Pigmans V, Bolhuis, A, Sips AJBI, Van Berkum H, Boukes 5 , Romeijnders ACM, Wherma T. NHG-Standaxd Osteoporose. Huisarts Wet 1999;42:115-128.

4. Wiersma T. De standard osteoporose van het Nederlandse Huisartsen Genootschap vergeleken met het rapport wan de gezondheidsraad. Ned Tijdsch Geneeskd $1999 ; 1602-1605$

5. Marshall D, Johnell O, Wedel H. Meta-analysis of how well measures of bone mineral density predict the occurrence of osteoporotic fractures. BM/ 1996;312:1254-1259.

6. Cooper $\mathrm{C}_{r}$ Aithie-Sayer A. Osteoporosis: recent advances in pathogenesis and treatment. Quart I Med 1994-87:203-209.

7. The Royal College of Physicians, Osteoporosis, Clinical guidelines for prevention and treatment. Suffolk, UK: The Lavenham Press, 1999.

8. World Heaith Organization. Assessment of fracture risk and its applicauion to screening for postmenopausalosteoporosis. World Health Organ Tech Rep Ser 1994; 843:1-129.

9. Compston JE, Cooper C, Kanis JA. Bone mineral density in clinical practise. Br Med I $1995 ; 310: 1507-1510$.

10. Al-Azzawi F, Hart DM. Oestrogen sensitivity of the post-menopausal skeleton: 15 years follow-up of a placebo controlled trial. 5th Int Congr Menopause, Abstract 21, 1987.

11. Felson DT, Zhang Y, Hannan MT, Kiel DP, Wilson PWF, Anderson II. The effect of postmenopausal oestrogen therapy on bone density in elderly woman. N Engl I Med $1993,329: 1141-1146$.

12. Nyugen TV, Jones $G$, Sambrook PN, White $C P$, Kelly PI, Eisman IA. Effect of oestrogen exposure and reproductive factors on bone mineral density and osteoporotic fractures.) Clin Endocrinol Metab 1995;80:2709-2714.

13. Michaelsson $K$, Baron IA, Farahmand FA, Johnell O, Magnusson C, Persson PG, Persson 1. Ljunghall $S$, the Swedish Hip Fracture Study Croup. Hormone replacement therapy and the risk of hip fracture. BMJ 1998;316:1858-1863.

14. Dupont WD, Page DL. Menopausal oestrogen replacement therapy and breast cancer. Arch Intern Med 1991:151:67-76.

15. Steinberg KK, Thaker SB, Smith SI, Straup DF, et al, A meta analysis of the of oestrogen replacement therapy on the risk of breast cancer. J Am Med Assoc 1991;265:1985-1990.

16. Grady D, Rutain SM, Pettiti DB, Fox CS, et al. Hormone therapy to prevent disease and prolong life in postmenopausal women. Ann Intem Med 1992:117:1016-1037.

17. Sillero Arenas M, Delgado Rodrigues M, Canteras R, Bueno Cavanillas A, Galkey Vargas R. Menopausal hormone replacement therapy and breast cancer: a metamanalysis. Obstet Gynecol 1992;79:286-294.

18. Colditz GA, Egan KA, Stampter MI. Homone replacement therapy and risk of breast cancer: results fromepidemiologicstudies. Am / Obstel Gynecol 1993;168:1473-1480.

19. Beral $V$. Breast cancer and hormone replacement therapy: collaborative reanalysis of data from 51 epidemiological studies of 52,705 women with breast cancer and 108411 without breasin cancer. Lancet 1997;350:1047-1059.

20. Willis DB, Calle EE, Miracle-McMahill HL, Heath CW. Oestrogen replacement therapy and risk of hat breast cancer in a prospective cohort of postmenopausal women in the United States. Cancer Causes Control 1996;7:449-457.

21. Sellers TA, Mink PJ, Cerhan IR, Zheng W, etal. The role of hormone replacement therapy in the risk of breast cancer and total mortality in women with a family history of breast cancer. Ann Intern Med 1997;127:973-980. 
22. LaCroix A, Burke W. Breast cancer and homone replacement therapy. Lancet 1997:350:1042-1043.

23. Stampfer MJ, Colditz GA, Willett WC, Manson JE, et al. Postmenopausal oestrogen therapy and cardiovascular disease ten year follow up from the Nurses' Health Study. N Engl Med 1991,325:756-762.

24. The Postmenopausal Oestrogen/Progestin Interventions (PEP) Trial Investigators. Effects of oestrogen/progestin regimen on heart disease risk factors in postmenopausal women. IAMA 1995:278:199-208.

25. Hulley $S$, Grady D, Bush T, Furberg C, et al, Randomised trial of oestrogen plus progestin for secondary prevention of coronary heart disease in postmenopausal women. Heart and Oestrogen/Progestin Replacement Study (HERS) research group. I Am Med Assoc $1998 ; 280: 605-613$.

26. Lees B, Garland SW, Walton C, Ross D, Whitehead MI, Stevenson JC. Role of oral pamidronate in preventing bone loss in postmenopausal women. Osteoporos Int $1996 ; 6: 480-485$.

27. Landman 10, Hamdy NA, Pauwels EK, Papapoulos SE. Skeletal metabolism in patients with osteoporosis after discontinuation of long-term treatment with oral pamidronate. I Clin Endocrinol Metab 1995;80:3465-3468.

28. Reid IR, Wattie DI, Evans MC, Gamble GD, Stapleton JP, Comish J. Continuous therapy with pamidronate a potent bisphosphonate in postmenopausal osteoporosis. I Clin Endocrinol Metab 1994;79:1595-1599.

29. Halminn et al, Pamidronate is effective in the treatment of osteoporosis, Uppsalla I Med Soc $96: 199 \pi: 205-212$

30. Elders PIM. Perimenopausal bone loss. 1991. Thesis, University of Amsterdam.

31. AloiallF, Vaswani A, Yeh JK, Flaster E, Dilmanian FA. Calcium supplementation with and without homone replacement therapy to prevent postmenopausal bone loss. Ann Intern Med 1994;120:97-103.

32. Kanis \A. Calcium nutrition and its implications for osteoporosis, Part I. II Eur I Clin Nutr 1994:48:757-767.

33. Pocock SJ. Clinical Trials. A Practical Approach. UKK: John Wiley \& Sons Ltd. 1993.

34. Cummings SR, Black DM, Nevitt MC, Browner WS, Cauley IA, Genant HK, Mascloli SR, Scott IC, Seeley DG, Steiger P, Vogt TM. Appendicular bone density and age predict hip fracture in wonen. JAMA 1990;263:665-668.

35. Le Pen C, Maurel F, Breart G, Lopes P, Plouin PF, Allicar MP, Roux C. The long term effectiveness of preventive strategies for osteoporosis in postmenopausal women: A modelling approach. Osteoporos Int 2000;11:524-532. 
CHAPTER 9

\section{Summary}


Osteoporosis has been the subject of intensive research over the past 20 years, and the results are encouraging. Therefore, it is generally accepted that, today, osteoporosis can be diagnosed, and to a large extert prevented and treated.

The objectives of the randomised controlled study presented in this thesis were as follows:

- to determine and compare the efficacy of two treatment regimens compared to calcium for preventing postmenopausal bone loss in women in the lowest tertile assessed by dual $X$-ray absorptiometry $(D X A)$ measurements after screening;

- to assess the rate of change in bone mineral density (BMD) once treatment has been withdrawn and,

- to evaluate the compliance rate in the respective treatment regimens.

Chapter 2 provides a general overwiew of the epidemiology, prevention, and treat. ment of osteoporosis. Moreover, it considers the effect of medications used in the prevention and treatment of osteoporosis, as well as the different measuring instruments used in this thesis, such as DXA and electronic caps for measuring compliance.

Chapter 3 describes the background and rationale of the study on the prevention of low BMD in early postmenopausal women presented in this thesis. The study was conducted in two parts: a screening study and a drug intervention study designed as a randomised clinical trial. All women living in the city of Eindhoven and born between 1941 and 1947 (aged between 46 and 54 years), were invited by the Diagnostic Centre Eindhoven (DCE), a diagnostic centre for general practitioners, and the Department of Municipal Public Health Services, Eindhoven, to participate in the study. All the women were interviewed and BMD of the lumbar spine was measured by dual energy $X$-ray absorptiometry (DXA).

The study population in the intervention study consisted of healthy perimenopausal women who met the selection criteria and who were willing to participate in the study. The intervention study was designed as a randomised clinical trial (RCT). Women who were eligible were randomised to one of the treatment groups, and no reallocation to a different treatment group was offered.

Chapter 4 presents the baseline characteristics of the 5896 women born between 1941 and 1947 (aged between 46 and 54 years) and living in the city of Eindhoven, who participated in the study (the Eindhowen Perimenopausal Osteoporosis Study, EPOS), as well as the relationship between these characteristics and osteopenia and osteoporosis.

Osteopenia and osteoporosis were defined according to the criteria proposed by a World Health Organisation (WHO) working group. The prevalence of osteopenia and osteoporosis was $27.3 \%$ and $4.1 \%$, respectively. With progression from premenopause to menopause, the prevalence of asteoporosis increased from $0.4 \%$ to $12.7 \%$, and that of osteopenia from $14.5 \%$ to $42.8 \%$. Of the women studied, $24 \%$ 
were using oestrogen preparations and $19 \%$ had undergone hysterectomy, with or without oophorectomy.

An increased risk of low BMD losteopenia and osteoporosis) was associated with age, menopausal status, and smoking, while alcohol consumption, high body mass index (BMI), and the use of oestrogen's, had a protective effect.

Previous studies have shown an association between depression and decreased BMD.

Chapter 5 describes the relationship between depressive mood and low BMD in a population-based cohort consisting of 4944 healthy women aged between 46 and 54 years. These women completed a questionnaire aboul their lifestyle habits, such as smoking, alcohol intake, medication intake, and physical activity, and completed a validated depression self-rating scale, the Edinburgh Depression Scale (EDS). BMD of the lumbar spine was measured. One thousand and fourteen (20.5\%) of the women were depressed according to the EDS (cut-of score $>11$ ). The women with depressed mood had a significanty lower BMD compared to the non-depressed women. This study confirmed the relationship between depressed mood and decreased BMD at a univariate level. However, after adjustment for several important determinants of bone mass related to lifestyle habits, depressed mood showed no relationship to decreased $B M D$. These findings suggest that the relationship between depressed mood and low BMD is influenced by lifestyle habits.

Chapter 6 describes the outcome of the two-year intervention study designed as a randomised clinical trial, and the follow-up of 392 perimenopausal women, all of whom were treated with $400 \mathrm{mg}$ calcium. The first group (129 women) received callcium only, while the second group (133 women) also received hormone replacement therapy (HRT) treatment, and the third group (130 women) received pamidronate in addition. After one and two years, the mean increases in lumbar spine BMD were significantly higher in the HRT group $(4.5 \%$ and $5.2 \%$, respectively) and the pamidronate group (1.4\% and $0.5 \%$, respectively) compared to the calcium-only group $(-1.1 \%$ and $-2.3 \%$, respectively). No bone loss was observed at the proximal femur or femoral neck in any of the treatment groups. Moreover, in the group women treated with HRT, there was a highly significant rise in BMD. We can conclude that, in the early postmenopausal period, in women with low bone mass, bone loss can be prevented by HRT and pamidronate. in the HRT-treated group, a consistent increase in $\mathrm{BMD}$ was observed at all measurement sites.

This chapter also describes the change in bone loss during the year following cessawon of treatment. Lumbar and femoral BMD remained increased in the HRT group. while in the pamidronate group, BMD decreased slightly. The highest decrease of spinal BMD was observed after three years in women in the calcium group.

Chapter 7 presents the compliance rate of patients receiving pamidronate during the two years of treatment, as measured by electronic microcircuitry, which monitored the opening and closing of the medication package. This is the first study on the prevention of osteoporosis in which an electronic instrument has recorded the time 
and date of the opening of medication phials. The compliance rate was calculated, and data was available for 86 women. Overall, taking and timing compliance rates were high.

Instructions regarding the time of ingestion were given for pamidronate, because of the low gastrointestinal absorption and drug-food interaction. We evaluated the relationship between the time of bisphosphonate intake and changes in the lumbar spine. There was no difference in BMD response between women who took pamidronate correctly (more than 30 and less than 120 minutes before breakfast or dinner) and those who took it at other time intervals. There was no difference in BMD response between the women who took the bisphosphonates in the morning and those who took it in the evening. These results suggest that the instructions regarding bisphosphonates, may perhaps be too stringent and need to be further evaluated.

Chapter 8, the general discussion, reflects on how this study was designed and carried out. It evaluates the relevance of population-based screening for BMD with DXA in women around the menopause. Furthermore, it describes the revised recommendations on the prevention and treatment of osteoporosis by the Health Council of the Netherlands in 1998. This advice is compared with the first standard on osteoporosis of the Dutch College of General Practioners, published in 1999. Finally, recommendations are made and suggestions given for further research on the prevention and treatment of low BMD in early postmenopausal women. 
CHAPTER 10

Samenvatting 
In de afgelopen 20 jaar is osteoporose veelvuldig het onderwerp van studie geweest. De resultaten wan dit onderzoek zijn hoopgevend. Osteoporose kan tegenwoondig wordev gediagnosticeerd en voor een belangrijk deel worden voorkomen en succesvol worden behandeld.

Het doel van de in dit proefschrift gepresenteerde studie was drieërlei:

1. het bepalen en vergelijken van de effectiviteit van twee behandelingen, hormoonsubstitutie en pamidronaat, afgezet tegen een behandeling met calcium. De medicaties hadden als doel het voorkomen wan post-menopausale botontkalking bij vrouwen met een lage botdichtheid.

2. het bepalen van de compliance (therapietrouw) in de verschillende behandelregimes (hormoonsubstitutie, pamidronat en calcium); en

3. het vaststellen van de mate van verandering in de botdichtheid madat de behandeling is gestopt.

Hoofdstuk 2 geeft een algemeen overzicht van de epidemiologie, de preventie en de behandeling van osteoporose. Er wordt ingegaan op hef effect van medicatie om osteoporose te voorkomen en te behandelen. Eveneens worden de in deze studie gebruikte meetinstrumenten zoals Dual X-ray absorptiometry (DXA) en de elektronische deksells die gebruikt werden bij de compliance meting besproken.

Hoofdstuk 3 beschrijft de achtergrond en de rationale van de studie naar lage botdichtheid bij vrouwen in de overgang zoals gepresenteend in dit proefschrift. De studie bestond uit Iwee delen; een screenings studie en een medicijn interventie studie in de vorm van een gerandomiseerd onderzoek. Alle vrouwen woonachtig in de stad Eindhoven die geboren zijn tussen 1941 en 1947 werden witgenodigd door het Diagnostisch Centrum Eindhoven (DCE) om deel te nemen aan de studie, het DCE is een centrum voor diagnostiek voor patiënten van huisartsen. Alle vrouwen werden geinterviewd en de botdichtheicl van de Jumbale wervelkolom werd gemeten met behulp van een DXA.

Hoofdstuk 4 presenteert de basis gegevens van deze vrouwen (5896) geboren tussen 1941 en 1947 en die woonachtig zijn in Eindhoven.

De prevalentie wan osteopenie en osteoporose in dit cohort was respectievelijk 27.3 en $4.1 \%$. Met de overgang van pre-menopausaal naar menopausaal steeg de prevalentie vam osteoporose van 0.4 nat $12.7 \%$ en die van osteopenie van 14.5 naar $42.8 \%$. Van deze vrouwen slikten $24 \%$ oestrogenen en $19 \%$ onderging een hysterectomie met of zonder ovariectomie.

Fen verhoogd risico voor een lage botdichtheid (osteopenie en osteoporose) werd geassocieerd met leeftijd, menopausale status en roken, terwijl alcoholgebruik een hoge body mass index (BMI) en het gebruik van oestrogenen een beschermend effect hadden.

Hoofdstuk 5 beschrijt de relatie tussen depressie en een lage botdichtheid in ditzelfde cohort van gezonde vrouwen (4944) tussen de 46 en 54 jaar. De vrouwen vulden een vragenlijst naar leefistijl gewoontes zoals roken, alcoholgebruik, medica- 
tiegebruik en fysieke activiteit in. Zij wulden eveneens de gevalideerde depressie zelf - score, Edinburgh Depression Scale (EDS) in. De botdichtheid van de lumbale wervelkolom wan deze vrouwen werd gemeten. Duizend wiertien vrouwen $(20.5 \%)$ waren depressief volgens de EDS score, met een afkappunt van $\geq 12$. De vrouwen met depressie hadden een significant lagere botdichtheid in vergelijking met niet depressieve vrouwen.

Deze studie bevestigt de relatie tussen depressie en een verlaagde botdichtheid op univariaat niveau. Depressie vertoonde echter geen relatie meer met een verlaggde botdichtheid na correctie voor een aantal belangrijke deteminanten gerelateerd aan levensstijl.

Hoofdstuk 6 beschrift de uitkomsten van de twee jaar durende interventie studie en het daaropwolgende vervolgjaar van 392 vrouwen rondom de overgang die allen behandeld werden met $400 \mathrm{mg}$ calcium. Een groep van 133 wrouwen kreeg aanvullend hormoonsuppletie en een groep van 130 vrouwen kreeg aanvul lend pamidronaat. Na een en twee jaar was de gemiddelde toename in botdichtheid van de lumbale wervelkolom hoger in de hormoonsubstitutiegroep, respectievelijk 4.5 en $5.2 \%$, en de pamidronaatgroep, respectievelijk 1.4 en $0.5 \%$, vergeleken met de alleen-calcium groep, respectievelijk -1.1 en $-2.3 \%$. In geen van de groepen werd botverlies gezien van de heup. Er werd in de hormoonsubstitutie groep juist een significante toename te zien van de botdichtheid. We kumnen concluderen dat, vrouwen rondom de overgang met een lage botmassa, botverlies voorkomen kan worden door hormoonsubstitutie of door pamidronaat. Maar in de hormoonsubstitutiegroep was er consistente toename in botdichtheid van alle gemeten punten.

Dit hoofdstuk beschrift ook de verandering in botdichtheid gedurende het vervolgjaar zonder medicatie. De botdichtheid van de lumbale wervelkolom en de heup bleven gedurende dit jaar verhoogd in de hormoonsubstitutiegroep, terwijl in de pamidronaatgroep de botdichtheid daalde. De grootste afname in de botdichtheid van de lumbale wervelkolom werd gezien in de calciumgroep.

Hoofdstuk 7 presenteert de compliancegegevens van de patiënten die pamidronat kregen gedurende de twee studiejaren. De compliance werd gemeten met behulp van een elektronisch microcircuit dat het openen en sluiten van het deksel registreert. Dit is de eerste studie naar de preventie van osteoporose watbij een elektronisch instrument datum en tijd wan openen van de medicatie inmame registreert.

De compliance werd berekend als de inname compliance en compliance met betrekking tot tijd in total 86 vrouwen. Beide vormen van compliance waren hoog"

Pamidronaat werd gegeven met instructies ten aanzien wan de tijd van inname, dit vanwege de lage gastro-intestinale absorptie en de interactie ussen het medicin en voedsel. Daarom onderzochten wij de relatie tussen de tijd van panuidronat-inname en de veranderingen in de lumbale wervelkolom. Er was geen verschil in botdichtheid response tussen vrouwen die pamidronat volgens voorschrift namen, d.w.z. tussen 30 en 120 minuten voor het ontbijt of avondeten, en vrouwen die zich niet aan dit voorschrift hielden. Er was ook geen verschil in botdichtheid response tussen 
vrouwen die pamidronaat 's-ochtends namen in vergelijking met die het 's-avonds namen. Deze resultaten suggereren dat de huidige inname instructie zoals voorgeschreven voor bisfosfonaten misschien te strikt zijn en verdere evaluatie verdienen. Hoofdstuk 8 bediscussieert het studiedesign en de uitwoering van de studie. De relevantie van population-based screening van botdichtheid van vrouwen rond de menopauze met behulp van DXA wordt geëvalueerd. Het beschrijft ook de aanbevelingen van de Nationale Gezondheidsraad in 1998 over de preventie en behandeling van asteoporose. Dit wordt vergeleken met de eerste Huisartsen standaard gepubliceerd in 1999. Tenslotte worden aanbevelingen en suggesties gedaan voor verder onderzoek naar de preventie en behandeling van lage botdichtheid bij vrouwen. 


\section{Publications}

Leusink GL, Smeets-Goevaers CG, Keyzer IJ, Pelt van JH

References values of Carbohydrate-Deficient Transferrin in pre-and postmenopausal women. Alcohol Clin Exp Res 2000 24:172-175

Smeets-Goevaers CG, Leusink CL, Papapoulos SE, Maartens I.W, Keyzer II, Beijers $\mathrm{LM}_{r}$ Zwindermann AH, Knottnerus IA, Pols HA, Pop VI.

The prevalence of low mineral bone density in Dutch perimenopausal women: the Eindhoven Perimenopausal Osteoporosis Study. Osteoporos Int 1998 8:404-409.

Pop V), Maartens LW, Leusink GL, Son van M, Ward AM, Metcalfe R, Weetman AP Are auto immune thyroid dysfunction and depression related? I Clin Endocrinol Metabolism 1998 83: 3194-7.

Maartens LW, Leusink GL, Knottnerus JA, Pop V]. Hormonal substitution what are we treating? Maturitas $200034(2): 113-118$

Van Pelt JH, Leusink GL, Van Nierop P, Keyzer JJ. Test characteristics of carbohydrate-deficient transferrin and $y$-Clutamyltransferase in alcohol-using perimenopausal women. Alcohol Clin Exp Res 2000 24:176-179.

Maartens LW, Leusink GL, Knottnerus IA, Smeets-Goevaers CG, Pop VI. Climacleric complaints in an open community sample. Family Practice 2000 in press.

Leusink CL, Osteoporose. Fysioscoop, maart 1996.

Leusink $G L$, Maartens LW. De behandeling vam postmenopauzale osteoporose.

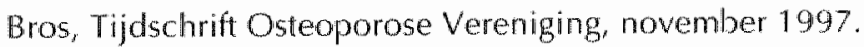

Leusink GL en Pop VIM. De prevalentie van lage botdichtheid bij Nederlandse vrouwen rond de overgang. Nederlands Tijdschrift voor osteoporose en andere botziekten, april 2000 


\section{Published abstracts}

Leusink GL, Hofhuis WJD. Osteoporosis as the presenting sign of acute lymphocytic leukemia. First World Conference on Children Bone Health, Maastricht, Mei 1999

Leusink GL, De Klerk E, Pop VI, Keyzer II, Knottnerus JA, Pols HAP, Papapoulos SE. Patient compliance on bisphosphonates in women with early postmenopausal bone loss. Calcified Tissue, Maastricht Mei 1999

Leusink GL, Maartens IW, Pop VI, Keyzer JI, Knottnerus IA, Pols HA, Papapoulos SE. Antiresorptive therapies for the prevention of early postmenopausal bone loss; a randomised trial of calcium, hrt and pamidronate in women at risk selected from a population based cohort. San Fransisco, 1998

Smeets-Goevaers CG, Leusink CL, Papapoulos SE, Maartens LW, Keyzer II, Knottnerus IA, Pols HA, Pop VI.The prevalence of low mineral bone density in Dutch perimenopausal women: the Eindhoven Perimenopausal Osteoporosis Study. Osteoporos Int Volume 6, Supplement 11996

Pelt van JH, Poelmans EWC, Keyzer JJ, Smeets-Goevaers CG, Leusink GL Cdtect in een populatie onderzoek bij matig drinkende vrouwen. Ned Tijdsch Klin Chem 1997 vol 22, no 3.

Pelt van JH, Velmans MH, Keyzer IJ, Smeets-Goevaers CG, Leusink GL. Referentie waarden van Cdtect bij vrouwen. Ned Tijdsch Klin Chem 1997 vol 22, no 3.

Pelt van JH, Keyzer JI, Smeets-Goevaers CG, Leusink GL. Reference values, sensitivity and specificity of cdtect in perimenopausal women. Alcoholism Clin and Experimental Research 1998, vol 22, no 3. 
Appendix 
Geachte mevrouw,

patiënt nummer:

Wij weter dat u mogelijk een deel van de volgende vragen tijdens ww bezoek al heeft beantwoord. Zou u desondanks zo vriendelijk willen zijn alle vragen in te vullen?

Hierdoor krijgen wij een beter inzicht hoe vrouwen zich rondom de overgang voelem.

Het zal ons erg veel hetpen on de vragen wan vrouwen over hun gezondheid beter te kunnen beantwoorden.

Zoals beloofd in de brief worden de gegevens volledig vertrouwelijk werwerkt, zij vallen onder thet medisch geheim.

\section{A. Overgangsklachten.}

Wij willen u graag enkele wragen stellen over typische overgangsklachten, zoals opvliegers en zweetanvallen.

Een opvlieger is een plotseling abrupt gevoel van hitte, met of zonder zweten.

Fen zweetalanval is je zweterig en warm voden, geen plotseling abrupt gevoel van thitte.

1. Hoeveel nachien bent u afgelopen week zwetend wakker geworden?

O geen éen nacht, ga naar vralag $\mathrm{A} 3 \quad \mathrm{O}$ vier nachten

$O$ eén nach: $\quad O$ vijf nachien

O twee nachten $O$ zes nachten

O drie machten $\quad$ O elke nacht van deze week

2. Werd u de afgelopen week wel eens meerdere keren op één nacht zwetend wakker?

$\mathrm{O}$ nee

O ja .............. nachten per week.

3. Hoveel dagen heeft u overdag opvliegers gehad in we afgelopen week?
O helemaal geen opwliegers gehad
$\mathrm{O}$ vier dagen overdag, ga naar vraag A6
O én dag
$\mathrm{O}$ twee dagen
$O$ vijf dagen
O drie dagen
$\mathrm{O}$ zes diagen
O elke dag van deze week

4. Hoeveel opvliegers had u gemiddeld overdag in de afgelopen week?
O ik theb helemal geen opvliegers
O 5-6 opvliegers per dage gehad overdag, ga nat vragg $A 6$
O 7-8 opvliegers per dag
O soms geen, soms éćn per dag
O 9-10 opvliegers per dag
O $1-2$ opviliegers per dag
O 3-4 opviligers per dag
O meer dan 10 opvliegers per dag

5. Wat was de afgelopen week het hoogste aantal opvliegers op cen dag? opvliegers op eên dag. 
6. Hieronder volgen een atatal voorbeelden wan klachten die kunnen woorkomen rondon de overgang. Wilt u yoor elk van de onderstaande klachten aangeven wh hoverre u hiervan de afgelopen 4 weken last heeft gehad? S.w.p. een cirkel plaatsen rondom het antwoord dat her meeste van toepassing is.

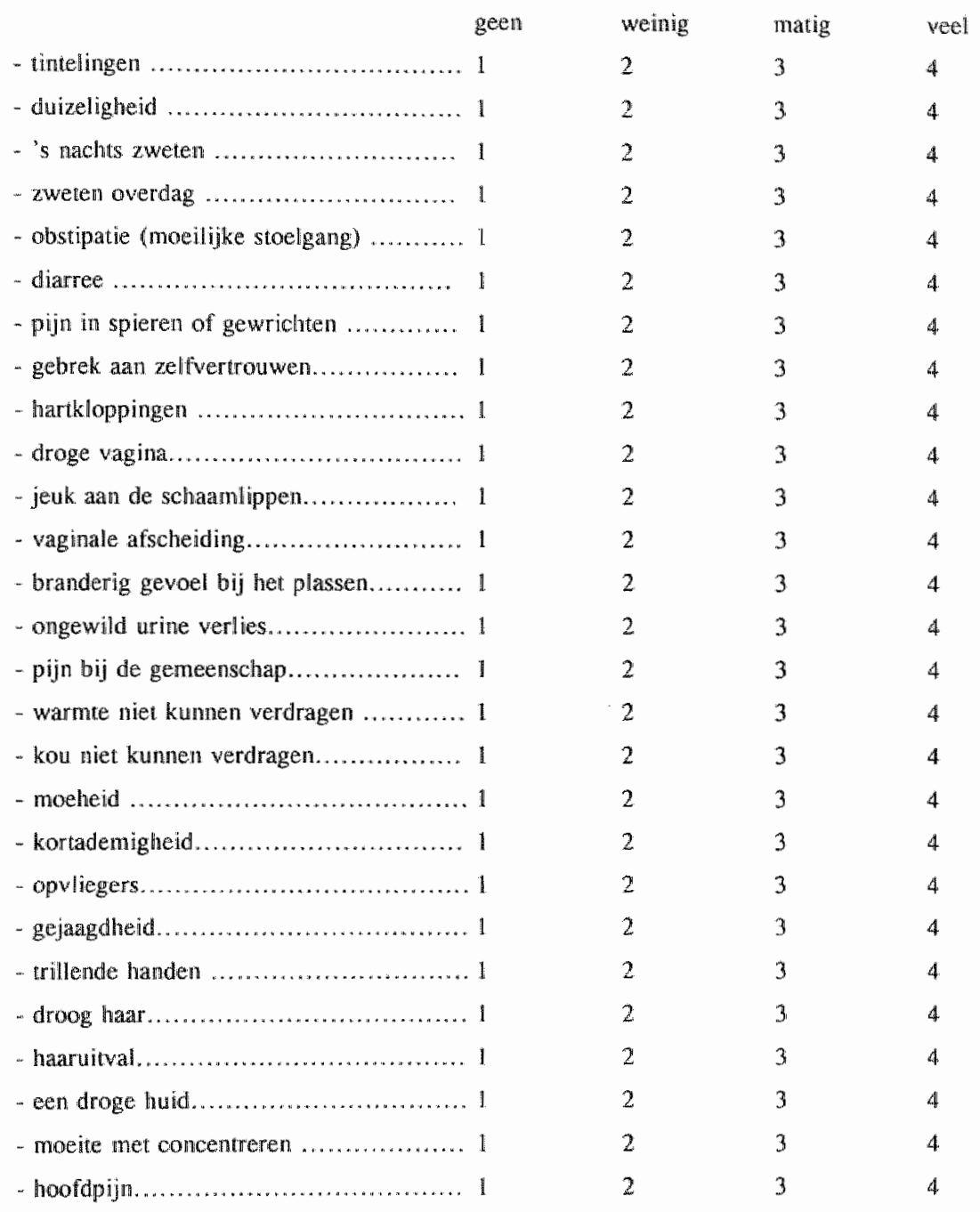


Hieronder volgen nog ten atantul woorbeelden van klachten die kumen woorkomen rondom de owergang. Wilt u voor elk wan de onderstande klachten aangeven, in hoverre u hiervan de afgelopen 4 weken last heeft gehad? S.y.p. een cirkel plaatsen rondom het antwoord dat het meeste van toepassing is.

\begin{tabular}{|c|c|c|c|}
\hline & geen & weinig & matig \\
\hline - moe bij het opstan......................... & 1 & 2 & 3 \\
\hline - prikkelbaarheid........... & 1 & 2 & 3 \\
\hline - vergeetachtigheid ............. & 1 & 2 & 3 \\
\hline - moeite met inslapen........................ & 1 & 2 & 3 \\
\hline - gewichusverlies .................. & 1 & 2 & 3 \\
\hline - het plotseling koud hebben................ & 1 & 2 & 3 \\
\hline - neerslachtigheid. & 1 & 2 & 3 \\
\hline - migraine ..................................... & 1 & 2 & 3 \\
\hline - Iusteloosheid ............................... & 1 & 2 & 3 \\
\hline - 's nachts wakker worden .................. & 1 & 2 & 3 \\
\hline - rusteloos gevoel in de benen & 1 & 2 & 3 \\
\hline - somber..................................... & 1 & 2 & 3 \\
\hline - toxgenomen gewicht...................... & 1 & 2 & 3 \\
\hline - opgeblazen gevoel.......................... & 1 & 2 & 3 \\
\hline - verminderde eetlust .................... & 1 & 2 & 3 \\
\hline - minder zin in vrijen ......................... & 1 & 2 & 3 \\
\hline - rugpijn...................................... & 1 & 2 & 3 \\
\hline - angstig zijn, gespannen .................. & $\mathbb{1}$ & 2 & 3 \\
\hline - panielkaanvallen hebben ................... & 1 & 2 & 3 \\
\hline - minder interesse in dingen hebben ....... & 1 & 2 & 3 \\
\hline - snel bezorgd $2 \mathrm{ijn} . . . \ldots \ldots \ldots \ldots \ldots \ldots \ldots \ldots . . . . .$. & 1 & 2 & 3 \\
\hline - cen toegenomen eetlusi hebben ........... & 1 & 2 & 3 \\
\hline - afgenomen zelfwaardering................. & 1 & 2 & 3 \\
\hline
\end{tabular}




\section{Stemming em Gevoel.}

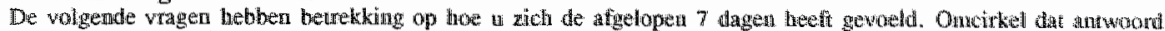
dat her beste aangeeft thoe u zich woelde. Per vragg is slechis I antwoord nuggelijk.

1. In heb kunnen lachen en de leuke kanu van de dingen kunnen inzien:
1. zoweel als ik allitu kon.
2. niet $z o$ veel un als anders
3. zeker nitet $z 0$ vell au als anders
4. helemal nier

2. Ik heb met piezier trar dingen witgekeken:
1. zoals altigu of meer
2. wat minder dan ik gewend was
3. absolunt nuinder dan uk gewend was

4. naumelijks.

3. Ik heb mijzelf onnodig werwijten gemaakt als er iets fout ging:
1 . ja, heel vaak
2. ja, soms
3. niet erg vaak
4. nee, noonit.

4. Ik ben bang of bezorgd geweest zonder dat er een andeiding was:
2. nauwelijks
3. ja, soms

1. nees. helemalal nie

4. jia, zeer vaak

5. In reageende schrikachtig of paniekerig zonder echt goode redea:
1. ja, tomelijk wask
2. $\mathrm{ja}_{*}$ soms
3. nee, niei vaak
4. noot:

6. De dingen groeiden mid bowen het hoofd:
1. ia, meestal was ik er niet tegen opgewassen
2. Ja, soms wass ik minder goed tegen dirgen opgewassen dan anders.
3. mee, meestal kon ik de dingen erg goed aan.

4. ales, ik kon alles even goed an als anders

7. Ik woelde mij zo ongelukkig dat ik er bijna nuet wan kon slapent.
1. ja, meesta
2. ja, soms
3. nivet vaak
4. helemalal niet

8. 【k voelde mij somber en beroerd:
1. ja, bijna steeds
2. fu, tanclijk walk
3. wiet erg wak
4. nee, helenatal niet

9. Ik was zo ongelukkig dat ik heb xilten luvilen:
1. ja, liveel valk
2. ja, thitielijk wak
3. alleen af en toe

4. nee, nowi

10. Ith heb er aan gedacho mijzelf iets atan to doets:
1. ja, tannelijk watak
2. soms
3. nauwelijks
4. nooit 


\section{Bewegen en Sport.}

1. Deofent u momentel een sport?

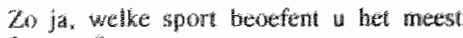
irequent?

In watk julat bent to mef deze sport begotinen?

Howed thu per week?

Howeel mathden per jaar?

Wet of aiet bij een sportvereniging?

Op wetk nivo?

Oja

O nee, ga natar wrage $\mathrm{C} 3$

............... unur per week

maanden per jour

O sportwereniging

O ongeorganiseerd

O recreatief

O competitieverband

O (semititop

2. Mis us een tweede sport beofent, welke sport is dat?

In welk jaar bent u met deze sport begonnem?

Hicerseel unr per week?

Hoeweal manden per jaar?

Wel of niet bij ecen sportwereniging?

Op welk nivo?

3. Heet u vroeger gesport?

Zo ja. welke sport beoefiende $u$ het messt frequent?

In welk jaar bent is met deze sport begonnen?

In welk jaar bent u met deze sport opgehouden?

Hoeweel uur per week?

Hoeweel manden per jaar?

Wel of niet bij cen sportvereniging?

Op welk niwo?

$\ldots \ldots \ldots, \ldots, \ldots \ldots \ldots$. nur per week maanden per jagar

$O$ wel bij een sportwereniging

$\mathrm{O}$ miet bij een sportwereniging

0 recreatief

O competitieverband

$\mathrm{O}$ (semi)top

$\mathrm{O}_{\mathrm{ja}}$

O nee, ga maar wraag $\mathrm{C} 6$.

unr per week maanden per jatar

0 wel bij ten sportvereniging

O niet bij ben sportvereniging

0 recreatief

$\mathrm{O}$ competitieverband

$O$ (semi)top 
4. Als a meer sporten heef beocfend, welke sport was dat?

In welk jaal beat a mat deze sport begonnen?

In welk juar bent th met deze sport opgebouden?

Hoevel tur per week?

Hoeveel maanden per jast?

Wel of niet bij een sportwereniging?

uwir per wrek

matanden per jast

$\mathrm{O}$ wel bij een sporverenigh

O niet bi fi een sportvereniging

Op welk nivo?

O recreatief

O. competitieverband

O) (semilop

5. Als u meer dan twee sponten heef beosfend, welke sport was dat?

In welk jaar bent $u$ met deze sport begonnen?

In welk jaar bent $u$ met deze sport op-

gehouden?

Hoeveel hur per week?

Hoeveel maanden per jaar?

Wel of niet bij een sportvereniging?

uhir per week

matandem per jaar

$O$ well bij cen sportvereniging

O niet bij en spontwereniging

Op wellir nivo

O recreatief

$O$ competitiewerband

$\mathrm{O}$ (semi)top:

6. Hoeveel uren loopt/hep u gemiddeld per week naar hell werk en/of naar de winkel? Ongeveer ......... uren per week voor uw $25^{\circ}$ jadr.

Ongeveer ......... unten per week na uw $25^{\circ}$ jaar.

7. Hoeveel uren van uw wrije tijd besteedt $u$ per week in totaal aan bezigheden zoals, tuinieren, fietsen (niet wielrennen), wandelen, de hond uitlaten, klussen, huis opknappen, schoonmaken en reparaties?

Ongeveer ........... uren per week voor uw $25^{\mathrm{c}}$ jaar.

Ongeweer .......... uren per week na uw $25^{\text {e jaar. }}$ 


\section{Leefgewoonten: Eet-, drink-en rookgewoonte.}

Uit onderzoek is gebleken dat weell mensen min of meer geregeld zes of meer glazen alcoholhoudende drank per dag gebruiken.

1. Op howeel dagen per week gebruikt u gemiddeld genomen alcoholhoudende drank?
O 7 digen per week.
O 3 dagen per week
O 6 dagen per week
$\mathrm{O} 2$ dagen per week
O 5 dagen per week
O 1 dag per week
O 4 dagen per week
O 0 dag per week, ga waar vraag D3

2. Ais u op een dag alcohol drinkt, hoeveel glazen drinkt u dan gemiddeld?

N. Il. halve glazen naar boven afronden.
O 11 glazen of meer
O 3 glazen
O 7 a $10 \mathrm{glaxen}$
$\mathrm{O} 2$ glazen
O 6 glazen
$\mathrm{O} 4$ a. 5 gtazen
O I glas

3. Rrooki u nu sigaretten of een andere vorm van tabalk (aankruisen wat voor u het meest van toepassing is)?

O nee

O sigaretten $\quad$...... sig. per week ga naar vragg D5

O sigaretten $\quad$...... sig. per dag ga naar vrag DS

O shag/zelfgerolde sigaretten ...... sig. per week ga naar vraag D5

O shaglzelfgerolde sigaretten ...... sig. per dag ga naar vratag D5

O sigaren $\quad$...... sig. per week ga naar wraag D5

O sigaren $\quad$...... sig. per dag ga naar wraag D5

4. Heeft u vroeger sigaretten of een andere vorm van tabak gerookt (aankruisen wat voor u het meest van toepassing is)?

O nee, nooit ga naar vraag D8
O sigaretten
O sigaretten
sig. per week ga naar vraag D5
O shag/zelfgerolde sigaretten
sig. per dag ga naar vraag D5
O shaghelfgerolde sigaretten
$O$ sigaren
sig. per week ga naar wraag D5
O sigaren
...... sig. per dag ga naar vraag D5
...... sig. per week ga naar vraag D5
...... sig. per dag ga naar vraag D5

5. Op welke leeftijd bent u begonnen met roken?

Ik was toen ..... jaar

6. Heeft u oot bewust geprobeerd te stoppen met roken?

$\mathrm{O} \mathrm{ja}$

O nee, ga naar vraag D8

7. Bent u dasma weer gaan roken?
O ja
Onee 
8. Rooki den wan uw husgenoten?

O ja

O nee

Welke aanduiding beschrijft het beste hoevel melkproduktten gebrulkt heeft bij de verdere vermoemde periodes (denk hierbuj ook aam 0.4. pap en vla):

9. Hoeveel melkprodukten gebruikte u voor uw $25^{\circ}$ jaar?

O 3 of meer glazen per dag (haasi bij elke maaltijd)

O $1-2$ glazen per dag (hatast elke dag doch niet bij elke maralijd)

O elke week maar niet elke dag

$O$ minder dan é̃ keer per week

geen:

10. Hoeveal melkprodukten gebruikte u na uw $25^{\mathrm{e}}$ jaar?

O 3 of meer glazen per dag (haast bij elke maaltijd)

O 1.2 glazen per dag (hast elke dag doch niet bij elke malltijd)

$\mathrm{O}$ elke week maar niet elke dag

O minder dan tén keer per week

O geen

11. Komen er bij u in uw familie (vader, moeder, broer, zus) veel botbreuken voor (denk bijwoorbeeld ook aan breuken van heupen en wervels)?

O nee

O jai, bij

\section{Medicijngebruik.}

Medicijnen tijdens ziekenhuisopmame hoeft a niet mee te mekenen. Onder medicijnen verstaan we alle middlelen die u voor een aandoening gebruilk. Dit zijn bijvoorbeeld ook poeders, zalf, druppeltjes en injecties. Wilt a ook de poill vermelden indien a deze gebruikt?

1. Heefi u de laarste 14 dagen medicjinen gebrulkt die zonder recept waren gekocht?

O nee, ga naar vraag $\mathrm{E3}$

$0 \mathrm{ja}$ 
2. Wal zijn de namen valt die medicijnen? Wilt u de naam zo nauwkeurig mogelijk noteren? Eventueel kunt u de verpakking radplegen.

3. Heeft u de afgelopen 14 dagen medicijnen op recept gebruikt?

O mee, ga naar wraag F1.

O ja

4. Wilt u deze medicijnen hieronder aankruisen?

O Pijn-en koorstswerende middellen

O Medicijnen tegen hoest, verkoudheid, griep en keelpijn

O Middelen tegen bloedarmoede, zoals ijzertabletten

O Versterkende middelen zoals vitaminen, mineralen en tonicum

O Medicijnen voor thet hart of de bloedvaten

O Medicijnen woor de bloeddruk

O Medicijnen voor een te hoog cholesterol

$O$ bloedverdunnende middelen

O plaspillen

O laxeermiddelen (voor de stoelgang)

O medicijnen woor maag- en darruklachten

O slaap-en kalineeringsmiddelen, middelen tegen de zenuwen

O antibiotica, zoals penicilline en sulfapreparaten

O medicijnen woor de huid (bv jeugdpuistjes, eczeem, jeuk, roos, wonden)

O medicijnen woor reuma, gewrichtspijn enz.

$O$ medicijnen tegen allergie

$\mathrm{O}$ medicijnen tegen astma

O hormonen

O medicijnen tegen suikerziekte

O medicijnen woor de ogen (zalf, druppeis)

$O$ de pil, namelijk

$\mathrm{O}$ andere medicijnen "namelijk 


\section{F. Opleiding en Beroep.}

1. We zijn geintenesseerd in de hoogste opleiding die u met een diploma hoefi afgeslofen. Kunt u aangeven in wetke categor ie deze opleifing thuishoort? (én antwoord aankruisen)

O Lager onderwigs (basisonderwijs).

O Lager beroepsonderwijs (LTS, LHNO, LEAO, huishoudschool, lagere land-en tuimbouwonderwijs enz.)

O Middelbaar algemeen onderwijs (LAVO, ULO, MULO, MAVO, 3-jaar HBS enz, )

O Middelbaar beroeps onderwijs (MTS, MEAO, praktijkdiploma boekhouden, kleuterkweekschool enz.)

O Voortgezet algemeen onderwijs (HBS, MMS, gymnasium, HAVO, VWO enz.)

O Hoger beroepsonderwijs (HTS, HEAO, HHNO, sociale academie, lerarenopl. enz.)

O Wetenschappelijk onderwijs (doctoraal/ ingenieursexamen enz.)

O Anders, namelijk

2. Volgt u op dit moment een dag-(ot avond-jopleiding? Zo ja, welke?

O nee

O ja, namelijk

3. Welke omschrijwing is op dit moment op u het meest van toepassing?

$O$ ik heb een betaalde werkkring

$\mathrm{O}$ ik ben werkeloos (geregistreerd bij het GAB)

$\mathrm{O}$ ik ben arbeidsongeschikt (WAO, AWW, enz.)

$\mathrm{O}$ ik ben remtenier

$\mathrm{O}$ ik ben gepensioneerd/ vervroegd met pensioen (AOW, VUT, enz.)

$\mathrm{O}$ ik ben huisvrouw

4. Wat is uw beroep of functie? of, als u geen betalde baan heeft, wat was dan uw laatitis beroep of functie? N.B. wilt ul tw beroep zo matweurig nogeltik omschrijyen? Bijwoorbeeld: directie-secretaresse, metaallasser, hoofd boekhouding ten niet: amblenaar, manager, arbeider enz.) 


\section{Tot Slot.}

1. Als er har aenleidung van deze wagenlijst nog onduidelijkheden zijn, mogen wij dan met conact opmenten voor naxtere informaite?

Onese

O ja, mijn telefoonimmmer is

2. Hoe lang heeft u erower gedaan om de vragenligs in te vullen en heef u deze vragenijgit alleen ingevuld?

O ja ik heb de vragenlijst alleeti ingevuld.

$O$ nee ik heb deze vragenlijist met mijn partner ingevuld.

O nee ik heb deze wagenlijst met een derde (bijwoorbeeld met een tolk) ingevuld.

3. Wat is de reden geweest wan uw anmelding voor dit onderzoek?

4. Hoe wond u het om deze wragen in te vullen.

Wilt $u$ als u klaar bemt controleren of u alles heeft ingewuld.

WIJ WILLEN U HEEL HARTELUK BEDANKEN WOOR DE TUD EN DE MOETTE DIE U HEEFT GENOMEN OM DE VRAGEN TE BEANTWOORDEN.

Mocht u nog op- of aanmerkingen hebben, dan zouden wij het zeer op prijs stellen als u dat zou willen opschrijven.

Met vriendelijke groeten,

Diagmostisch Centrum Eindhoven. 
Patient Identificatie

patiènt nummer
Soreeningsdatum

datum (dd/mm/in)

\section{A. Patiënten identificatie/administratie}

1. Wat is uw gebooried ahum?

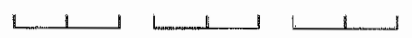

2. Wat is uw postcode en huisnummer?

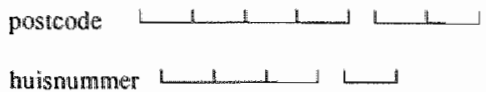

3. Wat is uk telefoonnummer waarop u overdag bereikbaar bent?

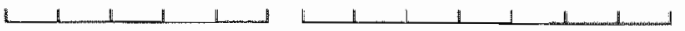

4. Wie is uw huisarts en in welke plaats heeft uw huisarts zijn praktijk?

5. Bent u momenteel onder controle bij uw huisarts of bij cen specialist?

Onee

$\mathrm{O}$ ja, voor

6. Denkt u er over bimnenkort te verthuizen?

O nee, ga naar vraag 8

O ja

7. Indien uw nieuswe adres al bekend is wilt u dit dan hieronder opschrijven. Indien dit nog riet bekend is wilt u ons dan een adreswijziging toesturen?

naam:

adres:

woonplaats

telefoonnummer

\section{B. Menstruatie anamnese}

8. Heeft u onit de (prik)pil gebruikt?

O nee, ga fiar vriagill.

O ja, gebruik ik nog steeds, ga nar vuag 10 .

$O$ ja, matr grebraik ik al $>3$ jaar niet mear.

$\mathrm{O}$ ja, matr gebruik ik al $<3$ maanden niet meer.

$\mathrm{O}$ ja, matr gebrujk ik al 3 maanden to 3 jaar niet meer. 
9. Wanter bent u gescopt met de pil (maand + jaar)? 19 matud

10. Dexe wrage allind siellen! Magrom gebruht(e) a de pill (nog) en hoe lang gebruikt(e) u de pill al?

11. Heeft il ooit oestrogetenpleister/andere wouwelige hormoonpreparaten (overgangspil) gebruikt? O nee

O ja. getbruik ik nog steeds, ga naar waag 13 .

O ja, mar gebruik ik al > 3 jak niet meer, ga nar vragg 12 .

0 ja, mar gebruik ik al $<3$ manden nict meer, ga natar vaag 12 .

O ja, maar gebruik ik al 3 magnden tot 3 jaar niet meer, ga naar wrag 12 .

$\mathrm{O}$ weet ik nie*

12. Wanneer but a gestopt met het gebruk wan cestrogeenpleisters of andere vrouwelijke hormoonpreparaten (overgangpil) (maand to jaar)?

$19, \ldots \ldots, \ldots \ldots$ mo mand $\ldots \ldots \ldots \ldots \ldots . . . .$.

13. Waarom, gebruikt(e) a deze ostrogeenpleisters/ andere wrouwelijke hormoonpreparaten (overgangspil) en howe lang?

14. Hoe owd was u toen u voor het eerst menstrueerde? jatair

15. Menstruevert u nog?

O nee

$\mathrm{O}$ ja

16. Hoe vaak bent $u$ de laatste 12 matanden ongesteld geweest?
$\mathrm{O}$ niet
$\mathrm{O}$ vier keer
O dên keer
$O$ vilf keer
$O$ twee keer
$\mathrm{O}$ zes keer of meer
$\mathrm{O}$ drie keer

17. Deze vragagaltijd stellen !I!

Hoe lang is het geleden dat u uw latste natumijike menstruatie had? (niet metellen als de menstruate wed veroorzakt doo het innemen wan wrouwelijke hormoonpreparaten , overgangs. pil, stritionceptiepili). Graag matand en jagr inwullen.

mantad:

19

$0<1$ mand geleden

O 1 to 3 matuden geleten

O 3 tot 6 maknden geleden

O 6 manaten tot 4 jatar geleden

$0>1$ far geleden

$0>2$ jaar geleden, ga naar wrag 23

$\mathrm{O}>3$ jaar geleden, ga narr vraag 23 
Indien men mu die pil, oestrogeenpleisters of de owergangspil gebruikt, doorgan naar ycaha 21.

18. Is de regelmat van uw menstruatie de labste jaren verandend (matud + juar)? Onee

O jat sinds 19

$\mathrm{O}$ is altijd al onregelmatig geweest

19. Om de hoveel dagen word u ongesteld? dagen

20. Hoeveel dagen verliest bloed thidens de menstruatine? dagen

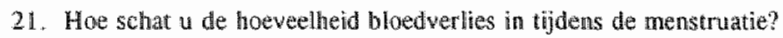

$\mathrm{O}$ weinig

O normal

$O$ weel

22. Is uw thoeweelheid bloedverlies tijdens de laatste 12 matanden werandend?

Onee

$\mathrm{O} \mathrm{ja}$, minder geworden

O ja, meer geworden

O ja, afwisselend

23. Is uw barmoter verwijderd, 20 ja, wanneer is dit gebeurd (mand wa jar)?

Onee

$\mathrm{O} \mathrm{ja}$ 19

24. Is en ooit een eierstok bij u verwijderd?

O nee, ga natar vraag 27.

$O$ jal, eên

O ja, beide

$\mathrm{O}$ weet ik niet:

25. Warneer is uw elerstok verwijderd (maand en jaar invulen)?

De eerst:

..............., 19

De nweede: 19

26. Menstrueerde u nog steeds na deze operatie?

$\mathrm{O}$ nee

O jia

$\mathrm{O}$ weet ik miet

27. Hoewel eigen kinderen theeft u in totallit? ...... kinderen. 


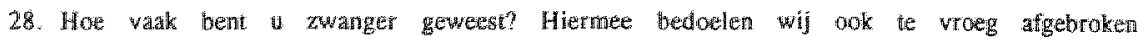
zwaingerschappen.

....... zuargerschappen. Indien u noont zwanger bent geweest door nat wrad 32.

29. In welk jar werd uw eerste en latate kind geboren?
19.... geboonte werste kind
19 .... gelboorte latatste hind

30. Heeft u uw kinderen borstroeding gegeven?

O new, ga nar vraag 32

O ja, gemiddeld

31. Hoeveel kinderen gaf $u$ borstwoeding?

............... kinderen

32. Heft uw arts o oois wel eens verteld dat u een afwijking an de schildklier heeft (gehad) en bent $u$ hiervoot nog steeds in behandeling?

O nex

O ja, te snel werkend

$O \mathrm{ja}$, te tragg werkend

O vergrote schildklier

O weer ik niet

33. Komen er in uw familie schildklierziekten voor?

Onee

O ja, bij uw

O weet ik nitil:

34. Heeft uw arts u coit wel eens werteld dat u een kwadardige aandoening heeft (gehad), 20 ja* wat?

O nee

O ja, namelijk

O weet ik niet 


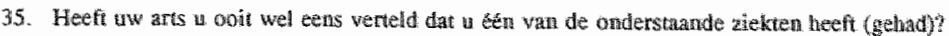

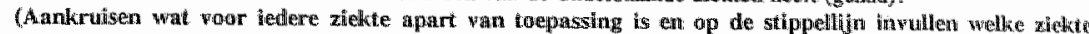
men heeft gehad. Indien men cen wan onderstaande ziekten heoft (gelwad) wragen of men thiervoor nog steeris in behandeling is).

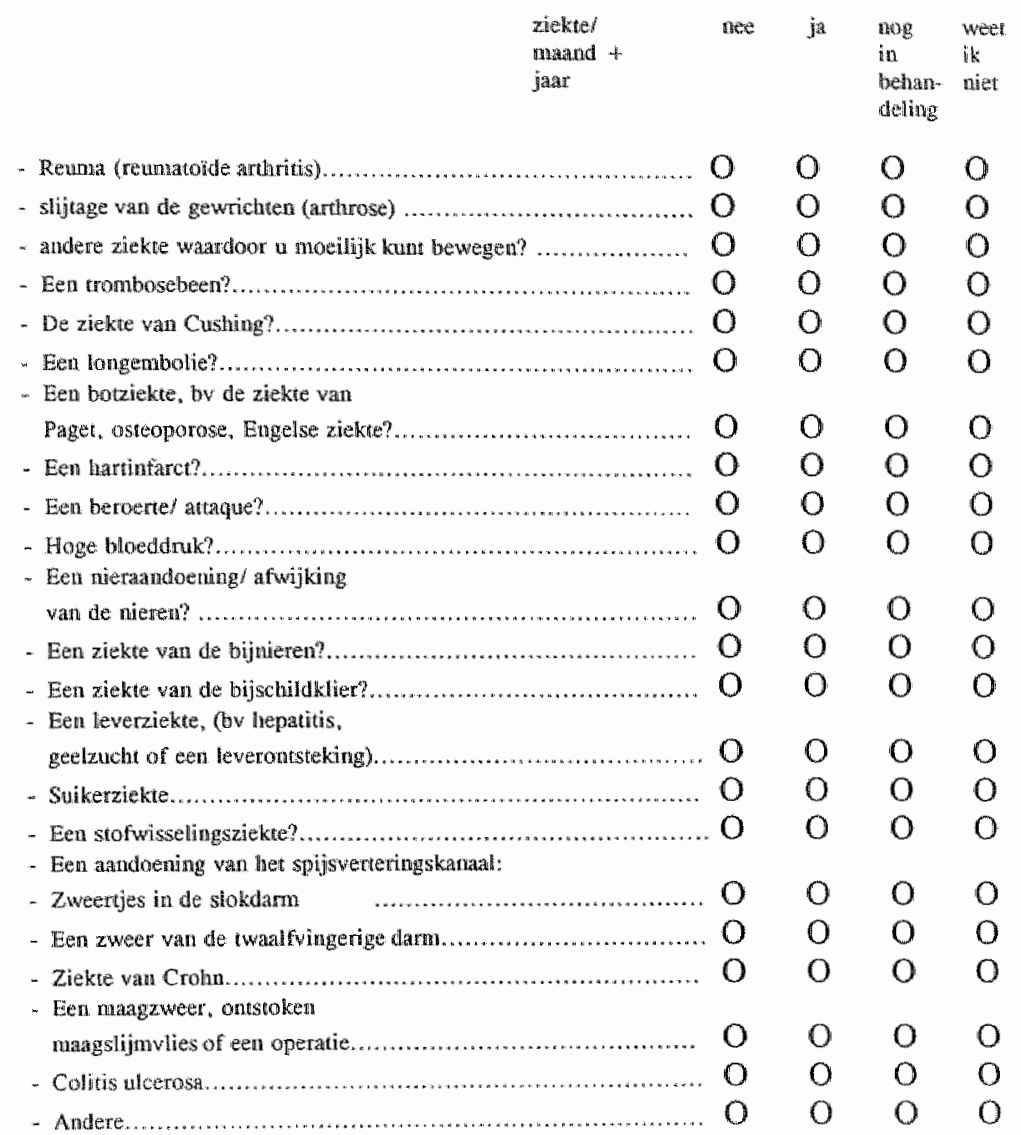

36. Bent u onit langer dan 1 matand bedlegerig geweest?

Ondere

$\mathrm{Oja}$

$\mathrm{O}$ weet ik niet 
We volgende tragen gas ower drinkgewoonten.

37. Drinkt us wel eens alcohol?

O nee nowt, ga naar vraga 40

O ja, elke dag

0 ja, 5-6 dagen per week

O ja, 34 dagen per week

O ja, 1.2 dagen per wiek

0 ja, minder dan exn mal per week

38. Als u dan drinkt howeel glazen alcohol drinkt u dan gemiddeld per dag? glazen per dag,

De volgende vragen gatan over medicljngebrutik.

39. Heeft $\mathrm{w}$ her latste jaar geneesniddelen tegen botontkalking (osteoporose) gebruikt? $\mathrm{Zo}$ ja, wellke?

Onee

O ja,

$\mathrm{O}$ weet ik niet

40. Heef u het laats jaat én wan de wolgende geneesmiddellen gebruiki?

- Pluoride (tableties)

mee ja weet $i k$

(bv. SAN $(0,56 \mathrm{mg}$ NaF, $0,25 \mathrm{mg}$ per tabletge,

Zymafluor $00,56 \mathrm{mg} \mathrm{NaF}, 0,25 \mathrm{mg}$ per tabletje)

- calcitonines.

- hormoner.

$\begin{array}{lll}\mathrm{O} & \mathrm{O} & \mathrm{O}\end{array}$

anabole sterouden

$\begin{array}{lll}\mathrm{O} & \mathrm{O} & \mathrm{O}\end{array}$

- bijnierhormonen (glucocorticoüden)

$\begin{array}{lll}\mathrm{O} & \mathrm{O} & \mathrm{O}\end{array}$

(hv. prednison, dexametason)

O O O

Heeft a oolt bisfosfonaten gebruikt (bv Didrokit, APD)

O $\mathrm{O} O$

41. Indien w medicijnen gebnuikt welke medicijnen zijo dit?

42. Vindi u het goed als ww huisarts de uitslag van de botmeting krijgi?

$O$ nee

O ja 


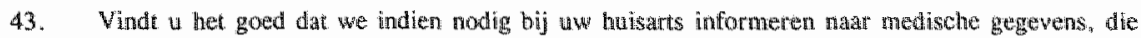
mogelijk beirekking hebben op dif onderzoek?

nere

$\mathrm{O}$ ja

44. Als blikkt dat er sprake is van enige afwijkingen of klachen mogen we u dan beraderen on aan sen vervolgonderzoek moe de doen.

Onee

$\mathrm{O}$ ja

45. Mogen wij u, ook ais er nu geen afwijkingen gevorden zijn, in de doekomst nogmals uimodigen woor een vervolg onderzoek?

Onge

$\mathrm{Oja}$

46. Als er naar anuleiding van deze vragenlijst nog onduidelijkheden zijn " nnogen wij dan met u contact opnemen woor nadere informatie?

O niee

O ja, dit kan het beste onder telefoonnummer:

\section{Medisch onderzoek}

1. bloeddruk sys.

2. bloeddruk dia.

3. pols

4. gewicht

5. lengte

6. Quetelet-index (gewicht//engte

7. spanwijdte van de armen

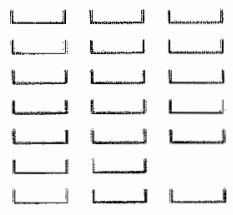





\section{Dankwoord}

Dit proefschrift is het verslag van een onderzoek dat alleen mogelijk werd gemaakt door de professionele, waardevolle en plezierige samenwerking met vele mensen. Graag wil ik, gekomen aan de eindstreep een aantal mensen speciaal bedanken.

Allereerst gaat mijn dank uit naar all de vrouwen die mee deden aan mijn onderzoek. Zonder jullie deelname was dit onderzoek niet mogelijk geweest.

Het werk is gefinancierd door het voormalige Praeventiefonds (huidige ZON, Zorg Onderzoek Nederland); hiervoor mijn dank.

Uiteraard ben ik veel dank verschuldigd aan het management team bestaande uit mijn beide promotoren Prof.dr. J.A. Knottnerus en Prof.dr. V.J.M. Pop, Dr. J.J. Keyzer, directeur van het Diagnostisch Centrum Eindhoven, Prof,dr. H.A.P.Pols (Erasmus Universiteit Rotterdam) en Prof.dr. S. Papapoulos (Leids Universitair Medisch Centrum).

Beste André, jouw wil ik bedanken voor de continue steun die je aan dit onderzoek hebt verleend. Je was steeds bereid om te helpen naar oplossingen te zoeken waar dat nodig was. Ook bedankt voor het kritisch lezen van mijn manuscripten en de feedback die ik kreeg in besprekingen.

Victor, jouw creativiteit en tomeloze enthousiasme voor wetenschappelijke onderzoek heb ik als erg stimulerend en motiverend ervaren. Nooit heb ik tevergeefs een beroep op je gedaan.

Jules, op jouw centrum is alles begonnen en had ik mijn werkplek, ik heb er altijd met zeer veel plezier gewerkt. ( ook al was dit in de kelder) Jouw deur stond en staa! altijd open voor stimulerende en verfrissende discussies. De soms "vaderlijke peptalks" waren een verademing en stimuleerde mij om door te gaan ook als de bergen soms erg hoog leken. Bedankt voor de goede samenwerking en het waanzinnig goede idee van de voorkant.

Huib, bedankt voor je wetenschappelijke input en jouw begeleidingsactiviteiten rondom het onderzoek.

De leden van de leescommissie, Prof.dr. S. van der Linden, Prof.dr. G.J. Dinant, Prol.dr. I.M.W.M. Merkus, Dr. R. de Vet en Dr. B. Wolffenbuttel wil ik bedanken voor het kritisch doorlezen van dit proefschrift.

Speciale dank gaat uit naar Simone Sanders, Annelies van Gool, Ineke Roothans en Cecile Smeets. Onze "kelder" discussies waren zonder uitzondering van een bijzonder hoog wetenschappelijke gehalte. De hoeveelheid werk die jullie verzet hebben met brieven versturen (meer dan 4000), afspraken maken en afspraken weer verzetten (meer dan 5000), patiënten visites voorbereiden, data-invoer en al de 
verdere administratieve handelingen is onbeschrijfelijk. Zonder jullie geen onderzoek. Met heimwee denk ik soms terug aan onze "keldertijd", bedankt!!!

Dr. Maartens, beste Luc jouw wil ik bedanken voor de samenwerking, jouw medewerking en visie als huisarts op deze studie was van groot belang voor het slagen van dit onderzoek.

Marie-Louise van Amelsvoort, bedankt woor het maken van meer dan 1000 botdichtheidsmetingen (DXA), je welwillend en enthousiasme on altijd te komen, ook's avonds, jouw aanwezigheid stond garant voor een goede kwaliteit van de botdichtheidsmetingen. Joke, Noor en Marianne jullie ook bedankt voor jullie inzet.

Luc Harms ook jouw wil ik bedanken voor je getoonde interesse, leuke discussies, goede adviezen en gezelligheid. Bedankt, voor het delen van je kamer in de laatste fase van het onderzoek, leuke en fijne kamer, trouwens.

Vele andere medewerkers van het DCE die direct en indirect hebben meegeholpen of betrokken waren bij deze studie, bedankt. Velen hebben gevraagd "hoe lang duurt dat nog dat proefschrift". $\mathrm{Nu}$, het is af!

Erik de Klerk jouw wil ik bedanken voor de constructieve bijdrage aan hoofdstuk 7, jouw kennis en enthousiasme over compliance van medicatie is verbluffend zonder jouw medewerking had dit proefschrift een interessant hoofdstuk moeten missen.

Dr. Komproe, beste Ivan. Bedankt dat je steeds bereid was om vragen over de statistiek te beantwoorden.

Monique Brood en Corine Vermeulen, bedankt voor de ondersteuning en de gezelligheid tijclens "het monitoren" van het onderzoek.

Gay Wylie, hartelijk bedankt woor het kritisch "engels lezen" van het manuscript.

Gera, Hannie en Mariëlle (de eliteclub), studievriendinnen en "collegae" in de ruimste zin van het woord. Onze dineetjes, patiënten discussies en gedachten uitwisselingen waren en zijn nog steeds erg gezellig. Het jaar 2001 is voor een ieder van ons een heel speciaal jaar, waarschijnlijk gaan onze gesprekken daarom in de toekomst meer over onze meiden dan over patiënten. Op het moment van schrijven van dit dankwoord bedacht ik dat onze eliteclub 12,5 jaar bestaat, vandaar mijn wens om nog veel jubilea te vieren. Bedankt voor jullie steun, aanwezigheid, vriendschap en vertrouwen. Jammer dat 3 paranimfen niet toegestaan is.

Ook mijn andere vrienden en kennissen bedankt voor jullie steun en gezelligheid. We hebben elkaar de afgelopen jaren minder gezien dan dat we hadden gewild.

\section{'The Family'}

Mijn ouders, bedankt dat jullie met liefde mij de ruimte en de gelegenheid gegeven hebben om te studeren en dat ik mij kon ontwikkelen tot wie ik nu ben. Paatje bedankt dat je me geleerd hebt datgene na te streven wat binnen je mogelijkheden mogelijk is. De werklust, energie en doorzettingsvermogen heb ik van geen vreemde. Maatje, jouw sociale begaafdheid, optimisme, humor zijn een voorbeeld voor mij. Bedankt voor het oppassen op de meiden. 
Lenet, mijn zusje en vriendin jouw wijze raad, morele steun en de vele dingen die we samen gedaan hebben en die we nog gaan doen, de momenten die we gelachen en gehuild hebben, What would I be without you? Henk-Jaap en Li-jane fijn om jullie als broertje en zusje te hebben, wanneer gaan we een feestje bouwen? Li-jane ook namens Renée en Janne Jet, bedankt.

Simon en Nettie veel dank voor jullie steun en jullie bereidheid altijd te komen om op te passen of te helpen.

Renée en Janne Jet laten we leuke dingen gaan doen, naar de Efteling of met Davidje naar Artis.

Arno, je vond het wel een goed idee dat ik wilde promoveren maar nu het eindelijk af is, vind je dat toch leuker. Bedankt voor je commentaar op de verschi lende versies van mijn hoofdstukken. Al waren onze discussies erover soms wel erg verhit, het scherpte mij in mijn denken. Geweldig dat je telkens weer wilde geloven dat het nu echt de laatste keer was dat ik aan dit boekje moest werken en jij het geheel kon relativeren als ik het even niet meer zag zitten. Arnie, bedankt! 



\section{Curriculum vitae}

1965

1983

$1983-1987$

1988-1994

1994-1995

1995

geboren te Nunspeet op 27 maart 1965

eindexamen Havo Lodensteyn college te Amersfoont

HBO-Verpleegkunde Hogeschool de Vijverberg te Ede

Studie Geneeskunde aan de Universiteit van Maastricht:

Alberta Children's Hospital, Calgary Canada. Arts op de kinderoncologieafdeling.

Zuiderzeeziekenhuis, Lelystad, Assistent Geneeskundige niet in opleiding (AGNIO) op de eerste hulp

Catharina Ziekenhuis Eindhoven, AGNIO Interne Geneeskunde

1995-1999 Arts-onderzoeker, Eindhoven Perimenopausal Osteoporosis Study (EPOS) bij het Diagnostisch Centrum te Eindhoven

1998 opleiding epictemiologie VU Amsterdam, status als Epidemioloog-A

1999-2000 Medical Adviser Organon International, Oss

2000-2001 Medisch Coördinator van het Diagnostisch Centrum te Eindhoven 